\title{
Facilitating training transfer effects : the case of MBA programs in Vietnam
}

Citation for published version (APA):

Pham, N. T. P. (2010). Facilitating training transfer effects : the case of MBA programs in Vietnam.

[Doctoral Thesis, Maastricht University]. Maastricht University. https://doi.org/10.26481/dis.20101001np

Document status and date:

Published: 01/01/2010

DOI:

10.26481/dis.20101001np

Document Version:

Publisher's PDF, also known as Version of record

\section{Please check the document version of this publication:}

- A submitted manuscript is the version of the article upon submission and before peer-review. There can be important differences between the submitted version and the official published version of record.

People interested in the research are advised to contact the author for the final version of the publication, or visit the DOI to the publisher's website.

- The final author version and the galley proof are versions of the publication after peer review.

- The final published version features the final layout of the paper including the volume, issue and page numbers.

Link to publication

\footnotetext{
General rights rights.

- You may freely distribute the URL identifying the publication in the public portal. please follow below link for the End User Agreement:

www.umlib.nl/taverne-license

Take down policy

If you believe that this document breaches copyright please contact us at:

repository@maastrichtuniversity.nl

providing details and we will investigate your claim.
}

Copyright and moral rights for the publications made accessible in the public portal are retained by the authors and/or other copyright owners and it is a condition of accessing publications that users recognise and abide by the legal requirements associated with these

- Users may download and print one copy of any publication from the public portal for the purpose of private study or research.

- You may not further distribute the material or use it for any profit-making activity or commercial gain

If the publication is distributed under the terms of Article $25 \mathrm{fa}$ of the Dutch Copyright Act, indicated by the "Taverne" license above, 


\title{
Facilitating Training Transfer Effects The case of MBA Programs in Vietnam
}

\author{
PROEFSCHRIFT \\ Ter verkrijging van de graad van doctor \\ aan de Universiteit Maastricht \\ op gezag van de Rector Magnificus, \\ Prof. Mr. G. P. M. F. Mols \\ volgens het besluit van het College van Decanen, \\ in het openbaar te verdedigen
}

op vrijdag 1 oktober 2010 om 10:00 uur

door

PHAM THI PHUONG NGA 
Promotores

Prof. Dr. W.H. Gijselaers, Maastricht University School of Business and Economics

Prof. Dr. M.S.R. Segers, Maastricht University School of Business and Economics

\section{Beoordelingscommissie}

Prof. Dr. Andries de Grip, ROA, Maastricht University School of Business and Economics (voorzitter)

Prof. Dr. Wil Foppen, O\&S, Maastricht University School of Business and Economics

Dr. David Gijbels (Universiteit Antwerpen, Instituut Onderwijsen Informatiewetenschappen 
The research in this dissertation was supported by a grant from the Dutch Government of Nuffic-NFP (Netherlands Universities' Foundation for International Cooperation), grant number PHD.05/193-V

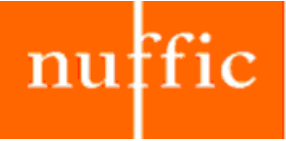

Netherlands organization for international cooperation in higher education

(C) Phạm Thị Phương Nga, The Netherlands, 2010

ISBN 978-90-5681-340-6

NUR: 841

Omslagontwerp: Océ Business Services, Maastricht

Print: Océ Business Services, Maastricht 
Dedicated to my parents (Mr Phạm Đình Hành and Mrs Phạm Thị Thuân), my husband (Nguyễn Lê Tâm), my sons (Nguyễn Ngọc Phương and Nguyễn Lê Quân), my sister (Phạm Thị Thu Hà), my brother (Phạm Đình Đạt) and all of my family members. 


\section{Acknowledgement}

This dissertation is the result of years of hard work on my part as well as support and encouragement by many people including my family, promoters, colleagues and friends.

I am especially grateful to my parents (Mr Pham Đình Hành and Mrs Phạm Thị Thuân), my husband (Nguyễn Lê Tâm), my sons (Nguyễn Ngọc Phương and Nguyễn Lê Quân), my sister (Phạm Thị Thu Hà), my brother (Phạm Đình Đạt), my niece Phạm Đặng Tường $V y$ and all of my family members. Without their love, I would not have been able to work on this dissertation. I am deeply indebted to their love, support, patience and being suffer a pain of my trips abroad and odd working hours.

I would like to express my extreme gratitude to my Prof. Dr. W.H. Gijselaers and Prof. Dr. M.S.R. Segers of the University of Maastricht (UM) for their wisdom, guidance, encouragements, timely and indispensable supports. Their contributions, detailed comments and insight have been of great value in helping me to improve the quality of this dissertation. Without their care and contributions, I would not have been able to accomplish the work on this dissertation. I could not forget every Friday appointment which we had, since year of 2006, with a lot of inspiriting discussions. I could not have wished for better Promoters.

My much sincere appreciation also goes to the Doctoral Committee members for their truly valuable comments and suggestions.

Special thanks go to the Vietnamese Government (Academy of Public Administration - Ho Chi Minh National Academy of Political and Public Administration and the Vietnamese Embassy in the Netherlands) that facilitated my obtaining a PhD from the great country, the Netherlands.

Most importantly, this dissertation would not have been successfully completed without the financial support from the Dutch Government (Nuffic) and Maastricht School of Management (MsM). I thank them all sincerely.

Finally, I would like to thank all my colleagues and friends at UM and MsM, especially those from the Department of Educational Research and Development (specially Mrs Henny Dankers), School of Business and Economics (UM) and Doctoral Department (MsM, especially Prof. Beatrice van der Heijden, Prof. Dr. Fred Phillips, Prof. Eno L. Inanga) for their cooperation and extraordinary friendship which have supported me in various ways to finalize this Thesis.

Xin chân thành cảm ơn!

Phạm Thị Phương Nga, Maastricht, 2010. 



\section{Table of Contents}

Chapter 1 Introduction...............................................

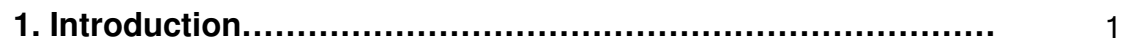

2. Structure of the Thesis .................................................. 6

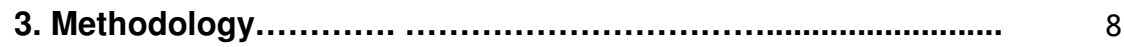

3.1 Sample of the Studies ............................................. 8

3.2 Data collection Studies .......................................... 9

\section{Chapter 2 The Effects of the Training Design on Training}

Transfer Effects

Based on: Pham, N.T.P., Gijselaers, W.H. \& Segers, M.S.R.(2010, in press). The effect of the trainees' perception of the training design on transfer of training: the case of Master of Business Administration (MBA) in Vietnam. In P. Van den Bossche, W. Gijselaers, \& R. Milter (Editors). Advances in Business Education and Training III. Dordrecht: Springer.

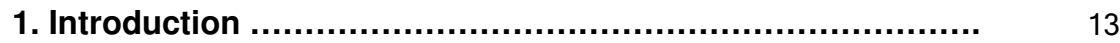

2. Conceptual framework ...................................................

2.1 Training design characteristics: the traditional approach .......... 15

2.2 Training design characteristics: a constructivist approach ......... 17

2.3 Use of transfer strategy ......................................... 19

2.4 Training transfer effects ....................................... 19

3. Research question and hypotheses .................................. 20

4. Methodology and research design ................................... 20

4.1 Participants ......................................................... 20

4.2 Setting.............................................................. 21

4.3 Measures ............................................................. 23

4.4 Procedures .......................................................... 27

4.5 Method of analysis ............................................... 27 


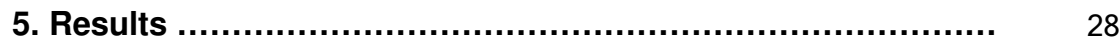

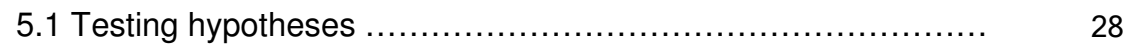

5.2 Testing the model ............................................... 31

6. Conclusion and discussion ......................................... 32

7. Implications for practice and recommendations for future research

Chapter 3 Understanding Training Transfer Effects from a Motivational Perspective ........................................... Based on: Pham, N.T.P., Segers, M.S.R. \& Gijselaers, W.H. (2010). Understanding Training Transfer Effects from a Motivational Perspective: A Test of MBA Programs. In Business Leadership Review, 7:3 (July 2010), 1-25.

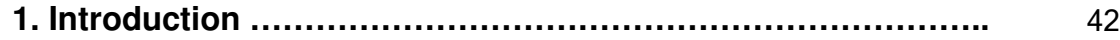

2. Conceptual framework ..................................................... 44

2.1 Motivational Perspectives influencing Training Transfer Effects . $\quad 44$

2.2 Use of transfer strategy .........................................

2.3 Training transfer effects ........................................ 48

3. Research question and hypotheses ................................. 48

4. Methodology and research design ..................................... 49

4.1 Participants ........................................................ 49

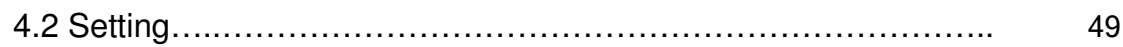

4.3 Measures .............................................................. 50

4.4 Procedures ......................................................... 51

4.5 Method of analysis ............................................. 52

5. Results ......................................................... 52

5.1 Testing hypotheses .............................................. 54

5.2 Testing the model ................................................ 56

6. Conclusion and discussion ......................................... 57

7. Implication for practice and recommendations for future research .......................................................................... 59

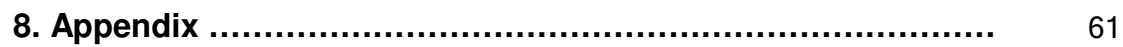

8.1 Appendix A: Descriptions of MBA programs in Vietnam ............ 61

8.2 Appendix B: Variables, scales and examples ...................... 62 


\section{Chapter 4 Effects of the Work Environment on Training}

Transfer Effects

Based on: Pham, N.T.P., Segers, M.S.R. \& Gijselaers, W.H. (2010). Effects of the Work Environment on Training Transfer Effects: the case of Master of Business Administration (MBA) in Vietnam. In International Journal of Training and Development (Under review)

1. Introduction

2. Conceptual framework .................................................

2.1 Work environment factors influencing training transfer effects... $\quad 72$

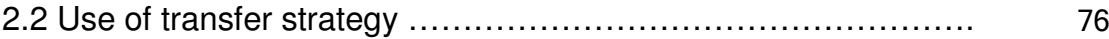

2.3 Training transfer effects ....................................... 76

3. Research questions and hypotheses ............................. 77

4. Methodology and research design. .................................. 77

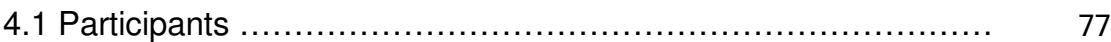

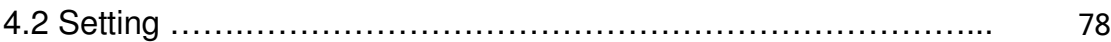

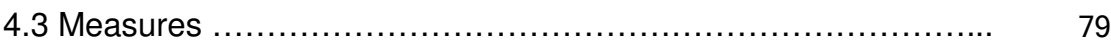

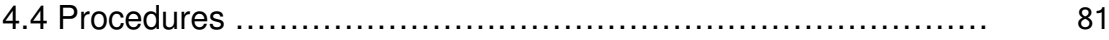

4.5 Method of analysis ............................................ 82

5. Results .................................................................. 82

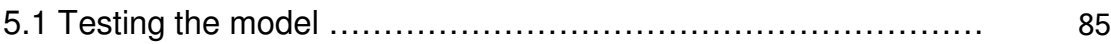

6. Conclusion and discussion ............................................ 87

7. Recommendations for future research ............................ 89

8. Appendix ............................................................. 91

8.1 Appendix A: Descriptions of MBA programs in Vietnam ........... 91

8.2 Appendix B: Variables, scales and examples .................. 92

Chapter 5 Facilitating Training Transfer Effects based on Simultaneous Influences of Training Design, Trainees' Motivation and Work Environment................................... Based on: Facilitating Training Transfer Effects based on Simultaneous Influences of Training Design, Trainees' Motivation and Work Environment on Training Transfer Effects: the case of Master of Business Administration (MBA) programs in Vietnam (Submitted)

1. Introduction

2. Conceptual framework 
2.1 Training design factors influencing training transfer effects

2.2 Trainees' motivational perspectives influencing training transfer effects

2.3. Work environment factors influencing training transfer effects

2.4 Use of transfer strategy

2.5 Training transfer effects

3. Research questions and hypotheses

4. Methodology and research design ................................. 109

4.1 Participants ................................................... 109

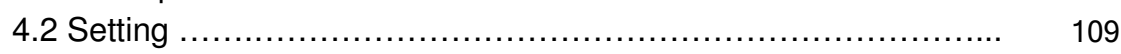

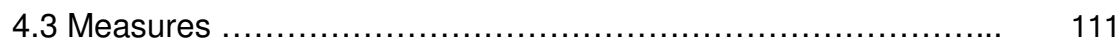

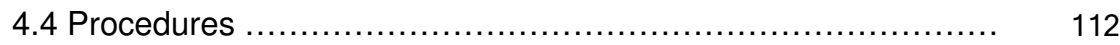

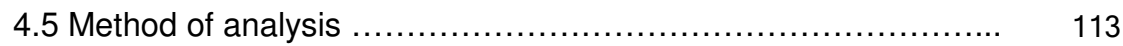

5. Results .................................................................. 114

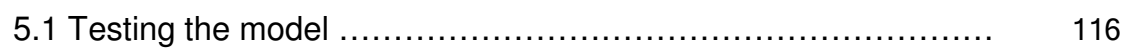

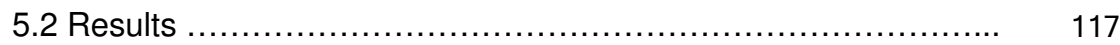

6. Conclusion and discussion ....................................... 119

7. Implication for practice and recommendations for future research........................................................................ 121

8. Appendix Descriptions of MBA programs in Vietnam........... 124

Chapter 6 Summary and General Conclusions \& Discussion 131

1. Thesis overview ..................................................... 131

2. Results ................................................................. 135

3. General conclusion and discussion ................................ 141

4. Implications of the research for MBA programs and

Recommendations for further training programs...................... 143

$\begin{array}{ll}\text { 5. What is next? } & 147\end{array}$

$\begin{array}{lr}\text { Tóm tắt (in Vietnamese) } & 151\end{array}$

$\begin{array}{ll}\text { About the author } & 157\end{array}$ 


\section{List of Figures and Tables}

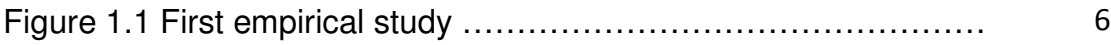

Figure 1.2 Second empirical study ................................. 7

Figure 1.3 Third empirical study ................................. 7

Figure 1.4 Comprehensive model study ............................ 7

Table 2.1 Description of MBA programs in Vietnam .................. 21

Table 2.2 Variables, scales and examples .......................... 24

Figure 2.1 Research Model ......................................... 27

Table 2.3 Cronbach's Alphas and Intercorrelations among variables ... 28

Table 2.4 Regression analysis for training design and training transfer effects

Table 2.5 Regression analysis for training design and transfer strategy predicting training transfer effects

Figure 2.2 Path analysis model toward training transfer effects ........ 31

Figure 3.1 Research model ...................................... 51

Table 3.1 Cronbach's Alphas and Intercorrelations among variables ... 53

Table 3.2 Regression analysis for trainees' motivational perspectives predicting training transfer effects

Table 3. 3 Regression analysis for trainees' motivational perspectives and transfer strategy predicting training transfer effects

Figure 3.2 Path analysis model toward training transfer effects ........ 57

Figure 4.1 Research model ....................................... 80

Table 4.1 Cronbachs' Alphas and Intercorrelations among variables ... 84

Figure 4.2 Path analysis model toward training transfer effects ........ 85

Figure 5.1 Research model ...................................... 109

Table 5.1 Variables, scales and examples ........................ 112

Table 5.2 Cronbachs' Alphas and Inter-correlations among variables .. 115

Figure 5.2 Path analysis model toward training transfer effects ........ 117

Figure 6.1 Overview of Thesis ................................ 134

Figure 6.2 The effects of training design on training transfer effects ... 136

Figure 6.3 The effects of trainees' motivational perspectives on

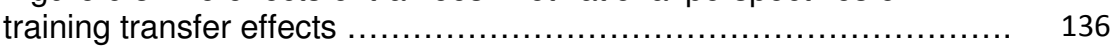

Figure 6.4 The effects of work environment on training transfer effects 137

Figure 6.5 Path analysis model toward training transfer effects ........ 139

Table 6.1 Recommendations for further training programs ........... 146 

Introduction | 1

\title{
Chapter 1
}

\section{INTRODUCTION}

\author{
'Changing the Face' can change nothing. \\ But 'Facing the Change' can change everything. \\ - Unknown
}

\section{INTRODUCTION}

When learning is not applied in the workplace, corporate training is useless and a waste of money. Therefore, one of the most significant current discussions in the field of Human Resource Development (HRD) is what happens with the knowledge and skills trainees acquire when training is completed? Can trainees effectively apply/transfer the acquired knowledge, skills and attitudes to their job? What transfer success factors can be identified and to what extent do they influence the transfer of newly acquired knowledge, skills and attitudes to the job?

Over the past twenty years, researchers have repeatedly addressed the question of whether as the result of training, trainees can effectively apply (or transfer) the trained knowledge, skills and attitudes to the workplace. This question is known as the issue of training transfer effects, or transfer of training (Baldwin \& Ford, 1988; Burke \& Hutchins, 2007; Cheng \& Ho, 2001; Holton, Bates, Seyler, \& Carvalho, 1997; Velada, Caetano, Michel, Lyons, \& Kavanagh, 2007). Researchers have cast doubt about the potential return of training investments is realized in terms of trainees' applying on the job what has been learned during the training (e.g. Kirwan \& Birchall, 2006). Substantial evidence exists that the transfer of training to the workplace is problematic (Burke \& Hutchins, 2007). Researchers claim that only a small amount of acquired training is actually transferred to the trainees' job. (e.g. 
Baldwin \& Ford, 1988; Curry, Caplan, \& Knuppel, 1994; Kaufman, 2002). It may not be a surprise that as a consequence of empirical research on this issue, transfer of training has become a critical concern for the field of HRD (Burke \& Hutchins, 2007; Salas \& Cannon-Bowers, 2001). This has led to a growing interest in understanding the transfer process. Can conditions be identified which are necessary to achieve better training transfer effects?

The training transfer literature shows that, in general, three groups of variables influence training transfer: training design, trainee characteristics, and the work environment (e.g. Baldwin \& Ford, 1988; Burke \& Hutchins, 2007; Cheng \& Hampson, 2008; Ford \& Weissbein, 1997; Pugh \& Bergin, 2006). Transfer of training has been studied by mainly analyzing singular effects of training design, trainee characteristics, and the work environment, and assess their impact with training transfer. For example, concerning training design, Alvarez, Salas, and Garofano (2004) focus on instructional techniques and learning principles; Tziner, Haccoun, and Kadish (1991) Wexley and Nemeroff (1975) emphasized self-management and relapse prevention strategies; and Gist, Bavetta, and Stevens (1990) and Brown (2005) stressed goal setting affecting transfer of training. The trainee characteristics such as achievement motivation, motivation to learn, motivation to transfer and self-efficacy influencing transfer of training are indicated by a number of studies such as Colquitt, Lepine, and Noe (2000); Mathieu, Tannenbaum, and Salas (1992); and Velada and Caetano (2007). The work environment factors related to transfer of training such as supervisor support, supervisor sanctions, peer support, and performance feedback are highlighted in research of Baldwin and Ford (1988); Colquitt, Lepine, and Noe (2000); Holton, Bates, and Ruona (2000); Tracey and Tews (2005).

Despite many studies addressing the impact of these variables on transfer effects of training programs, it has been argued that our knowledge of the subject is not advanced. For example, the recent review study of Cheng and Hampson (2008, p. 335) states that the "inconsistent and unexpected findings alert us that our previous models may not be adequate for studying the transfer process. Perhaps other schools of thought may provide us with plausible answers". This leaves us with the question of how research can be designed in such a way that key conditions for effective transfer can be identified, and whether effective training practices can be designed to improve transfer of training. There is increasing concern that training transfer is a complex phenomenon which is influenced by a group of variables and the interaction of these variables (e.g. Merriam \& Leahy, 2005). New approaches studying the issue of transfer of training focus more and more on multidimensional models. In studies of the training transfer process, attention has shifted to - next to training design factors - 
organizational factors which are assumed to have an impact on successful training transfer. Especially, Holton, Bates and Ruona (2000) provide a case in point. They challenged current expectations about how the factors having an impact on training transfer may be captured and assessed. They developed a broad conceptual transfer model addressing trainee characteristics, motivation, work environment, and ability. An instrument (including 16 constructs) was designed capturing these factors in the socalled learning transfer system inventory (LTSI). However, Holton et al also admit that their model needs to be examined to strengthen the reliabilities of several of the scales, as well as to examine the convergent and divergent validity of the constructs. Since then, LTSI has been used in several studies to analyze how transfer of training is affected by variables making use of LTSI scales. For example, Kirwan and Birchall (2006) examined the LTSI in Ireland, Yamnill and McLean (2005) in Thailand and Khasawneh, Bates and Holton (2004) in Jordan. Kirwan and Birchal (2006) found - amongst others - that increased levels self-efficacy were positively related to motivation to transfer. In general, research on LTSI indicates that peer support in the work environment, and feedback and coaching, independently and positively affect the motivation to transfer. In addition, the managers' support facilitated transfer of training. Especially, organizational support exerts effects on trainees' desire and ability to transfer. Yamnill and McLean (2005) indicated that peer support is a strong factor for enhancing transfer. Moreover, according to them, a reward system is a promising key to enhancing motivation level of employees to learning transfer.

Although research based on the LTSI provides better understanding of how training design, trainee characteristics and work environment affect transfer of training, the LTSI has been criticized as well. For example, Yamnill and McLean (2005) conducted a study in Thailand and identified some weaknesses of the LTSI. They pointed out that LTSI demonstrates several psychometric problems such as different number of items across factors, and low reliability (internal consistency) in some factors. This calls for revision of LTSI (Yamnill \& McLean, 2005). Burke and Hutchins (2007) indicated that no published work links the use of the LTSI to concrete enhancement in transfer outcomes. Also, the authors argue that there is not yet empirical evidence as to what extent the factors, identified in the Holton, Bates and Ruona (2000) model, jointly affect transfer in terms of improved performance.

Recently, a study of Velada, Caetano, Michel and Kavanagh (2007) related training design, trainee characteristics and work environment to transfer of training. It found that (1) transfer design significantly predicted transfer of training $(\beta=0.31, p<0.01)$; (2) self-efficacy $(\beta=0.30, p<0.01)$ and training retention $(\beta=0.30, p<0.01)$ significantly predicted transfer of 
training; and (3) the environmental variables (performance feedback) significantly predicted transfer of training $(\beta=0.42, p<0.01)$. Overall, these variables explained 42 per cent of the total variance in transfer of training. Their results indicate that these three major determinants were indeed significantly related to transfer of training, suggesting the need to examine more aspects of the training process when conducting research on transfer of training.

Based on these empirical findings, it is argued that there has been little discussion about studying transfer of training from a system perspective. It has been stressed that in order to fully understand the transfer of training issue, a system approach is needed, looking at the simultaneous effects of the training design, trainee characteristics and work environment. This suggests the need to extend the research base to a better understanding of whether and how different training design, trainee characteristics and work environment factors jointly influence training transfer.

In addition, Cheng and Hampson (2008) indicate that, in order to reach a better understanding of the transfer process, attentions should be given to other crucial but unseen variables in the transfer process. In practice, learning in training does not automatically result in transfer (e.g. Hesketh \& Laidlaw, 1997; Kraiger, Ford, \& Salas, 1993). Once trainees re-enter the workplace after training, they have to cope with environmental and situational factors which in many cases confront the trainee with barriers instead of support for using the newly acquired skills and knowledge, such as the negative attitudes of their co-workers (Nikandrou, Brinia, \& Bereri, 2009; Taylor, 2000). Therefore, it has been argued that trainees need to use appropriate strategies, to transfer learned skills and knowledge, which have been called transfer training strategy (Burke \& Baldwin, 1999). According to Noe, Sears and Fullenkamp (1990) (cited in Roberson, Kulik, and Pepper (2009), transfer strategies are cognitive and behavioral techniques, that include setting goals, analyzing work situations, preparing to deal with difficulties, identifying and using the necessary support, and recognizing and monitoring opportunities to use acquired knowledge and skills on the job.

Foxon $(1994$, p. 3) has argued that transfer strategies have to be formulated, and "implemented during the design, development and delivery of instruction". She believes that such strategies tend to increase the possibility of transfer through acknowledgement of the impact of organizational system factors that simultaneously assist the individual to focus on potential applications of learning. Olsen (1998) also emphasizes the need of understanding how to develop trainee's intention to use the new knowledge and skills. 
The literature confirms the relations between using transfer strategies and transfer (Burke, 1997; Burke \& Baldwin, 1999; Tziner, Haccoun, \& Kadish, 1991). For example, Tzinner et al (1991) believed that paying attention to goal-setting and self-management as transfer strategies resulted in a significantly higher level of transfer. Machin and Fogarty (2003) and Ford and Weissbein (1997) revealed that the use of transfer strategies for facilitating the transfer process is a crucial prerequisite for transfer of training. A few studies proposing the importance of transfer strategies as a key mediator of the link between influencing factors and transfer outcomes. Examples include Gollwitzer (1999), Latham (1997) and Noe, Sears, and Fullenkamp (1990).

There are several transfer strategies outlined in the literature which can be incorporated into training courses such as (1) the trainees' situation (e.g. identifying situations at work to apply the trained skills), (2) the trainees' thoughts/feelings (e.g. thoughts about the necessary support needed in order to use the trained skills; retaining self-confidence when experiencing resistance or burdens), (3) the trainees' behavior (e.g. creating and maintaining a social network), and (4) consequences of the trainees' behavior (e.g. being prepared to deal with skepticism of colleagues) (Burke \& Baldwin, 1999).

However, further research to understand the role of transfer strategy for enhancing transfer of training is needed. It is still unclear to what extent transfer strategies influence the relations among training design, trainee characteristics and trainees' work environment factors and transfer of training. Therefore in addition to the direct (separate as well as simultaneous) relationship between training design, trainees' motivation and work environment and transfer of training, we include the trainee's use of transfer strategies as a mediating variable. We propose it will influence the strength of the relation between the aforementioned factors and transfer of training. We hypothesize that training design, trainees' motivation and work environment affect trainee's use of transfer strategy, which in turn, influence transfer of training.

In summary, while transfer of training has been studied by analyzing singular effects of training design, trainee characteristics and work environment, very few studies exist following a more comprehensive approach examining joint effects of these variables, especially when the role of trainees' transfer strategies is at issues. This Thesis, therefore, explores the separate as well as the joint role of training design, trainee characteristics and work environment factors and its interaction with the mediating role of transfer strategy as a systematic way towards training transfer. This aims to create a new framework, which includes a multidimensional approach to the transfer process, to assess how various factors within this framework interact, influencing transfer of training. 


\section{STRUCTURE OF THE THESIS}

In the present thesis, a theoretical model of how training design, trainee characteristics, and work environment factors contribute to training transfer was developed by reference to training transfer theory. Additionally, some important qualifications and extensions to this model are developed, in order to adequately explain the role of transfer training strategies. This aims to contribute to research on transfer of training by exploring the empirical and simultaneous effects of the above factors, taking into account the role of transfer training strategies. However, before building the comprehensive model, a series of three studies is presented, each dealing with one factor that influence transfer of training. This deepens our understanding of the unique impact of each factor, and of how the results affect the main theories in the training field.

Firstly, the influence of the training design, taking into account the role of transfer training strategies, is analyzed.

Secondly, effects of trainee's motivation, taking into account the role of transfer training strategies, are reported.

Thirdly, the impact of the work environment, taking into account the role of transfer training strategies, are uncovered.

Finally, we analyze the joint effects of these three groups (the training design, trainee's motivation and the work environment), taking into account the role of transfer training strategies, to study the effectiveness of transfer of training as a system.

Concretely, the present study, excepting chapter 1- Introduction and chapter 6-Conclusion, contains four empirical study chapters:

Chapter 2 explores the impact of training design, focusing on the influence of constructivist features of the design of the training programs as well as the mediating role of trainee's transfer strategy, on training transfer (figure 1.1).

Figure 1.1 First empirical study (Chapter 2)

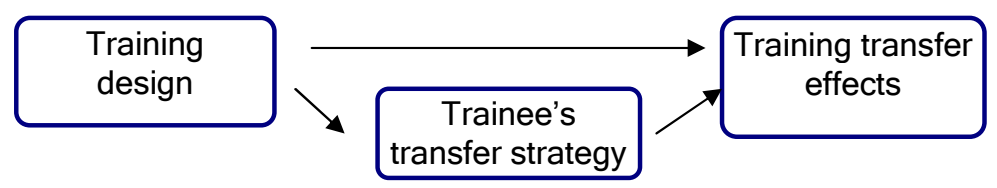

Chapter 3 focuses on the impact of trainee's motivation taking into account the mediating role of trainees' transfer strategies, on training transfer (figure 1.2). 
Figure 1.2 Second empirical study (Chapter 3 )

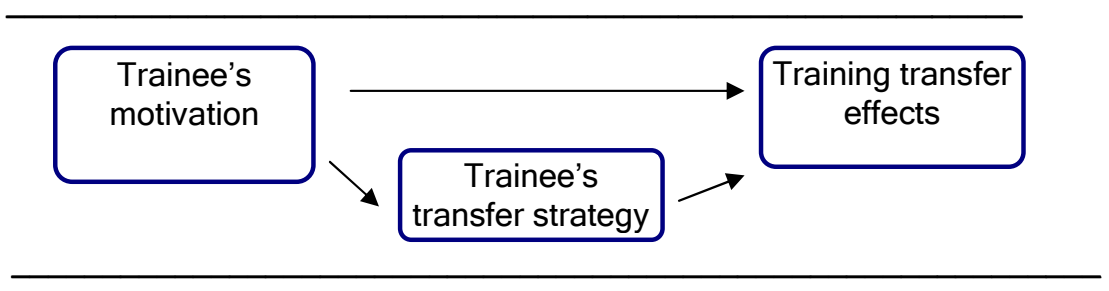

Chapter 4 identifies the impact of the work environment on training transfer effects and the mediating role of role of the trainees' transfer strategies (figure 1.3).

Figure 1.3 Third empirical study (Chapter 4)

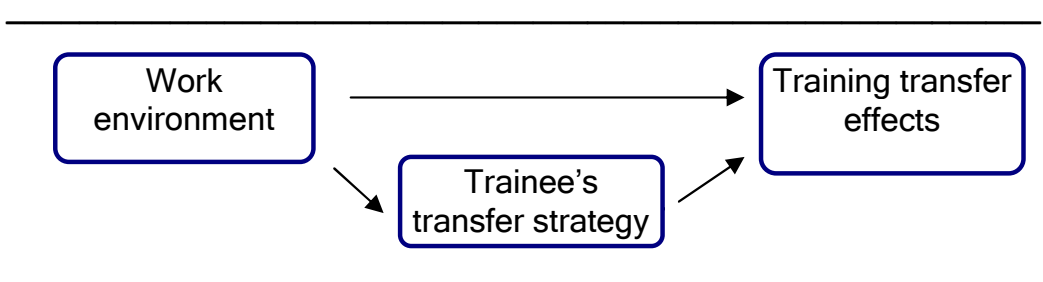

Chapter 5 demonstrates the joint role of training design, trainee's motivation and work environment, taking into account the participants' transfer strategies as a mediator, and how they contribute to transfer of training (figure 1.4).

Figure 1.4 Comprehensive empirical study (Chapter 5)

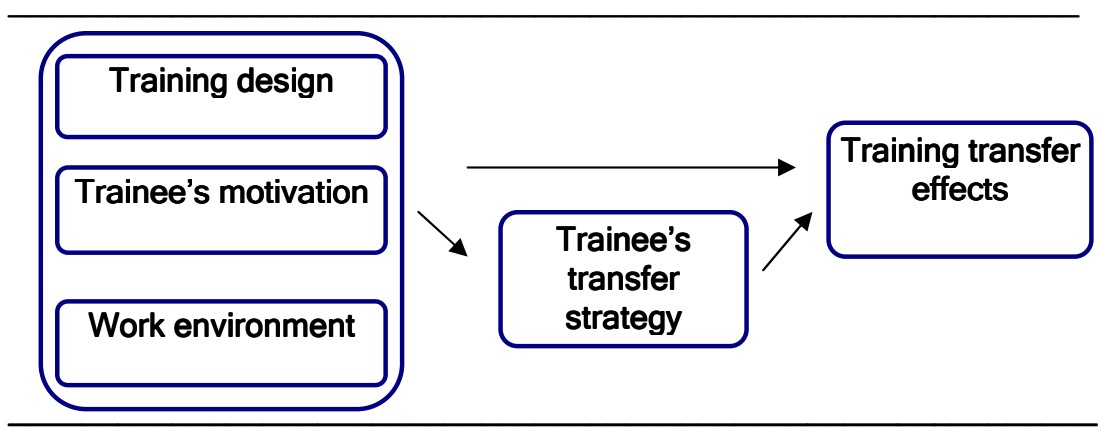




\section{METHODOLOGY}

\subsection{Sample of the studies}

The present study was conducted in the setting of Master of Business Administration (MBA) programs. The first MBAs were offered by Harvard University about 100 years ago, in a two-year, full-time format. To date, MBA degree programs have spread around the world, with a diversity of master's degree in management-related subjects."Master's qualification is becoming almost a prerequisite for success as a senior manager" (Cameron, 2005, p. 4). The MBA setting provides a good opportunity to study transfer of training for the following reasons. First, the MBA degree has become a big attraction as demand for higher education skyrockets. Gijselaers and Milter (2010, in press) mention that in the 1990s, about 75000 MBA students graduated each year in the US. The numbers of MBA programs and students has continued to grow since that time and growth is prominent across the US, Europe (1980 onwards), and Asia (Thailand, 1995). About 500 European business school produce more than 20.000 graduates/year (Cameron, 2005, p. 4). Second, MBA programs are professionally oriented and focus on the development of professional competence (Mintzberg, 2004). They aim to improve the functional and managerial competencies of trainees (Camuffo, Gerli, \& Chiara, 2006), since most MBA participants are professionals with a considerable amount of experience, and they perceive the training as a competitive advantage for their professional development (Cheng \& Ho, 2001). Therefore, the possibilities training programs offer trainees to transfer the competencies they have been practicing during the training to the workplace, are of utmost importance for the trainees. Third, MBA programs provide trainees with "a highly analytical approach to managerial problem solving, and the ability to approach new problem in a structured fashion" (Cameron, 2005, p. 14). A question is if and under what conditions MBA programs really reach these high ambitions. Finally, MBA programs produce economic benefits and career success to MBA trainees, to the extent that MBA graduates receive more promotions than those who did not receive an MBA degree (Inderrieden, Holtom, \& Bies, 2006). Given these benefits, studying MBA programs in order to contribute to optimizing their transfer effects, is appropriate.

The current study took place in a sample of MBA programs in Vietnam. A growing market of MBA programs with varying trainees' working conditions provides opportunities for researchers to examine the different variables incorporated in the transfer process. It also emphasizes a need of 
the assessments in order to ascertain whether these programs have a positive impact on Vietnamese corporate practice. In Vietnam, education has been considered as top priority by the Vietnamese government in its attempt to develop the economy and join the global arena. After nearly 30 years of economic reform, the country is now facing with more vigorous challenges than ever before. Consequently, the Vietnamese government has established robust educational institutions which include MBA training programs (for instance, the Hanoi National Economics University (NEU), Vietnam National University (VNU), Foreign Trade University (FTU), Solvay Business School (Université Libre de Bruxells, Belgium), Centre FrancoVietnamien de Formation a' la Gestion (CFVG), Maastricht School of Management (MsM) in Vietnam). Although education is highly important in Vietnam, the question how the knowledge and skills obtained by trainees are transferred into work is inadequately understood. Not only such knowledge application assessment is in its infancy, but unfortunately MBA programs have never been researched to find out if MBA graduates can bring their knowledge to application. Meanwhile, there is an increasing need of the assessments to ascertain whether these programs have a positive impact on Vietnamese corporate practice. Thus, providing a comprehensive understanding of real training transfer issue in Vietnam is an urgent necessity. This will help educational organizations in Vietnam effectively and efficiently enhance transfer process by diagnosing the factors that impact on training transfer systems.

The duration of these Vietnamese MBA programs (one up two years) also is one of the positive points in favor of the present study compared to previous studies. While almost all other training programs studied in the literature are very short; for example, a three-day course (Lim \& Morris, 2006), one five-and-a-half-day week (Xiao, 1996), 12 days' duration (Kirwan \& Birchall, 2006) or one month program (Velada, Caetano, Michel, Lyons, \& Kavanagh, 2007), these Vietnamese MBA programs have higher probability that trainees will have opportunities to internalize the training and develop a transfer strategy.

\subsection{Data collection}

The current study took place in a sample of Vietnamese MBA programs. Data were collected from 305 trainees attending eight different part-time MBA programs in Vietnam. All trainees combined a job with an MBA study. 167 trainees answered the 1st survey, 126 trainees answered the 2nd one. The majority of the sample was male $(n=102 ; 61 \%)$. Average age was 32 . 
To measure the variables, we used and extended questionnaires which have been validated in similar settings. The analyses are based on regressions and path analyses.

Note:

The present dissertation consists of a collection of related articles addressing different parts of the comprehensive model discussed in this chapter. Specially, this dissertation is based on a series of four articles which either published/in press or under review/submitted. These four articles include the certain theoretical and practical parts such as Use of Transfer strategy, Training transfer effects, Participants, Settings, etc which are identical in the four articles. So repetitions and overlap across articles are inevitable.

\section{References}

Alvarez, K., Salas, E., \& Garofano, C. M. (2004). An integrated model of training evaluation and effectiveness. Human Resource Development Review 3, 385-416.

Baldwin, T. T., \& Ford, J. K. (1988). Transfer of training: a review and directions for future research. Personnel Psychology, 41(1), 63-105.

Brown, T. C. (2005). Effectiveness of distal and proximal goals as transfer-of-training interventions: a field experiment. Human Resource Development Quarterly, 16(3), 369-387.

Burke, L. A. (1997). Improving positive transfer: A test of relapse prevention training on transfer outcomes. Human Resource Development Quarterly, 8(2), 115-128.

Burke, L. A., \& Baldwin, T. T. (1999). Workforce training transfer: a study of the effect of relapse prevention training and transfer climate. Human Resource Management, 38(3), 227-242.

Burke, L. A., \& Hutchins, H. (2007). Training Transfer: An Integrative Literature Review. Human Resource Development Review, 6, 263-296.

Cameron, S. (2005). The MBA handbook: skills for mastering management (5th ed.): FTPrentice Hall.

Camuffo, A., Gerli, F., \& Chiara, F. (2006). Tracking Careers to Improve Competency-Based Management Education: A longitudinal Study of Italian MBAs. In Charles Wankel \& R. DeFillippi (Eds.). In New Vision of Graduate Management Education. Greenwich, Connecticut: IAP-Information Age Publishing.

Cheng, E., \& Hampson, I. (2008). Transfer of training: A review and new insights. International Journal of Management Reviews, 10(4), 327-341.

Cheng, E., \& Ho, D. (2001). The influence of job and career attitudes on learning motivation and transfer. Career Development International, 6(1), 20-27.

Colquitt, J. A., Lepine, J. A., \& Noe, R. A. (2000). Toward an Integrative Theory of Training Motivation: A Meta-Analytic Path Analysis of 20 Years of Research. Journal of Applied Psychology, 85(5), 678-707. 
Curry, D. H., Caplan, P., \& Knuppel, L. (1994). Transfer of training and adult learning (TOTAL). Journal of Continuing Social Work Education, 6(1), 8-14.

Ford, J. K., \& Weissbein, D. A. (1997). Transfer of training: An updated review and analysis. Performance Improvement Quarterly, 10, 22-41.

Foxon, M. (1994). A process approach to the transfer of training. Australian Journal of Educational Technology, 10(1), 1-18.

Gijselaers, W. H., \& Milter, R. G. (2010, in press). Issues in Accounting / Business Education. Business. In Barry McGaw, Penelope Peterson and Eva Baker (Eds.), The International Encyclopedia of Education, 3rd Edition. Elsevier (in press). International Encyclopedia of Education, Third Edition. Oxford: Elsevier.

Gist, M. E., Bavetta, A. G., \& Stevens, C. K. (1990). Transfer training method: Its influence on skill generalization, skill reflection, and performance level. Personnel Psychology, 43, 501-523.

Gollwitzer, P. M. (1999). Implementation intentions: Strong effects of simple plans. American Psychologist, 54, 493-503.

Hesketh, E. A., \& Laidlaw, J. M. (1997). 'Selling' educational events to healthcare professionals: Twelve tips on the function and design of trigger leaflets. Medical Teacher, 19(4), 250-256.

Holton, E. F., Bates, R. A., \& Ruona, W. E. A. (2000). Development of a Generalized Learning Transfer System Inventory. Human Resource Development Quarterly, 11(4), 333-360.

Holton, E. F., Bates, R. A., Seyler, D. L., \& Carvalho, M. B. (1997). Toward construct validation of a transfer climate instrument. Human Resource Development Quarterly, 8(2), 95-113.

Inderrieden, E. J., Holtom, B. C., \& Bies, R. J. (2006). Do MBA Programs Deliver? In Charles Wankel \& Robert DeFillipi (Eds.), New Vision of Graduate Management Education. Greenwich, Connecticut: IAP-Information Age Publishing.

Kaufman, R. (2002). Resolving the (often deserved) attacks on training. Performance Impermanency, 41(6).

Khasawneh, S., Bates, R. A., \& Holton, E. F., III. . (2004). Construct validation of an Arabic version of the Learning Transfer System Inventory (LTSI) for use in Jordan. Paper presented at the Proceedings of AHRD conference Bowling Green, $\mathrm{OH}$ : Academy of Human Resource Development.

Kirwan, C., \& Birchall, D. (2006). Transfer of Learning from Management Development Programmes: Testing the Holton Model. International Journal of Training and Development, 10(4), 252-268.

Kraiger, K., Ford, J. K., \& Salas, E. (1993). Application of cognitive, skill-based, and affective theories of learning outcomes to new methods of training evaluation. Journal of Applied Psychology, 78, 311-328.

Latham, G. P. (1997). Overcoming mental models that limit research on transfer of training in organisational settings. Applied Psychology: An International Review, 46, 371-375.

Lim, D. H., \& Morris, M. L. (2006). Influence of Trainee Characteristics, Instructional Satisfaction, and Organizational Climate on Perceived Learning and Training Transfer. Human Resource Development Quarterly, 171), 85-115. 
Machin, M. A., \& Fogarty, G. J. (2003). Perceptions of training-related factors and personal variables as predictors of transfer implementation intentions. Journal of Business and Psychology, 18(1), 51-75.

Mathieu, J. E., Tannenbaum, S. I., \& Salas, E. (1992). Influences of individual and situational characteristics on measures of training effectiveness. Academy of Management Journal, 35, 828-847.

Merriam, B. S., \& Leahy, B. (2005). Learning Transfer: A Review of the Research in Adult Education and Training. PAACE Journal of Lifelong Learning, 14, 1-24.

Mintzberg, H. (2004). Managers not MBAs: a hand look at the soft practice of managing and management development. London: Prentice Education.

Nikandrou, I., Brinia, V., \& Bereri, E. (2009). Perspective on practice. Trainee perceptions of training transfer: an empirical analysis. Journal of European Industrial Training, 33(3), 255-270.

Noe, R. A., Sears, J., \& Fullenkamp, A. M. (1990). Relapse training: Does it influence trainees' post training behavior and cognitive strategies? Journal of Business and Psychology, 4(3), 317-328.

Olsen, J. H. J. (1998). The evaluation and enhancement of training transfer. International Journal of Training \& Development, 2(1), 61-75.

Pugh, K. J., \& Bergin, D. A. (2006). Motivational Influences on Transfer. Educational Psychologist, 41(3), 147-160.

Roberson, L., Kulik, C. T., \& Pepper, M. B. (2009). Individual and Environmental Factors Influencing the Use of Transfer Strategies After Diversity Training. Group \& Organization Management, 34(1), 67-89.

Salas, E., \& Cannon-Bowers, J. A. (2001). The science of training: A decade of progress. Annual Review of Psychology, 52, 471-499.

Taylor, M. (2000). Transfer of learning in workplace literacy programs. Adult Basic Education, 10(1), 3-20.

Tracey, J. B., \& Tews, M. J. (2005). Construct validity of a general training climate scale. Organizational Research Methods, 8, 353-74.

Tziner, A., Haccoun, R. R., \& Kadish, A. (1991). Personal and situational characteristics influencing the effectiveness of transfer of training improvement strategies. Journal of Occupational Psychology, 64(2), 167-177.

Velada, R., \& Caetano, A. (2007). Training transfer: the mediating role of perception of learning. Journal of European Industrial Training, 31(4), 283-296.

Velada, R., Caetano, A., Michel, J., Lyons, B., \& Kavanagh, M. (2007). The effects of training design, individual characteristics and work environment on transfer of training. International Journal of Training and Development, 11(4), 282-294.

Wexley, K. N., \& Nemeroff, W. (1975). Effectiveness of positive reinforcement and goal setting as methods of management development. Journal of Applied Psychology, 64, 239-246.

Xiao, J. (1996). The relationship between organizational factors and the transfer of training in the electronics industry in Shenzhen, China. Human Resource Development Quarterly, 7, 55-73.

Yamnill, S., \& McLean, G. N. (2005). Factors affecting transfer of training in Thailand. Human Resource Development Quarterly, 16(3), 323-344. 


\section{Chapter 2}

\section{THE EFFECT OF TRAINING DESIGN ON TRAINING TRANSFER EFFECTS}

\section{INTRODUCTION}

Global competition, technological advances, and other rapidly changing economic forces create greater challenges to organizations than ever before. In order to survive and maintain sustainable competitive advantage in such a turbulent environment, organizations must investigate and utilize intellectual capital as a strategic resource (Kriegesmann, Kley, \& Schwering, 2005; Pfeffer, 1994). Training is one of the important ways to develop employees and hence to achieve the goals of an organization. Thus, billions of dollars are spent by organizations on employee training to increase their performance for achieving the organization's goals. For example, it is estimated that in 2007, U.S. organizations spent $\$ 134.39$ billion on employee learning and development. (ASTD, 2008). Although a large of money is spent on training, evidence shows that only about $10 \%$ to $20 \%$ of learning is transferred to the job (Baldwin \& Ford, 1988; Curry, Caplan, \& Knuppel, 1994; Kaufman, 2002). This evidence has triggered

This Chapter is based on Pham, N.T.P., Gijselaers, W.H. \& Segers, M.S.R. (2010, in press). The effect of the trainees' perception of the training design on transfer of training: the case of Master of Business Administration (MBA) in Vietnam. In P. Van den Bossche, W. Gijselaers, \& R. Milter (Editors). Advances in Business Education and Training III. Dordrecht: Springer. 
many researchers to look into such an application process to develop a better understanding of the conditions for trainees to effectively apply the trained knowledge, skills and attitudes to their work practice, the so-called transfer of training (e.g. Baldwin \& Ford, 1988; Cheng \& Ho, 2001; Ford \& Weissbein, 1997; Pidd, 2004). A group of three main variables that influence training transfer has been identified: the training design, the trainee characteristics, and the work environment (Cheng \& Hampson, 2008; Ford \& Weissbein, 1997; Pugh \& Bergin, 2006). However, literature has emerged that offers inconsistent findings about transfer process, revealing that we have not attained an adequate understanding of transfer issues. Especially, training design characteristics have received less attention though training approaches have been changing significantly during the past decades (e.g. Smith-Jentsch, Payne, \& Johnston, 1996). Looking from a learning sciences perspective, it is clear that the training principles that have been applied in previous transfer of training research have their origin mainly in behaviorist and cognitivist teaching theories, addressing training design characteristics such as identical elements, overlearning, relapse prevention and goal-setting. Nevertheless, the effectiveness of the design of training programs implementing the aforementioned principles has been under debate during the past ten years. In the new global economy, an important challenge for today higher education is how to develop and implement instructional practice that promote trainees' competencies such as skill communication, critical thinking, problem solving, team working, making meaning of learned information (Pellegrino et al 2001). This creates challenge not only for topics and goals of the training programs but also for the educational approach employed (Cho \& Schmeizer, 2000).

Since the early $1990 \mathrm{~s}$ the interest in constructivism as a learning theory has intensified. "The basic and most fundamental assumption of constructivism is that knowledge does not exist independent of the learner, knowledge is constructed" (Vrasidas, 2000, p. 6). Learning, therefore, is a process of constructing trainees' own knowledge, not the passive transmission information. Examples of training designs based on constructivist pedagogy are the use of simulation (Hwang, 2003), gaming and multimedia application in programs such as environmental crisis management trainings (Stolk, Alexandrian, Gros, \& Paggio, 2001). Given the changed educational approach in training programs, we claim that investigating the influence of training design on the transfer of training needs to take into account a constructivist perspective.

In addition, Cheng and Hampson (2008) indicate that, in order to reach a better understanding of the transfer process, attentions should be given to other crucial but unseen variables in the transfer process. In practice, 
learning in training does not automatically result in transfer (e.g.Hesketh \& Laidlaw, 1997; Kraiger, Ford, \& Salas, 1993). Once trainees re-enter the workplace after training, they have to cope with environmental and situational factors which might inhibit the used of the newly acquired skills and knowledge, such as the negative attitudes of their co-workers (Nikandrou, Brinia, \& Bereri, 2009; Taylor, 2000). Thus, in order to have opportunities to use acquired trained knowledge and successfully apply them to the job, it has been argued that trainees need to use appropriate strategies, i.e. a (training) transfer strategy (Burke \& Baldwin, 1999). Research revealed that the use of transfer strategies for facilitating the transfer process is a crucial prerequisite for transfer of training (Burke, 1997; Ford \& Weissbein, 1997; Machin \& Fogarty, 2003). Tzinner, Haccoun and Kadish (1991) believed that paying attention to goal-setting and selfmanagement as transfer strategies resulted in a significantly higher level of transfer. Foxon (1994) argued that transfer strategies enhance the transfer probability by simultaneously embracing the impact of organizational system factors and assisting the trainees in practically applying the training into their work. A few studies proposing the importance of transfer strategies as a key mediator of the link between influencing factors and transfer outcomes. Examples include Gollwitzer (1999), Latham (1997) and Noe, Sears, and Fullenkamp (1990). However, it is still unclear to what extent transfer strategies influence the relations between training design and transfer of training. Therefore in addition to the direct relationship between training design and transfer of training, we include the trainee's use of transfer strategies as a mediating variable. We propose it will influence the strength of the relation between the training design and transfer of training. We hypothesize that training design affects trainee's use of transfer strategy, which in turn, influence transfer of training.

To sum up, the present study addresses the influence of the training design on the trainee's transfer of training, focusing on the formerly studied training transfer design characteristics as well as the implementation of constructivist instructional principles. In addition, we study the extent to which the trainee's use of transfer strategies to clarify how the impact of these factors in the transfer process.

\section{CONCEPTUAL FRAMEWORK}

\subsection{Training design characteristics: the traditional approach}

Although many design characteristics have been proposed as influential for the transfer of training, for many of them, empirical evidence is still largely missing. According to Machin and Fogarty (2003), there are main 
relevance of the following training design characteristics need to be focused such as identical elements; over-learning; relapse prevention and goalsetting.

Identical elements refers to the correspondence between a training and an application setting. Several studies have revealed that the presence of similar stimulus and response elements and conditions improve transfer of training (Baldwin \& Ford, 1988; Machin \& Fogarty, 2003).

Russ-Eft (2002, p. 54) defines over-learning as "deliberate training and practice beyond a set criterion performance". It implies trainees are offered repeated practice beyond even after they perform successfully performance (Burke \& Hutchins, 2007; Machin \& Fogarty, 2003). It is expected that over-learning can improve transfer by providing a greater amount of information being learned and retained (Burke \& Hutchins, 2007; Nijman, Nijhof, Wognum, \& Veldkamp, 2006), therefore, "cognitive ability may be dedicated to solving novel or more complex tasks" ((Burke \& Hutchins, 2007, p. 275)

Burke and Baldwin (1999) suggest the necessity of preparing trainees for the possibility of setbacks of their work in applying what has been learnt. They use the concept of relapse prevention, "a self-management technique for individuals to become aware of environmental and intrapersonal threats to skill maintenance, in order to anticipate and recover from possible lapses into "old" behavior and prevent these in the future" (Nijman, Nijhof, Wognum, \& Veldkamp, 2006, p. 534). Research shows relapse prevention to correlate with learning outcomes (Machin \& Fogarty, 2003), and with the increased use of transfer strategies (Tziner, Haccoun, \& Kadish, 1991).

Goal setting refers to activities involving determining goals for the use of new knowledge, skills and attitudes when they return to the workplace (Machin \& Fogarty, 2003). Goal setting is seen as an important determinant of behavior because goals direct attention and action. It may enhance transfer of training since it helps to improve self-efficacy estimations (e.g. Tziner, Haccoun, \& Kadish, 1991). Therefore, goalsetting is often taking into account in transfer of training research, although studies differ in the positioning of this variable. Some studies define goal-setting as a trainee characteristic (Tziner et al., 1991; Wexley \& Baldwin, 1986). Others argue that it is a transfer enhancing activity (e.g.Machin \& Fogarty, 2003; Nijman, Nijhof, Wognum, \& Veldkamp, 2006). This difference in positioning is related to the theoretical perspective on goals-setting the authors take. From a traittheory perspective, goal-setting is defined as a trainee's individual characteristic (such as intelligence) (e.g. Dweck, 1986). However, other authors argue goal-setting is influenced by the learning environment the trainee is participating in. For example, Machin and Fogarty (2003, p. 54) considered that "Goal setting is a very specific activity that involves teaching the trainee to set goals for the implementation of new skills when they return to the workplace." Therefore, they position goal-setting as a training design characteristic. In this study, we follow the Nijman et al (2006) and Machin and Fogarty (2003) perspectives, identifying goalsetting as a training design characteristic. 
Looking at the aforementioned design principles from a learning theory perspective, it shows that the principles have their origin mainly in behaviorist and cognitivist learning theories.

In behaviorist approach, the stimulus response idea within the identical elements principle or over-learning provide trainees abilities to respond automatically to the specific goal. This instructional design emphasizes the role of feedback and reinforcement, not self-interpretations and selfreflections (Tenenbaum, Naidu, Jegede, \& Austin, 2001). It is clear that this approach is not considering the possibility of thought process occurring inside the mind. It results in trainees cannot respond in a novel situation.

Shifting from behaviorist approach, cognitivist learning theories based on the trainees' process information behind the behavior (e.g. relapse prevention or goal-setting). This instructional design has been aimed at encouraging problem solving in order to develop cognitive capacities, enable the trainees to make this memory-based interaction and stimulates their cognitive development (Tenenbaum et al, 2001).

There is a shift to constructivist paradigm in training practices, a continuing development of knowledge and learning in which a cognitive activity relating to the construction of mental structures of reality. Constructivism refers situated cognition in authentic activities (Brown, Collins, \& Duguid, 1989). Constructivist approach provides opportunities to trainees to interpret the world with a multiple perspective, based on their own experiences, interpretations, and (internal and social) negotiation (Jonassen, 1994). Thus, it facilitates trainees apply their knowledge to a new situation (Wagner \& McCombs, 1995). Given the current training practices where to a minor or major extent constructivist pedagogy is implemented, we argue the necessity of an extension of the traditionally measured design characteristics with features that reflect the constructivist learning environments in current training programs.

\subsection{Training design characteristics: a constructivist approach}

The past decade has seen the rapid development of constructivist learning approach, a continuing development of behaviorist and cognitivist approach in understanding learning. Researchers have tried to describe the key features of constructivist learning environments. One of pivotal studies is Jonassen (1994). He suggests crucial characteristics that differentiate constructivist learning environments:

1. Providing various representations of reality.

2. Avoiding oversimplification and stand for the complexity of the real in practice 
3. Encouraging 'construct' knowledge instead of 'copying' knowledge

4. Learning involves authentic tasks in a meaningful context rather than abstract instruction out of context.

5. Learning environments are real-world settings, not predetermined sequences of instruction.

6. Encouraging thoughtful reflection on experience.

7. Enabling context- and content-dependent knowledge construction.

8. Supporting collaborative construction of knowledge through social negotiation, not competition among learners.

The definition of constructivism is remaining somewhat vague (e.g. Gijbels, Van de Watering, Dochy, \& Van den Bossche, 2006; Loyens, 2007). However, the core idea of constructivist pedagogy considers learning as meaning making, and the negotiation of meaning. According to the constructivists, learning occurs when the learner interacts with the training and the wider social environment (Driver, 1988; Von Glaserfeld, 1987; Wheatley, 1993). The trainee adapts to the external world, and negotiates meaning with the fellow trainees and others with whom s/he interacts. Reality and meaning are "socially negotiated" (Candy, 1991), and it is through this negotiation that the differing perceptions of trainees is transformed into common meaning. Thus, effective training maximizes the trainees' opportunities to interact with each other, with the trainer, and with work situations and fellow workers (Tenenbaum, Naidu, Jegede, \& Austin, 2001).

Besides the theoretical elaborations on the concept of constructivist learning environments, a few researchers have tried to evaluate the extent to which learning environments incorporate constructivist instructional principles. Instruments have been developed that measure trainees' perceptions of the application of constructivist learning principles in the learning environment. The rationale is that not the design of the learning environment but how trainees perceive it, influence trainees' learning approaches and learning results (Entwistle \& Tait, 1990; Nijhuis, Segers, \& Gijselaers, 2005). The study of Tenenbaum, Naidu, Jegede, and Austin (2001) was an example. They developed and validated an instrument measuring the presence and/or absence of constructivist practices and principles in teaching and learning. Consequently, seven components of constructivist teaching and learning are discerned: (1) arguments, discussions, debates among learners (2) conceptual conflicts and dilemmas, (3) sharing ideas with others, (4) the use of materials and measures targeted toward solutions, (5) enhancing learners' reflections and concept investigation, (6) meeting the learners' learning needs, (7) making meaning by addressing real-life examples during the instructional unit. The Tenenbaum et al instrument has been used and validated in various studies 
in higher education (e.g. Gijbels, Segers, \& Struyf, 2008; Gijbels, Van de Watering, Dochy, \& Van den Bossche, 2006; Kanuka, Rourke, \& Laflamme, 2007). In this study, therefore, the Tenenbaum et al instrument is used.

\subsection{Use of transfer strategy}

According to Noe, Sears and Fullenkamp (1990) (cited in Roberson, Kulik, and Pepper (2009), transfer strategies are cognitive and behavioral techniques, that include setting goals, analyzing work situations, preparing to deal with difficulties, identifying and using the necessary supports, and recognizing and monitoring opportunities to use acquired knowledge and skills on the job.

Foxon (1994, p. 3) has argued that for training transfer to be considered seriously, transfer strategies have to be formulated, and "implemented during the design, development and delivery of instruction". She believes that such strategies tend to increase the possibility of transfer through acknowledgement of the impact of organizational system factors that simultaneously assist the individual to focus on potential applications of learning. Olsen (1998) emphasizes the need of understanding how to develop trainee's intention to use the new knowledge and skills.

There are several transfer strategies outlined in the literature which can be incorporated into training courses such as (1) the trainees' situation (e.g. identifying situations at work to apply the trained skills), (2) the trainees' thoughts/feelings (e.g. thoughts about the necessary support needed in order to use the trained skills; retaining self-confidence when experiencing resistance or burdens), (3) the trainees' behavior (e.g. creating and maintaining a social network), and (4) consequences of the trainees' behavior (e.g. being prepared to deal with skepticism of colleagues) (Burke \& Baldwin, 1999). Researchers have consistently emphasized the need for better understanding of the role of use of transfer strategies by trainees (e.g. Ford \& Weissbein, 1997; Machin \& Fogarty, 2004).

\subsection{Training transfer effects}

Many practitioners and researchers refer to Kirkpatrick's taxonomy (1998) to evaluate training effects. Kirkpatrick discerns four 'levels': (1) how trainees felt about the training; (2) whether they have learned anything; (3) whether the learning was transferred to the job or the extent of behavior and capability improvement and application and (4) the effects on the business or environment. In this study we focus on the third level. This means we question if the application of the trained knowledge, skills and attitudes in the workplace improves the performance of the job tasks as well 
as the work performance in general. In this respect, Xiao (1996) refers to the improvement of the productivity efficiency of the employee through training. Additionally, DeSimone, Werner, and Harris (2002, p. 3) claim that training programs aim to "provide its members (of the organization) with the opportunities to learn necessary skills to meet current and future job". This implies training programs do not only aim to enhance the quality of current task and work performance but also support the competence development of trainees in order to meet the demands of the future.

\section{RESEARCH QUESTION AND HYPOTHESES}

In order to better understand training design variables influencing training transfer effect, we measure the influence of earlier studied transfer design characteristics and add learning environment characteristics from a constructivist perspective. Moreover, we study the contribution of the trainees' use of transfer strategies.

The following research question is addressed: "To what extent does training design, taking into account the role of the trainees' transfer strategies, contribute to the training transfer effects".

Two hypotheses were tested:

$\mathrm{H1}$ ) "The training design is positively related to transfer of training".

$\mathrm{H} 2$ ) "The influence of the training design on the training transfer effects is mediated by the trainee's use of transfer strategies".

\section{METHODOLOGY AND RESEARCH DESIGN}

\subsection{Participants}

The current study took place in a sample of MBA programs in Vietnam (Table 2.1). The courses are taught in Vietnamese and/or English/French and use different instructional approaches. Data were collected from 305 trainees attending eight different part-time MBA programs in Vietnam. 167 trainees answered the 1st survey. 126 trainees answered the 2 nd one. The majority of the sample was male $(n=102 ; 61 \%)$. The average age was 32 . 
Table 2.1 Descriptions of MBA programs in Vietnam

\begin{tabular}{|c|l|l|l|}
\hline No & \multicolumn{1}{|c|}{ Program } & \multicolumn{1}{|c|}{ Instructional approach * } & \multicolumn{1}{|c|}{ Language } \\
\hline 1 & $\begin{array}{l}\text { Vietnam - } \\
\text { Belgium }{ }^{1} \text { MBA }\end{array}$ & Lecture; Tutoring & English \\
\hline 2 & NEU $^{2}$ MBA & Lecture & Vietnamese \\
\hline 3 & CFVG ${ }^{3}$ MBA & $\begin{array}{l}\text { Lecture; Consultancy project; } \\
\text { Simulation; Practical cases; } \\
\text { Problem solving; Conferences } \\
\text { competing }\end{array}$ & English/French \\
\hline 4 & VNU le ${ }^{4}$ MBA5 & $\begin{array}{l}\text { Lecture; Team working; } \\
\text { Seminars; Business consulting; } \\
\text { Group study; Guest speakers }\end{array}$ & Vietnamese \\
\hline 5 & VNU Re $^{5}$ MBA & $\begin{array}{l}\text { Lecture; Team working; } \\
\text { Seminars; Business consulting, } \\
\text { Group study; Guest speakers }\end{array}$ & English \\
\hline 6 & FTU $^{6}$ MBA & Lecture & Vietnamese \\
\hline 7 & MsM $^{7}$ MBA & $\begin{array}{l}\text { Lecture; Teaching assistants; } \\
\text { Project assignments }\end{array}$ & English \\
\hline 8 & HCMC UT $^{8}$ MBA & Lecture & Vietnamese \\
\hline
\end{tabular}

\subsection{Setting}

The present study was conducted in the setting of Master of Business Administration (MBA) programs. The first MBAs were offered by Harvard University about 100 years ago, in a two-year, full-time format. To date, MBA degree programs have spread around the world, with a diversity of master's degree in management-related subject. "Master's qualification is becoming almost a prerequisite for success as a senior manager" (Cameron, 2005, p. 4). The MBA setting provides a good opportunity to

- As described in the information in the program brochures. It can be questioned whether the practice in the classrooms is perfectly matching these information. Therefore we decided not to divide our sample in traditional vs. constructivist approach.

\footnotetext{
1 Solvay Business School (Universite. Libre de Bruxelles, Belgium)

2 Hanoi National Economics University

3 Centre Franco-Vietnamien de Formation a' la Gestion

4 Vietnam National University International Executive

5 Vietnam National University Regular Executive

6 Foreign Trade University

7 Maastricht School of Management in Vietnam

8 Ho Chi Minh City University of Technology
} 
study transfer of training for the following reasons. First, the MBA degree has become a big attraction as demand for higher education skyrockets. Gijselaers and Milter (2010, in press) mention that in the 1990s, about 75000 MBA students graduated each year in the US. The numbers of MBA programs and students has continued to grow since then across the globe (e.g. the US and Europe (1980 onwards), Asia (Thailand, 1995). About 500 European business school produce more than 20.000 graduates/year (Cameron, 2005, p. 4). Second, MBA programs are professionally oriented and focus on the development of professional competence (Mintzberg, 2004). They aim to improve the functional and managerial competencies of trainees (Camuffo, Gerli, \& Chiara, 2006), since most MBA participants are professionals with a considerable amount of experience, and they perceive the training as a competitive advantage for their professional development (Cheng \& Ho, 2001). Therefore, the possibilities training programs offer trainees to transfer the competencies they have been practicing during the training to the workplace, are of utmost importance for the trainees. Third, MBA programs provide trainees with "a highly analytical approach to managerial problem solving, and the ability to approach new problem in a structured fashion" (Cameron, 2005, p. 14). A question is whether and under what conditions MBA programs really reach these high ambitions. Finally, MBA programs produce economic benefits and career success to MBA trainees, to the extent that MBA graduates receive more promotions than those who did not receive an MBA degree (Inderrieden, Holtom, \& Bies, 2006). Given these benefits, studying MBA programs in order to contribute to optimizing their transfer effects, is appropriate.

In Vietnam, education has been considered as top priority by the Vietnamese government in its attempt to develop the economy and join the global arena. After nearly 30 years of economic reform, the country is now facing with more vigorous challenges than ever before. Consequently, the Vietnamese government has established robust educational institutions which include MBA training programs (for instance, the Hanoi National Economics University (NEU), Vietnam National University (VNU), Foreign Trade University (FTU), Solvay Business School (Université Libre de Bruxells, Belgium), Centre Franco-Vietnamien de Formation a' la Gestion (CFVG), Maastricht School of Management (MsM) in Vietnam). Although education is highly important in Vietnam, the question how the knowledge and skills obtained by trainees are transferred into work is inadequately verified. Not only such knowledge application assessment is in its infancy, but unfortunately MBA programs have never been researched to find out if MBA graduates can bring their knowledge to application. Meanwhile, there is a growing market of MBA programs with varying trainees' working conditions. These programs provide opportunity for researchers to examine 
the different variables incorporated in the transfer process. It also emphasizes a need of the assessments in order to ascertain whether these programs have a positive impact on Vietnamese corporate practice. Thus, providing a comprehensive understanding of real training transfer issue in Vietnam is an urgent necessity. This will help educational organizations in Vietnam effectively and efficiently enhance transfer process by diagnosing the factors that impact on training transfer systems.

The duration of these Vietnamese MBA programs (one up two years) also is one of the positive points in favor of the present study compared to previous studies. While almost all other training programs studied in the literature are very short; for example, a three-day course (Lim \& Morris, 2006), one five-and-a-half-day week (Xiao, 1996), 12 days' duration (Kirwan \& Birchall, 2006) or one month program (Velada, Caetano, Michel, Lyons, \& Kavanagh, 2007), these Vietnamese MBA programs have higher probability that trainees will have opportunities to internalize the training and develop a transfer strategy.

\subsection{Measurement}

To measure the variables, we used and extended questionnaires which have been validated in similar settings (Table 2.2). In some cases they were adapted for the specific purpose of data collection in MBA programs. All measures were assessed using a five-point Likert-type scale (1=strongly disagree; $2=$ disagree; $3=$ neither agree nor disagree; 4=agree; 5=strongly agree).

We indicated the scale names and their items as they resulted from the factor analyses we have conducted.

The questionnaires were completed by trainees at two points in time: (T1) - at the end of the training program, and (T2) - three months after the end of the training. At time 1, training design variables and trainee's perception of using training transfer strategies variables were measured. At time 2, trainee's perception of training transfer effects was measured. 
Table 2.2 Variables, scales and examples

\begin{tabular}{|c|c|c|c|}
\hline \multicolumn{2}{|r|}{ Variables } & Scales name and & Example items \\
\hline \multirow[t]{2}{*}{ 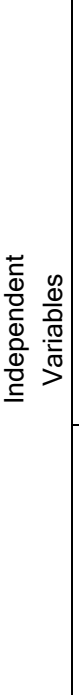 } & $\begin{array}{l}\text { Training transfer } \\
\text { design } \\
\text { characteristics } \\
\text { Nijman, Nijhof, } \\
\text { Wognum and } \\
\text { Veldkamp } \\
\text { (2006) }\end{array}$ & $\begin{array}{l}\text { - Relapse Prevention } \\
(n=1) \\
\text { - Goal setting } \\
(n=1) \\
\text { - Identical element } \\
(n=1) \\
\text { - Over learning } \\
(n=1)\end{array}$ & $\begin{array}{l}\text { - I am prepared for the possibility of } \\
\text { setbacks of my work in applying what } \\
\text { has been learnt } \\
\text { - I have intended to apply what has been } \\
\text { learnt in my work } \\
\text { - I found the contents of the training in } \\
\text { agreement with my daily work } \\
\text { - The training had lasted longer than } \\
\text { necessary for me to master the subject }\end{array}$ \\
\hline & $\begin{array}{l}\text { Constructivist } \\
\text { learning } \\
\text { Tenenbaum, } \\
\text { Naidu, Jegede } \\
\text { and Austin } \\
(2001)\end{array}$ & $\begin{array}{l}\text { - Personal course } \\
\text { benefits }(n=15) \\
\text { - Cognitive Conflicts } \\
(n=3) \\
\text { - Interactions and } \\
\text { Real life events } \\
(n=11)\end{array}$ & $\begin{array}{l}\text { - The course took into consideration my } \\
\text { needs and concerns } \\
\text { - The course caused conflicts for me } \\
\text { among various concepts } \\
\text { - The course allowed for arguments, } \\
\text { discussion and debates }\end{array}$ \\
\hline 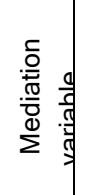 & $\begin{array}{l}\text { Trainees' } \\
\text { transfer } \\
\text { strategy } \\
\text { (Burke \& } \\
\text { Baldwin, 1999) }\end{array}$ & $\begin{array}{l}\text { Transfer strategy } \\
(\mathrm{n}=19)\end{array}$ & $\begin{array}{l}\text { I identified the appropriate setting for } \\
\text { applying what I have learnt }\end{array}$ \\
\hline 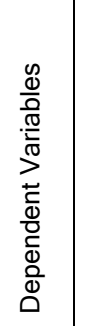 & $\begin{array}{l}\text { Training transfer } \\
\text { effect } \\
\text { (Xiao, 1996) } \\
\text { - The authors } \\
\text { - The authors }\end{array}$ & $\begin{array}{l}\text { - Task performance } \\
\text { improvement }(n=6) \\
\text { - Capacity building } \\
(n=6) \\
\text { - Job performance } \\
\text { in general }(n=5)\end{array}$ & $\begin{array}{l}\text { - I can accomplish my job task better } \\
\text { than by using new KSA } \\
\text { - My ability to organize my work in } \\
\text { general is increased } \\
\text { - In general, I think this training course } \\
\text { has helped me increase my work } \\
\text { performance }\end{array}$ \\
\hline
\end{tabular}


The questionnaires were completed by trainees at two points in time: (T1) - at the end of the training program, and (T2) - three months after the end of the training. At time 1, training design variables and trainee's perception of using training transfer strategies variables were measured. At time 2, trainee's perception of training transfer effects was measured.

Training transfer effects were measured at time 2, three month after training as literature revealed that transfer of training is changed by time (Awoniyi, Griego, \& Morgan, 2002). Especially, the period after training is considered the most important in facilitating positive transfer (Wexley \& Baldwin, 1986). Nikandrou, Brinia and Bereri (2009, p. 258) suggest that, "to understand the training transfer process we need to understand all the factors affecting trainees as they enter training, during the training process and after training when they return to their work environment". Alliger, Tanenbaum, Bennett, Traver and Shotland (1997, p. 355) also noted: "By gathering reaction data one, three, or six months after training, trainees will have experienced whether the training was in fact useful, and should be in a better position to judge the utility of the training". Actually, at the end of the training, trainees usually do not fully master the newly learned knowledge and skills because "They need to practice and learn more in their job context to internalize what they have learned" (Vermeulen, 2002, p. 369), Given the aforementioned arguments, trainee's perception of training transfer effects was measured at T2.

Because the purpose of a study is to summarize data with a smaller number of variables, we use principal component analysis (PCA) to extract the important information from the data set and to express this information as a set of new independent variables. Doing PCA help us to make sense of the data, generally thought of as more of a theory-generating procedure (Stevens, 1996) and get an empirical summary of the data set (Tabachnick \& Fidell, 1996).

For measuring the constructivist approach in the training program, we used the Tenenbaum, Naidu, Jegede and Austin (2001) questionnaire. This questionnaire is validated in Australian setting. We do not have sufficient evidence about if having the same number of factors underlying the data in Vietnamese setting. Therefore, we conducted a PCA, oblique rotation. The PCA results revealed the following three factors: (1) Personal course benefits: fifteen items loaded on this factor that explained $41.07 \%$ of the variance. Internal consistency was Cronbach's alpha $(\mathrm{C \alpha})=.93$; (2) Cognitive conflicts: three items loaded on this factor that explained $7.82 \%$ of the variance. $\mathrm{Ca}=.74$ and (3) Interactions (with the participants and the peers) and Real-life events: eleven items loaded on this factor that explained $5.24 \%$ of the variance. $\mathrm{C} \alpha=.91$ 
The training transfer design characteristics were measured with Nijman, Nijhof, Wognum and Veldkamp (2006) questionnaire. The PCA results showed four items loaded on one factor that explained $52.43 \%$ of the variance (these are all positive affect items- relapse prevention, goal setting and identical element) with $C \alpha=.82$. Only one item loaded on another factor that explained $20.05 \%$ of the variance. This item referred to the characteristic "over-learning" which Vietnamese participants interpreted as a negative point of the course and confused them. This item was therefore deleted from further analysis.

To measure transfer strategy scale, we used the Burke and Baldwin (1999) questionnaire. As this instrument has been validated in many studies in comparable settings, we did not conduct a factor analysis on the data. The Ca is very high for our sample $(0.88)$ and therefore confirms prior validation studies.

For measuring the transfer effect, the Xiao (1996) questionnaire was used. Moreover, the authors extended the questionnaires with 11 items in order to admeasure transfer effects with a more robust instrument. These items were based on an evaluation questionnaire used in Vietnamese training settings. The PCA results show three factors on which all items loaded high (minimum $=0.51$ ), except for one of the items of the perception task performance improvement factor, which also loaded onto two other factors, showing the lack of discriminative power. This item was therefore deleted from further analysis. The three factors are (1) Perception task performance improvement: five items loaded on this factor that explained $54.13 \%$ of the variance, $\mathrm{C} \alpha=.90 ;$ (2) Capacity building: six items loaded on this factor that explained $10.08 \%$ of the variance, Ca $=.92$ and (3) Job performance in general: five items loaded on this factor that explained $6.01 \%$ of the variance, $\mathrm{C} \alpha=.86$.

Based on the factors resulting from the factor analyses, the research model of this study can be depicted as follows (figure 2.1). In this model, we schematized the research model that will be investigate in this study, including training design factors as independent variables and transfer of training as dependent variables and transfer strategy as mediation variable. 
Figure 2.1 Research model

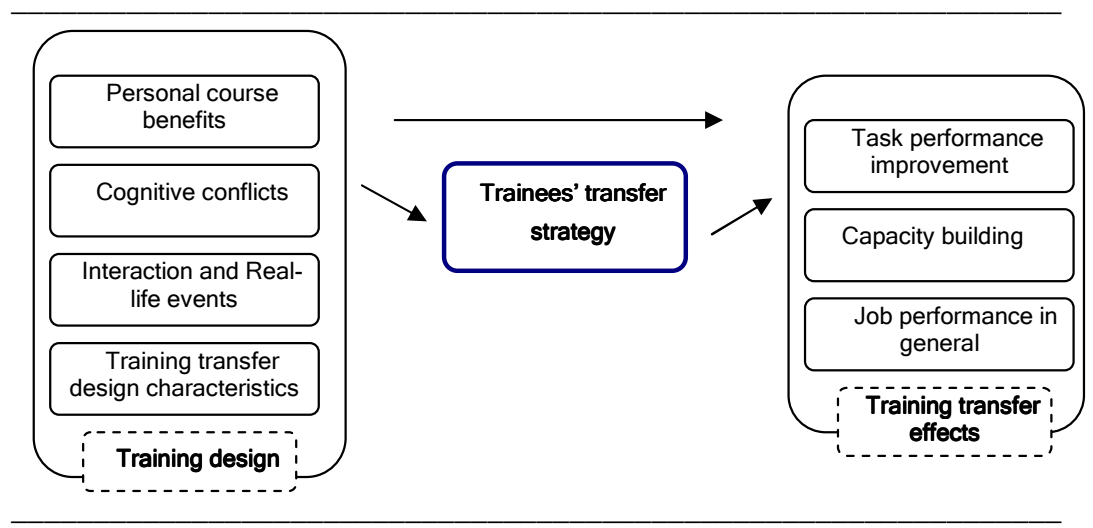

\subsection{Procedures}

Questionnaires were translated into Vietnamese language. To check the accuracy of the English - Vietnamese translation, the questionnaires were translated back to English to check whether changes would occur. This was not the case.

\subsection{Method of analysis}

The analysis is presented in three parts. According to the theoretical framework, it first tests whether the training design variables influence the transfer of training. Next, it analyzes whether the participants' transfer strategies contribute to the transfer of training. Finally, it analyzes whether the complete proposed model of training design (taking into account the mediating role of the participants' transfer strategies) is validated.

The first two parts of the analysis are primarily based on (multiple) regression analyses. The last part of the analysis will use path analyses to validate the complete proposed framework. The adequacy of the models is assessed by EQS version 6.1 (Bentler, 1985) (Only significant relations are shown). 


\section{RESULTS}

The descriptive statistics, Pearson correlations and reliability coefficient Cronbach Alpha (Ca) are presented in Table 2.3.

Table 2.3 Cronbach's Alphas and intercorrelations among variables

\begin{tabular}{|c|c|c|c|c|c|c|c|c|c|c|}
\hline Variables & M & SD & 1 & 2 & 3 & 4 & 5 & 6 & 7 & 8 \\
\hline $\begin{array}{l}\text { 1. Personal course } \\
\text { benefits }\end{array}$ & 3.6 & 0.61 & (.93) & & & & & & & \\
\hline 2. Cognitive conflicts & 1.9 & 0.72 & -.050 & $(.74)$ & & & & & & \\
\hline $\begin{array}{l}\text { 3. Interactions and } \\
\text { Real-life events }\end{array}$ & 3.6 & 0.66 & $.763^{* *}$ & .066 & (.91) & & & & & \\
\hline $\begin{array}{l}\text { 4. Training transfer design } \\
\text { characteristics }\end{array}$ & 3.6 & 0.68 & $.729^{\star *}$ & -.104 & $.633^{\star *}$ & (.82) & & & & \\
\hline 5. Transfer strategy & 3.6 & 0.47 & $.506^{* *}$ & -.080 & $.442^{\star *}$ & $.577^{\star *}$ & $(.88)$ & & & \\
\hline $\begin{array}{l}\text { 6. Task performance } \\
\text { improvement }\end{array}$ & 3.8 & 0.62 & $.462^{* *}$ & -.032 & $.439^{\star *}$ & $.465^{\star *}$ & $.507^{\star \star}$ & $(.90)$ & & \\
\hline 7. Capacity building & 4.0 & 0.46 & $.324^{* *}$ & .005 & $.290^{\star *}$ & $.391^{\star *}$ & $.420^{\star *}$ & $.597^{\star \star}$ & (.92) & \\
\hline $\begin{array}{l}\text { 8. Job performance in } \\
\text { general }\end{array}$ & 3.7 & 0.60 & $.577^{\star *}$ & -.002 & $.574^{\star *}$ & $.599^{\star \star}$ & $.491^{\star *}$ & $.707^{\star \star}$ & $.647^{\star *}$ & $(.86)$ \\
\hline
\end{tabular}

Note: ${ }^{* *} \mathrm{p}<.01$; values on the diagonal are Cronbach's Alphas

The results revealed that most of the training design variables in this study (Personal course benefits, Interactions and Real-life events and Training design characteristics) are positive and significantly associated with the use of transfer strategies and with transfer of training. This is clearly not the case for the variable Cognitive conflicts. Moreover, the use of (training) transfer strategies is strongly related to the transfer of training.

Mean scores in Table 3 also showed that the trainees demonstrated high mean scores on most variables with an acceptable standard deviation indicating variability in responses. However, this is not the case for the variable Cognitive conflict, which is scored very low. On the opposite, the effect variable Capacity building is scored relatively high. This is consistent with fact that the reason of most of the Vietnamese trainees to study MBA programs is increasing their competencies.

\subsection{Testing hypotheses}

Hypothesis 1: Training design is positively related to the training transfer effects

To test this hypothesis, three (stepwise) regression analyses were performed. It was tested if training design significantly predicts transfer of training, presented by the perception of the task performance improvement, 
the trainees' capacity building and the job performance in general. The results are presented in Table 2.4 .

Table 2.4 Regression analysis for training design predicting training transfer effects

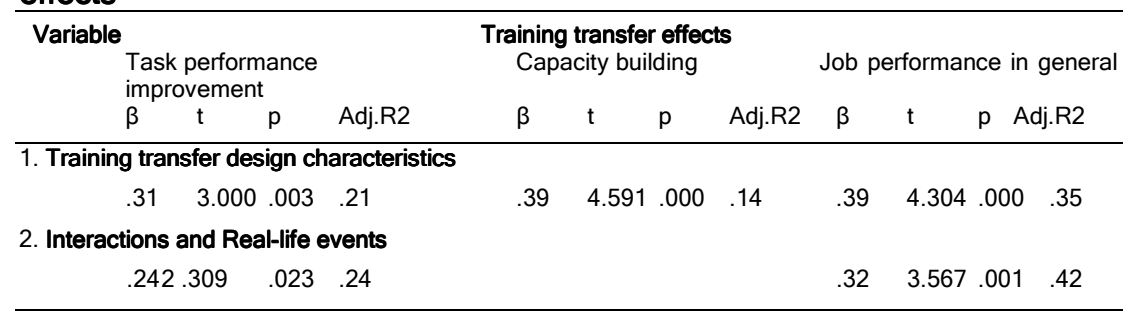

Note: $\beta=$ standardized coefficients

Table 2.4 shows that training transfer effects in terms of the trainees' task performance improvement, of improved capacity building and of a better job performance in general is significantly predicted by the trainees' perception of the implementation of transfer design characteristics in the training. Moreover, the perception of task performance improvement and of job performance in general is also significantly predicted by the perception of interactions and (the use of) real-life events during the training, a constructivist instructional principle. This implies the data (partly) support the first hypothesis.

Hypothesis 2: The influence of training design on training transfer effects is mediated by the trainees' transfer strategy

The second hypothesis was tested using (enter) regression analysis. To determine whether the transfer strategy is a mediator of the relationship between training design and training transfer effects, Baron and Kenny (1986) mediation principles have been applied.

Firstly we test if the training design predicts transfer strategy (block 1 in Table 2.5). Secondly, it was analyzed if the transfer strategy predicts training transfer effects (block 2). Finally, it was analyzed if the transfer strategy mediated the relation between the training design and training transfer effects (block 3). We test the effect of training design on training transfer effects in terms of Task performance improvement, Capacity building and Job performance in general. The results of these computations are presented in Table 2.5 .

Table 2.5 shows that, in terms of Task performance improvement, (1) training design significantly predicts transfer strategy $\left(\beta=.43, p=.000\right.$, adj. $R^{2}$ $=.33)$; (2) transfer strategy significantly predicts training transfer effects $\left(\beta=.51, p=.000\right.$, adj. $\left.R^{2}=25\right)$; and $(3)$ transfer strategy mediates the relation between training design and training transfer effects $\left(\beta=.33, p=.001\right.$, adj. $R^{2}$ $=.30)$. 
Similarly, in terms of Capacity building, (1) training design significantly predicts transfer strategy $\left(\beta=.43, p=.000\right.$, adj. $\left.R^{2}=33\right) ;(2)$ transfer strategy significantly predicts training transfer effects $\left(\beta=42, p=.000\right.$, adj. $\left.R^{2}=.17\right)$; and (3) transfer strategy mediates the relation between training design and training transfer effects $\left(\beta=.29, p=.006\right.$, adj. $\left.R^{2}=.18\right)$.

Finally, in terms of Job performance in general, (1) training design significantly predicts transfer strategy $\left(\beta=.43, p=.000\right.$, adj. $\left.R^{2}=.33\right) ;(2)$ transfer strategy significantly predicts training transfer effects $(\beta=.49$, $p=.000$, adj. $\left.R^{2}=.24\right)$; and (3) transfer strategy mediates the relation between training design and training transfer effects $\left(\beta=.18, p=.043\right.$, adj. $\left.R^{2}=.42\right)$.

Table 2.5 Regression analysis for training design and trainees' transfer strategy predicting training transfer effects

\begin{tabular}{|c|c|c|c|c|c|c|c|c|c|}
\hline \multirow[t]{2}{*}{ Variables } & \multicolumn{4}{|c|}{ Transfer strategy } & \multicolumn{5}{|c|}{$\begin{array}{c}\text { Training transfer effects } \\
\text { (Task performance improvement) }\end{array}$} \\
\hline & B & $\mathrm{t}$ & $\mathrm{p}$ & $\beta$ & $\mathrm{t}$ & $\mathrm{p}$ & $\beta$ & $\mathrm{t}$ & $\mathrm{p}$ \\
\hline $\begin{array}{l}\text { Training design } \\
\text { - Training transfer design } \\
\text { characteristics } \\
\text { Transfer strategy } \\
\text { Adj. R2 }\end{array}$ & $\begin{array}{l}.43 \\
.33\end{array}$ & 4.512 & .000 & $\begin{array}{l}.51 \\
.25\end{array}$ & 6.356 & .000 & $\begin{array}{l}.25 \\
.33 \\
.30\end{array}$ & $\begin{array}{l}2.032 \\
3.400\end{array}$ & $\begin{array}{l}.045 \\
.001\end{array}$ \\
\hline \multirow{2}{*}{ Adj. R2 } & \multicolumn{4}{|c|}{ Transfer strategy } & \multicolumn{5}{|c|}{$\begin{array}{l}\text { Training transfer effects } \\
\text { (Capacity building) }\end{array}$} \\
\hline & $\beta$ & $\mathrm{t}$ & $p$ & $\beta$ & $\mathrm{t}$ & $\mathrm{p}$ & $\beta$ & $\mathrm{t}$ & $p$ \\
\hline $\begin{array}{l}\text { Training design } \\
\text { - Training transfer design } \\
\text { characteristics } \\
\text { Transfer strategy } \\
\text { Adj. R2 }\end{array}$ & .33 & 4.512 & .000 & $\begin{array}{l}.42 \\
.17\end{array}$ & 5.031 & .000 & $\begin{array}{l}.33 \\
.29 \\
.18\end{array}$ & $\begin{array}{l}2.567 \\
2.796\end{array}$ & $\begin{array}{l}.012 \\
.006\end{array}$ \\
\hline \multirow{2}{*}{ Adj. R2 } & \multicolumn{4}{|c|}{ Transfer strategy } & \multicolumn{5}{|c|}{$\begin{array}{l}\text { Training transfer effects } \\
\text { (Job performance in general) }\end{array}$} \\
\hline & B & $\mathrm{t}$ & $p$ & $\beta$ & $\mathrm{t}$ & $p$ & $\beta$ & $\mathrm{t}$ & $p$ \\
\hline $\begin{array}{l}\text { Training design } \\
\text { - Training transfer design } \\
\text { characteristics } \\
\text { - Interactions and Real- } \\
\text { life events } \\
\text { Transfer strategy } \\
\text { Adj. R2 }\end{array}$ & .43 & 4.512 & .000 & $\begin{array}{l}.49 \\
.24\end{array}$ & 6.120 & .000 & $\begin{array}{l}.34 \\
.25 \\
.18 \\
.42\end{array}$ & $\begin{array}{l}3.227 \\
2.225 \\
2.046\end{array}$ & $\begin{array}{l}.002 \\
.028 \\
.043\end{array}$ \\
\hline
\end{tabular}

Note: $\beta=$ standardized coefficients 


\subsection{Testing the model}

Given the theoretical insights as described above, the originally hypothesized model is composed of paths leading from the three constructs measuring training design (Personal course benefits, Training transfer design characteristics and Interactions and Real-life events) toward transfer strategy and transfer training, and three paths from transfer strategy toward transfer training. The cognitive conflicts construct is dropped since it is not related to any corresponding construct (see Table 2.3).

Based on the exploratory design of the study, and as recommended by Anderson and Gerbing (1988), our proposed model was compared with several other models presenting plausible alternatives. The final 'best fitting' model surpassed all the goodness of fit indices $(x 2=15.30, d f=8, p=.05$, $\mathrm{CFI}=0.98, \mathrm{NNFI}=0.96, \mathrm{RMS}=0.25$ ) indicated that the appropriateness of the model structure and its theoretically acceptability.

The results as shown in figure 2.2 support partly both hypotheses of this study: (1) transfer of training is influenced by training design characteristics; (2) the trainees' use of transfer strategies plays a mediating role.

In more detail, personal benefits of the training and the use of interactions and real life events directly affect the transfer of training $(\beta=.17$ and $\beta=.36$ respectively). This is not the case for training transfer design characteristics variable. Also, personal benefits of the training and the use of interactions and real life events directly affect the transfer of strategy ( $\beta=.24$ and $\beta=.40$ respectively). This is not the case for interactions and real life events variable. The extent to which a trainee uses training transfer strategies influences directly and significantly the transfer of training $(\beta=.42$, $\beta=.41$ and $\beta=.35$ respectively). Moreover, the results indicate that the relation between personal benefits and transfer of training is stronger when the trainee uses strategies to improve transfer.

Figure 2.2 Path analysis model toward transfer of training

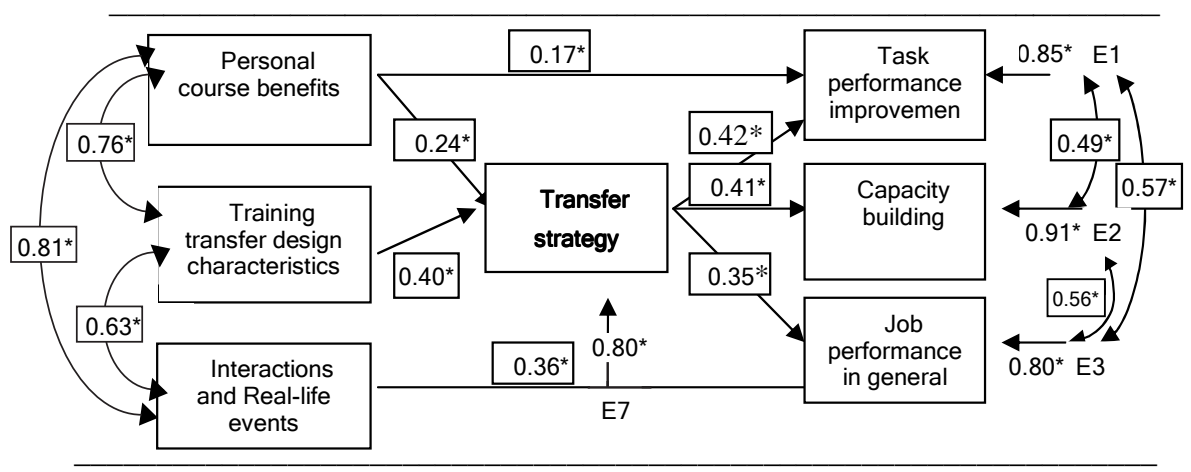




\section{CONCLUSION AND DISCUSSION}

We have argued about the necessity of an extension of the traditionally measured design characteristics to incorporate characteristics that reflect the constructivist learning environments in current training practices. In addition, we investigate the extent to which the trainee's use of transfer strategies to clarify how the impact of these factors in the transfer process. It was found that (i) the training transfer design characteristics, specially the presence of constructivist perspective, are positively related to transfer of training in terms of job task, capacity building and work performance improvement; (ii) the association between training design and transfer of training was mediated through the trainees' use of transfer strategies.

More precisely, the MBA trainees involved in our study will only transfer what they have learned to their jobs and therefore improve their performance as well as develop their competencies if (1) they perceive the MBA course is beneficial for them; (2) the course supports interactions among participants and makes use of real life events, (3) if transfer enhancing instructional methods are applied in the training design (use of relapse prevention, identical elements, goal setting; and (4) when they make use of strategies to transfer the learned knowledge and skills.

The results of this study confirm prior findings that the training transfer design characteristics are positively related to transfer of training. For example, relapse prevention strategies (e.g. Tziner, Haccoun, \& Kadish, 1991) and goal setting (e.g. Gist, Bavetta, \& Stevens, 1990) influence transfer of training. Additionally, the importance of two principles based on constructivist pedagogy is evidenced: the extent to which the trainee experiences the training as personal beneficial and the extent to which (s)he perceives that during the course interactions between trainees (and (trainees with trainers) as well as the use of real life situations have been implemented as instructional principles. It is important to note that personal benefits refer to what the value-added of the course is for the trainee and represents constructivist principles: motivating them toward reflections and concept investigation; encouraging them making meaning of the learning content; taking into account their need; and providing materials and resources to support learning.

In contradiction with what we expected, the interactions and real life situations was non-significant predictor of transfer strategy. This can be explained by the possibility of the suppressor effects. According to Facteau, Dobbins, Russell, Ladd, and Kudisch (1995), a suppressor variable can suppress the effect of other independent variables in explaining variance in a dependent variable. As shown in the correlation matrix, interactions and real life situations is significantly correlated with transfer strategy $(r=.44)$. 
Similarly, Personal course benefits and Training transfer design characteristics are significantly correlated with transfer strategy $(r=.51$ and .58 , relatively). Meanwhile, Personal course benefits, Training transfer design characteristics and Interactions and Real-life events are significantly correlated with each other. Therefore, Interactions and Real-life events is suppressed in its relationship with transfer strategy as shown by the path coefficient.

These results are of specific relevance within the setting of this study. It is conducted in MBA programs with participants who are experienced professionals aiming to further develop their competencies. Especially in this context, it can be expected that their perception of personal course benefits is a significant predictor of the effect of the program or of the transfer of what have been learnt to their work practice. Additionally, the impact of the use of real life events and the enhancement of interaction among trainees can be expected as relevant in a MBA setting. The explicit link between their daily work and the course content is of specific importance for this sample. Besides, results confirm research on knowledge sharing and creation in professional teams indicating the importance of interaction between team members. During team interaction, team members actively acquire process and share knowledge and information (Argote, Gruenfeld, \& Naquin, 2001). Therefore, interactions among professionals (the MBA trainees) are of significant importance for training transfer. Thus, training programs should be designed to include such factors that increase the possibility of transfer.

However it was surprising that the extent to which the program challenges the participants' thinking (Cognitive conflict) seems to play a minor role in Vietnamese MBA programs. It can be questioned to what extent this is due to the way the Vietnamese participants interpreted the items measuring this variable. Probably items such as "the course caused confusion among conceptual ideas" was seen as a negative point of the course, indicating the course content was not clear, even confusing. This interpretation might explain the low mean score on this variable (table 2.3) as well as the lack of relation with transfer effects (figure 2.2).

To date, although there is a growing market of MBA programs in Vietnam, many of them in cooperation with international partners, there is no existing research has examined the impact of training design on transfer of training, especially when the role of transfer strategies is at issues. The study provides indications of the cross-cultural validity of training design for enhancing transfer of training, more specifically the training transfer design characteristics formerly evidenced as well as constructivist instructional principles. 


\section{IMPLICATIONS FOR PRACTICE AND RECOMMENDATIONS FOR FUTURE RESEARCH}

For the practice of MBA programs and training programs aiming to develop professional competencies of experienced professionals, our results indicate that in order to enhance transfer, it is effective to apply constructivist pedagogy as well as transfer design characteristics. Moreover, it is effective to support trainees in the development and use of transfer strategies. Concretely, in order to design a transferable MBA program, designers and/or trainers should take into account some key implications as they will be said below.

Firstly, concentrate on constructivist principles when design training program. We found that constructivist principles training design, focus on substantial practical value which meet trainees' interest and benefits, significantly impact on transfer of training. Personal course benefit refers to what the value-added of the training is for the trainee in terms of motivating them toward reflections and concept investigation; encouraging them making meaning of the learning content; taking into account their need and providing materials and resources to support learning. Also, interactions and use of real life events focus on allowing arguments, discussions and debates; allow them to share their own opinions and for negotiation of the instructional goals and objectives of the course, especially trainees' supervisors should also negotiate instructional goals and objectives with trainees and trainers; provide a variety of learning activities; and making rich and real-life example.

Secondly, apply principles of transfer enhancing instructional methods such as relapse prevention, identical elements and goal setting.

Finally, focus on transfer strategy: preparing plan to apply what has been learnt. Our results indicate that (a) Trainers should encourage trainees to formulate transfer strategies, during the training. Even they should collect examples of training transfer strategy from previous students, and present these explicitly as part of the training. This helps clarify how trainees can be well prepared for applying new knowledge and skills to their work; and (b) Trainees' line' managers are advised to allow and award trainee to apply learning on the job. Especially, transfer rewards have been acknowledged for their effects on motivating employees to achieve certain goals (Cheng, 2000). In addition, managers and supervisors should inform employees that training transfer is valued by the organization; and even identify organizational reasons behind the failure of application training to the job. By doing so, organizations and supervisors will facilitate trainees to transfer their new learning (Richman-Hirsch, 2001). 
This study offers evidence for the validity of training design characteristics and the trainees' use of transfer strategies in a Vietnamese MBA context. While a number of former studies have used self report questionnaires to measure transfer effects, often with very few items, the present study extended the Xiao (1996) questionnaire, adding a more robust self-report measure. The present findings however, must be interpreted in the context of potential limitations. For future research, we suggest that, first, studies in different countries and different training contexts could strengthen the cross-cultural validity of the findings. Second, we suggest looking for possibilities to implement ratings from supervisors, peers, clients and other sources (360 degree assessment) in order to enhance inter-subjecting. Third, we recommend the additional use of qualitative research methods such as interviews in order to deepen our understanding of the transfer process. Finally, although our final sample of 167 participants provided statistical power to conduct our hypotheses testing, including larger sample sizes enhances generalization of the findings.

In conclusion, although transfer of training has been the focus of research for many years, the debate is still very lively, not only because even to date many questions are unanswered but also because the practice of training programs as well as the underlying learning theories have been changed. Our study therefore to take into account the characteristics of current training practices to contribute to a better understanding of the process of transfer of training.

\section{References}

Alliger, G. M., Tannenbaum, S. I., Bennett, W., Traver, J. H., \& Shotland, A. (1997). A metaanalysis of the relations among training criteria. Personnel Psychology, 50(2), 341358.

Anderson, J. C., \& Gerbing, D. W. (1988). Structural equation modeling in practice: A review and recommended two-step approach. Psychological Bulletin 103, 411-423.

Argote, L., Gruenfeld, D., \& Naquin, C. (2001). Group learning in organizations. Hillsdale, NJ: Lawrence Erlbaum \& Associates.

ASTD. (2008). State of the Industry Report (n.d.). Retrieved 31 August 2009. from http://store.astd.org/Default.aspx?tabid=143\&action=ECDProductDetails\&args=197 86.

Awoniyi, E. A., Griego, O. V., \& Morgan, G. A. (2002). Person-environment fit and transfer of training. International Journal of Training \& Development, 6(1), 25-35.

Baldwin, T. T., \& Ford, J. K. (1988). Transfer of training: a review and directions for future research Personnel Psychology, 41(1), 63-105.

Baron, R. M., \& Kenny, A. A. (1986). The moderator-mediator distinction in social psychological research: Conceptual, strategic, and statistical considerations. Journal of Personality and Social Psychology, 51, 1173-1182. 
Bentler, P. M. (1985). EQS 6. 1: Multivariate Software Inc.

Brown, J. S., Collins, A., \& Duguid, P. (1989). Situated cognition and the culture of learning. Educational Researcher, 18, 32-42.

Burke, L. A. (1997). Improving positive transfer: A test of relapse prevention training on transfer outcomes. Human Resource Development Quarterly, 8(2), 115-128.

Burke, L. A., \& Baldwin, T. T. (1999). Workforce training transfer: a study of the effect of relapse prevention training and transfer climate. Human Resource Management, 38(3), 227-241.

Burke, L. A., \& Hutchins, H. (2007). Training Transfer: An Integrative Literature Review. Human Resource Development Review, 6, 263-296.

Cameron, S. (2005). The MBA handbook: skills for mastering management (5th ed.): FTPrentice Hall.

Camuffo, A., Gerli, F., \& Chiara, F. (2006). Tracking Careers to Improve Competency-Based Management Education: A longitudinal Study of Italian MBAs. In Charles Wankel \& R. DeFillippi (Eds.). In New Vision of Graduate Management Education. Greenwich, Connecticut: IAP-Information Age Publishing.

Candy, P. C. (1991). Self direction for long life learning. San Francisco: Jossey-Bass.

Cheng, E. (2000). Test of the MBA knowledge and skills transfer. International Journal of Human Resource Management, 11(4), 837-852.

Cheng, E., \& Hampson, I. (2008). Transfer of training: A review and new insights. International Journal of Management Reviews, 10(4), 327-341.

Cheng, E., \& Ho, D. (2001). The influence of job and career attitudes on learning motivation and transfer. Career Development International, 6(1), 20-27.

Curry, D. H., Caplan, P., \& Knuppel, L. (1994). Transfer of training and adult learning (TOTAL). Journal of Continuing Social Work Education, 6(1), 8-14.

DeSimone, R. L., Werner, J. M., \& Harris, D. M. (2002). Human resource development. Mason, OH: South-Western.

Driver, R. (1988). Theory into practice II: a constructivist approach to curriculum development. In P. J. Fensham (Ed.), Development and dilemmas in science education. London: The Falmer Press.

Dweck, C. S. (1986). Motivational processes affecting learning. American Psychologist, 41(10), 1040-1048.

Entwistle, N. J., \& Tait, H. (1990). Approaches to learning, evaluations of teaching, and preferences for constrasting academic environments. Higher Education, 19(2), 169194.

Facteau, J. D., Dobbins, G. H., Russell, J. E. A., Ladd, R. T., \& Kudisch, J. D. (1995). The influence of general perceptions of the training environment on pre-training motivation and perceived transfer of training. Journal of Management, 21, 1-25.

Ford, J. K., \& Weissbein, D. A. (1997). Transfer of training: An updated review and analysis. Performance Improvement Quarterly, 10, 22-41.

Foxon, M. (1994). A process approach to the transfer of training. Australian Journal of Educational Technology, 10(1), 1-18.

Gijbels, D., Segers, M., \& Struyf, E. (2008). Constructivist learning environments and the (im)possibility to change students' perceptions of assessment demands and approaches to learning. Instructional Science, 36, 351-357. 
Gijbels, D., Van de Watering, G., Dochy, F., \& Van den Bossche, P. (2006). New learning environments and constructivism: The students' perspective Instructional Science 34(3), 213-226.

Gijselaers, W. H., \& Milter, R. G. (2010, in press). Issues in Accounting / Business Education. Business. In Barry McGaw, Penelope Peterson and Eva Baker (Eds.), The International Encyclopedia of Education, 3rd Edition. Elsevier (in press). International Encyclopedia of Education, Third Edition. Oxford: Elsevier.

Gist, M. E., Bavetta, A. G., \& Stevens, C. K. (1990). The effectiveness of self-management versus goal setting in facilitating training transfer. Proceedings of the 50th Annual meeting of the Academy of Management. 117-121.

Gollwitzer, P. M. (1999). Implementation intentions: Strong effects of simple plans. American Psychologist, 54, 493-503.

Hesketh, E. A., \& Laidlaw, J. M. (1997). 'Selling' educational events to healthcare professionals: Twelve tips on the function and design of trigger leaflets. Medical Teacher, 19(4), 250-256.

Hwang, M. H. (2003). Identifying equivalence of DEVSs: Language approach. Paper presented at the Summer Computer Simulation Conference, Montreal, Canada. SCS.

Inderrieden, E. J., Holtom, B. C., \& Bies, R. J. (2006). Do MBA Programs Deliver? In Charles Wankel \& Robert DeFillipi (Eds.), New Vision of Graduate Management Education. Greenwich, Connecticut: IAP-Information Age Publishing.

Jonassen, D. H. (1994). Thinking Technology: Toward a Constructivist Design Model. Educational Technology, 34(4), 34-37.

Kanuka, H., Rourke, L., \& Laflamme, E. (2007). The influence of instructional methods on the quality of online discussion. British Journal of Educational Technology, 38(2), 260-271.

Kaufman, R. (2002). Resolving the (often deserved) attacks on training. Performance Impermanency, 41(6).

Kirkpatrick, D. L. (1998). Evaluating Training Programs: The Four Levels (2nd Ed.): San Francisco: Berrett-Koehler.

Kirwan, C., \& Birchall, D. (2006). Transfer of Learning from Management Development Programmes: Testing the Holton Model. International Journal of Training and Development, 10(4), 252-268.

Kraiger, K., Ford, J. K., \& Salas, E. (1993). Application of cognitive, skill-based, and affective theories of learning outcomes to new methods of training evaluation. Journal of Applied Psychology, 78, 311-328.

Kriegesmann, B., Kley, T., \& Schwering, M. G. (2005). Creative errors and heroic failures:capturing their innovative potential. Journal of Business Strategy, 26(3), 5766.

Latham, G. P. (1997). Overcoming mental models that limit research on transfer of training in organisational settings. Applied Psychology: An International Review, 46, 371-375.

Lim, D. H., \& Morris, M. L. (2006). Influence of Trainee Characteristics, Instructional Satisfaction, and Organizational Climate on Perceived Learning and Training Transfer. Human Resource Development Quarterly, 171), 85-115. 
Loyens, S. M. M. (2007). Students' conceptions of constructivist learning. Unpublished Doctoral dissertation, Rotterdam, the Netherlands: Optima Grafische Communicatie.

Machin, M. A., \& Fogarty, G. J. (2003). Perceptions of training-related factors and personal variables as predictors of transfer implementation intentions. Journal of Business and Psychology, 18(1), 51-75.

Machin, M. A., \& Fogarty, G. J. (2004). Assessing the antecedents of transfer interventions in a training context. International Journal of Training and Development, 8(3), 222236.

Mintzberg, H. (2004). Managers not MBAs: a hand look at the soft practice of managing and management development. London: Prentice Education.

Nijhuis, J., Segers, M., \& Gijselaers, W. H. (2005). Influence of redesigning a learning environment on student perceptions and learning strategies. Learning environments research, 8, 67-93.

Nijman, D., Nijhof, W., Wognum, A., \& Veldkamp, B. (2006). Exploring differential effects of supervisor support on transfer of training. Journal of European Industrial Training, 30(7), 529-549.

Nikandrou, I., Brinia, V., \& Bereri, E. (2009). Perspective on practice. Trainee perceptions of training transfer: an empirical analysis. Journal of European Industrial Training, 33(3), 255-270.

Noe, R. A., Sears, J., \& Fullenkamp, A. M. (1990). Relapse training: Does it influence trainees' post training behavior and cognitive strategies? Journal of Business and Psychology, 4(3), 317-328.

Olsen, J. H. J. (1998). The evaluation and enhancement of training transfer. International Journal of Training \& Development, 2(1), 61-75.

Pfeffer. (1994). Competitive advantage through people: Unleashing the power of the workforce: Boston: Harvard Business School Press.

Pidd, K. (2004). The impact of workplace support and identity on training transfer: a case study of drug and alcohol safety training in Australia. International Journal of Training and Development, 8(4), 274-288.

Pugh, K. J., \& Bergin, D. A. (2006). Motivational Influences on Transfer. Educational Psychologist, 41(3), 147-160.

Richman-Hirsch, W. L. (2001). Posttraining Interventions to Enhance Transfer: The Moderating Effects of Work Environments. Human Resource Development Quarterly, 12(2), 105-120.

Roberson, L., Kulik, C. T., \& Pepper, M. B. (2009). Individual and Environmental Factors Influencing the Use of Transfer Strategies After Diversity Training. Group \& Organization Management, 34(1), 67-89.

Russ-Eft, D. (2002). A typology of training transfer design and work environment factors affecting workplace learning and transfer. Human Resource Development Review, 1(1), 45-65.

Smith-Jentsch, K. A., Payne, S., \& Johnston, J. H. (1996). Guided team self-correction: a methodology for enhancing experiential team training. In K. Smith-Jentsch (chair), When, how, and why does practice make perfect? Paper presented at the 11th 
annual conference of the Society for Industrial and Organizational Psychology, San Diego, CA.

Stevens, J. (1996). Applied multivariate statistics for the social sciences (3rd ed). Mahwah, NJ: Lawrence Erlbaum Associates. .

Stolk, D., Alexandrian, D., Gros, B., \& Paggio, R. (2001). Gaming and Multimedia Application for Environmental Crisis Management Training. Computers in Human Behavior, 17, 627-642.

Tabachnick, B. G., \& Fidell, L. S. (1996). Using multivariate statistics (4th ed.). New York: HarperCollins College Publisher. .

Taylor, M. (2000). Transfer of learning in workplace literacy programs. Adult Basic Education, 10(1), 3-20.

Tenenbaum, G., Naidu, S., Jegede, O., \& Austin, J. (2001). Constructivist pedagogy in conventional on-campus and distance learning practice: an exploratory investigation. Learning and Instruction, 11(2), 87-111.

Tziner, A., Haccoun, R. R., \& Kadish, A. (1991). Personal and situational characteristics influencing the effectiveness of transfer of training improvement strategies. Journal of Occupational Psychology, 64(2), 167-177.

Velada, R., Caetano, A., Michel, J., Lyons, B., \& Kavanagh, M. (2007). The effects of training design, individual characteristics and work envoronment on transfer of training. International Journal of Training and Development, 11(4), 282-294.

Vermeulen, R. C. M. (2002). Narrowing the transfer gap: the advantages of "as if" situations in training. Journal of European Industrial Training, 26(8), 366-374.

Von Glaserfeld, E. (1987). Learning as constructive activity. In E. Von Glaserfeld (Ed.), The construction of knowledge: contributions to conceptual semantics. California: Intersystems Publication.

Vrasidas, C. (2000). Constructivism versus objectivism: Implications for interaction, course design, and evaluation in distance education. International Journal of Educational Telecommunications, 6(4), 339-362.

Wagner, E. D., \& McCombs, B. L. (1995). Learner centre psychological principles in practice: designs for distance education. Educational Technology 35(32-35).

Wexley, K. N., \& Baldwin, T. T. (1986). Post-training strategies for facilitating positive transfer: An empirical exploration. Academy of Management Journal, 29, 503-520.

Wheatley, G. H. (1993). The role of negotiation in mathematics learning. In K. Tobin (Ed.), The practice of constructivism in science education Washington, DC: AAAS Press.

Xiao, J. (1996). The relationship between organizational factors and the transfer of training in the electronics industry in Shenzhen, China. Human Resource Development Quarterly, 7, 55-73. 


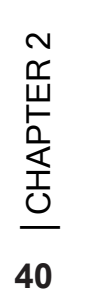




\section{Chapter 3}

\section{UNDERSTANDING TRAINING TRANSFER EFFECTS FROM A MOTIVATIONAL PERSPECTIVE: A TEST OF MBA PROGRAMS}

Training effectiveness is often operationalised as the training transfer effects: the extent to which professionals use their newly gained knowledge, skills and attitudes in their workplace. The question has been raised whether conditions can be identified which are necessary to achieve better training transfer effects. This research study tests the hypotheses that (1) motivational factors significantly predict the transfer effects and (2) the effects of motivational factors on transfer of training are mediated by the participants' transfer strategy.

MBA programs were chosen as the basis for this study. Data were collected from 305 trainees, the average was 32, who were sampled from eight different MBA programs in Vietnam. To measure the variables, we used and extended scales which have been validated. The analyses are based on regressions and path analyses.

The results indicate that the trainees' motivations (self-efficacy and motivation to transfer) significantly and directly predicted the extent of training transfer effects. Additionally, the trainees' use of transfer strategies mediates the relationship between the trainees' motivations and the training transfer effects.

In order to enhance training transfer in MBA programs, it is important and effective to reinforce trainee's self-efficacy and motivation to transfer, as well as to support them in the development of their own learning transfer strategies. This leads to increased job performance and in turn, can bring greater benefit to organizations that utilize such strategies.

This Chapter is based on Nga T.P. Pham, Mien S.R. and Wim H. Gijselaers. Understanding Training Transfer Effects from a Motivational Perspective: A Test of MBA Programs. In Business Leadership Review, 7:3 (July 2010), 1-25. 


\section{INTRODUCTION}

Western-style business education in Europe and North America is monopolized by professional degrees - the post-experience master of business administration (MBA) degree and the master of science degree in business (MSc - aimed at students without initial work experience). The MBA degree is pursued for career enhancement by business professionals with at least three years of work experience in various backgrounds (engineering, law, healthcare, etc.).

The present study was conducted in the setting of MBA programs. This setting provides a good opportunity to study transfer of training for the following reasons. First, the MBA degree is a higher education product in demand, with about 75000 MBAS graduating each year in the US in the 1990s (Gijselaers \& Milter, 2010, in press). The numbers of MBA programs and students has continued to grow since then across the globe. Second, MBA programs are professionally oriented and focus on the development of professional competence (Mintzberg, 2004). They aim to improve the functional and managerial competencies of trainees (Camuffo, Gerli, \& Chiara, 2006), since most MBA participants are professionals with a considerable amount of experience, and they perceive the training as a competitive advantage for their professional development (Cheng \& Ho, 2001). Therefore, the possibilities training programs offer trainees to transfer the competencies they have been practicing during the training to the workplace, are of utmost importance for the trainees. Third, MBA programs provide trainees with "a highly analytical approach to managerial problem solving, and the ability to approach new problem in a structured fashion" (Cameron, 2005, p. 14). The question is if and under what conditions, MBA programs really reach these high ambitions. Finally, MBA programs produce economic benefits and career success to MBA trainees, to the extent that MBA graduates receive more promotions than those who did not receive an MBA degree (Inderrieden, Holtom, \& Bies, 2006). Given these benefits, studying MBA programs in order to contribute to optimizing their transfer effects, is appropriate.

Although a large amount of corporate money is spent on employee training in general, in most cases only a small proportion of learning is actually transferred to the trainees' workplace (Baldwin \& Ford, 1988; Curry, Caplan, \& Knuppel, 1994; Kaufman, 2002). Over the past 20 years, researchers have shown an increased interest in such an application process to a better understanding of the conditions for trainees to effectively apply the learning to their work practice, i.e. training transfer effects or transfer of training (Baldwin \& Ford, 1988; Cheng \& Ho, 2001; Ford \& Weissbein, 1997). Generally, three groups of variables influencing 
training transfer are discerned. These variables represent aspects of the training design, trainee characteristics, and the work environment literature. (Baldwin \& Ford, 1988; Cheng \& Hampson, 2008; Ford \& Weissbein, 1997; Pugh \& Bergin, 2006). Although some progress has been made in addressing the impact of these variables on transfer process, inconsistent and unexpected results have challenged researchers (Cheng \& Hampson, 2008). For example, the recent review study of Cheng and Hampson (2008) suggest that investigating more on the decision role of trainees in transfer process is strongly recommended, as trainees play an important role in transfer since they are the agents who decide whether to transfer or not to transfer, and even how much knowledge gained they want to transfer. Similarly, in a meta-analysis study, Colquitt, Lepine, and Noe (2000) found that research must examine how personal characteristics relate to training effectiveness. Moreover, trainees' motivation is considered plays more important role to training achievement than are course-content elements (Fleishman \& Mumford, 1989; Quinones, 1997). This is consistent with the recent review study of Pugh and Bergin who argued that trainees' motivations have a significant impact on transfer because of their influence cognitive engagement which in turn, influences the transfer of trainingi. They conclude that "there is enough evidence from various sources to view motivation as a promising lens for future research on transfer, and we encourage others to pursue this intersection of fields" (p.157). Therefore, we argue that studying training transfer effects from a motivational perspective might contribute to a better understanding of such effects. This study explores how different motivational factors influence the extent to which trainees apply in their workplace what they have learned during the training program. The results will help theorists, designers and trainers (faculty) on MBA programs to think about questions such as what type of motivational factors need to be taken into account to enhance trainees' efforts to transfer?

Moreover, coping with the dynamics of the workplace when returning from a training program requires more than just motivation from the trainee. Once trainees re-enter the workplace after training, they have to cope with environmental and situational factors which in many cases confront the trainee with barriers instead of support for using the newly acquired skills and knowledge, such the negative attitudes of their co-workers. Taylor (2000, p. 15) cited a trainee: "When we come from our classes, many of our colleagues tease us about going to school ... These remarks hurt us a bit ... I don't want to show off what l've learned in front of them, because they will tease me even more". Or as a trainee said, organizations "don't even listen to our opinion ... They don't care about applying what we're learning... They don't give us that opportunity in any case ..." (Nikandrou, Brinia, \& Bereri, 2009 , p. 264). Thus, in order to have opportunities to use acquired trained 
knowledge and successfully apply them to the job, it has been argued that trainees need to use appropriate strategies, to transfer learned skills and knowledge, i.e. a (training) transfer strategy (Burke \& Baldwin, 1999). Also, research revealed that the use of transfer strategies for facilitating the transfer process is a crucial prerequisite for transfer of training (Burke, 1997; Machin \& Fogarty, 2003). Tzinner, Haccoun and Kadish (1991) believed that paying attention to goal-setting and self-management as transfer strategies resulted in a significantly higher level of transfer. Foxon (1994) argued that transfer strategies enhance the transfer probability by simultaneously embracing the impact of organizational system factors and assisting the trainees in practically applying the training into their work. A few studies proposing the importance of transfer strategies as a key mediator of the link between influencing factors and transfer outcomes. Examples include Gollwitzer (1999), Latham (1997) and Noe, Sears, and Fullenkamp (1990). This is consistent with research of Baldwin and Ford (1988) have posited both direct and indirect effects of trainees characteristics on training transfer. Recently, Pham, Gijselaers, \& Segers (2010, in press) have found the mediating role that transfer strategies play in the relationship between transfer design and transfer of training. Therefore in addition to the direct relationship between trainees' motivation and transfer of training, we include the trainee's use of transfer strategies as a mediating variable, proposing it will influences the strength of the relation between the trainees' motivation and transfer of training. We hypothesize that trainees' motivation affects trainee's use of transfer strategy, which in turn, influences transfer of training.

Currently, most of the cited transfer of training research either discussed the relation between trainees' characteristics and training transfer, or the relation between the transfer strategies and transfer separately. No existing research has examined the mediating role that trainee's transfer strategies can play in the relationship between trainees' characteristics and training transfer. This research therefore directs further thinking towards combining the above factors and to measure how these influence transfer training effects.

\section{CONCEPTUAL FRAMEWORK}

\subsection{Motivational perspective on transfer of training}

Following a meta-analytical study on training motivation and learning by Colquitt, Lepine, and Noe (2000) and a literature review examining trainees' motivations influence transfer of training of Pugh and Bergin (2006), this study addresses a group of prevalent and strong indications exist of 
motivational factors which have been empirically shown to affect the transfer of training such as (1) trainees' motivation (Axtell \& Maitlis, 1997; Colquitt, Lepine, \& Noe, 2000; Noe \& Schmitt, 1986; Pugh \& Bergin, 2006), (2) their perceived self efficacy (Colquitt, Lepine, \& Noe, 2000; Ford, Quiñones, Sego, \& Speer Sorra, 1992; Pugh \& Bergin, 2006) and (3) the extent to which they set achievement goals (Gist \& Steven, 1998; Pugh \& Bergin, 2006). Bases on previous empirical studies (e.g.Chiaburu \& Lindsay, 2008; Kontoghiorghes, 2002), this study differentiates between two different types of motivation: motivation to learn and motivation to transfer. According to Chiaburu and Lindsay (2008), although motivation to learn was related to motivation to transfer, which in turn predicted transfer of training, they are two distinct factors- both of them are important for transfer. Therefore, in order to increase the predictive power of trainees' motivation in transfer, this study explores the role of both factors separately. Previous research in this area focused primarily on children in school and undergraduate students, not on university students or adults (Coutinho \& Neuman, 2008). This study, thus investigates the direct as well as indirect effects of these motivational variables on the transfer of MBA training in a model that has not been empirically tested previously.

Motivation to learn is understood as the willingness of a learner to learn the content of a training program (e.g.Noe \& Schmitt, 1986). According to them, it is a trainee's intrinsic or extrinsic desire to achieve a higher level of learning. This important role of motivation to learn in the effects of training programs has been supported by a few empirical studies (e.g. Axtell \& Maitlis, 1997; Cheng, 2000; Tracey, Tannenbaum, \& Kavanagh, 1995). Researchers have concluded that motivation to learn influences either trainee's training performance or transfer outcome (Cheng \& Ho, 2001; Pugh \& Bergin, 2006).

Motivation to transfer learning is one of the key concepts in the human resource development literature (Egan, Yang, \& Bartlett, 2004). It can be described as the trainee's desire to use 'on the job' the knowledge and skills that have been learned in a training program (Axtell \& Maitlis, 1997; Kontoghiorghes, 2002; Noe \& Schmitt, 1986). Trainees' motivation to transfer are key influential variables in determining the level of transfer of training, since in order to transfer new learned knowledge and skills to the workplace, trainees first must also be committed to using what they have learned (Axtell \& Mailtis). In other words, the higher motivation to transfer, the more transfer will be occurred (e.g. Baldwin \& Ford, 1988; Kontoghiorghes, 2002; Noe \& Schmitt, 1986). This is consistent with the recent study of Liebermann and Hoffmann (2008) in which the relationship between transfer motivation and training transfer effects in one German bank was examined. The results show a positive relationship between 
transfer motivation and transfer effects. However, there is still very little research that has addressed the relationship between motivation to transfer and transfer of training (Gegenfurtner, Veermans, Festner, \& Gruber, 2009; Pugh \& Bergin, 2006).

Besides motivation to learn and to transfer, self efficacy is likely to be important in enhancing the transfer of training (Pugh \& Bergin, 2006). Selfefficacy is defined as a confidence of individual about their competency to perform specific task (Bandura, 1982). Putting effort into a task is dependent on the belief that they can do so, i.e. having positive or strong self-efficacy beliefs (e.g. Orpen, 1999). A number of previous studies evidenced that self-efficacy positively related to transfer (Chiaburu \& Marinova, 2005; Ford, Smith, Weissbein, Gully, \& Salas, 1998; Gaudine \& Saks, 2004; Mathieu, Tannenbaum, \& Salas, 1992; Saks, 1995; Stevens \& Gist, 1997). Self-efficacy has also a strong association with motivation to learn (Colquitt, Lepine, \& Noe, 2000; Quinones, Ford, Sego, \& Smith, 1995) and motivation to transfer (Chiaburu \& Lindsay, 2008). Cheng and Hampson (2008) and Elangovan and Karakowsky (1999) concluded that if employees lack self-efficacy, then transfer of training cannot be successful. Self-efficacy therefore is described as a powerful motivational predictor of transfer behavior.

Achievement goal (or achievement goal orientation/ goal orientation) refers to the pattern of cognition and action that results from the trainee's attempts to attain learning outcomes (DeShon \& Gillespie, 2005; Heyman \& Dweck, 1992). Two qualitatively different types of goals have been recognized - mastery goals and performance goals (e.g. Ames \& Archer, 1988; Dweck \& Leggett, 1988). According to Pugh and Bergin (2006, p. 149), "a mastery goal emphasizes developing skills and gaining competence while a performance goal emphasizes appearing competent". Gist and Stevens (1998) trained MBA students in salary negotiation with either mastery-oriented or performance-oriented conditions. In the masteryoriented condition, emphasis was located on improving negotiation skills. In the performance-oriented condition, emphasis was put on achieving the goal (i.e. negotiating a higher salary). The result revealed that students in the mastery condition negotiate salary more successfully than those in performance condition. These results are consistent with findings of Locke, Frederick, Lee, and Bobko (1984) who have shown that people with mastery goals have higher self-efficacy and show a better task performance than people with performance goals (e.g. Locke, Frederick, Lee, \& Bobko, 1984). Additionally, Kozlowski et al (2001) found that (trait) performance orientation did not predict transfer training, whereas (trait) mastery did. Other studies also found a negative or weak relationship between 
performance goal orientation and training transfer (Bell \& Kozlowski, 2002; Ford, Smith, Weissbein, Gully, \& Salas, 1998).

Researchers have additionally bifurcated mastery goals to masteryapproach and mastery-avoidance goals (Elliot, 1999; Pintrich, 2000a, $2000 \mathrm{~b})$ in which the mastery-approach focuses on attaining positive learning results ("I want to learn as much as possible from this course"), whereas the mastery-avoidance goal avoids negative learning results ("I worry that I may not learn all that I possibly could in this course"). Similarly, performanceapproach focuses on appearing competent ("It is important for me to do better than other students"), and performance-avoidance focuses on avoiding the appearance of incompetence ("My goal in this course is to avoid performing poorly") (Coutinho \& Neuman, 2008; Elliot \& McGregor, 2001). However, there is still little research emphasis on the direct effects of mastery and performance goals' effects on training transfer or the effects of the interactions of these goals (Chiaburu \& Tekleab, 2005). This study, therefore, explores the effects of both mastery and performance goals' on training transfer. More specific, the ' $2 \times 2$ achievement goal framework' proposing four goal orientations is used: mastery-approach, masteryavoidance, performance approach, and performance-avoidance (Coutinho \& Neuman, 2008; Elliot \& McGregor, 2001).

\section{$2.2 \quad$ Use of transfer strategy}

According to Noe, Sears and Fullenkamp (1990) (cited in Roberson, Kulik, and Pepper (2009), transfer strategies are cognitive and behavioral techniques, that include setting goals, analyzing work situations, preparing to deal with difficulties, identifying and using the necessary supports, and recognizing and monitoring opportunities to use acquired knowledge and skills on the job.

Foxon (1994, p. 3) has argued that for training transfer to be considered seriously, transfer strategies have to be formulated, and "implemented during the design, development and delivery of instruction". She believes that such strategies tend to increase the possibility of transfer through acknowledgement of the impact of organizational system factors that simultaneously assist the individual to focus on potential applications of the learning. Olsen (1998) emphasizes the need of understanding how to develop trainee's intention to use the new knowledge and skills.

There are several transfer strategies outlined in the literature which can be incorporated into training courses such as (1) the trainees' situation (e.g. identifying situations at work to apply the trained skills), (2) the trainees' thoughts/feelings (e.g. thoughts about the necessary support needed in order to use the trained skills; retaining self-confidence when experiencing 
resistance or burdens), (3) the trainees' behavior (e.g. creating and maintaining a social network), and (4) consequences of the trainees' behavior (e.g. being prepared to deal with skepticism of colleagues) (Burke \& Baldwin, 1999). Researchers have consistently emphasized the need for better understanding of the role of use of transfer strategies by trainees (e.g.Ford \& Weissbein, 1997; Machin \& Fogarty, 2004).

\subsection{Training transfer effects}

Many practitioners and researchers refer to Kirkpatrick's taxonomy (1998) to evaluate training effects. Kirkpatrick discerns four 'levels': (1) how trainees felt about the training; (2) whether they have learned anything, (3) whether the learning was transferred to the job or the extent of behavior and capability improvement and application and (4) the effects on the business or environment. In this study we focus on the third level. This means we question if the application of the trained knowledge, skills and attitudes in the workplace improves the performance of the job tasks as well as the work performance in general. In this respect, Xiao (1996) refers to the improvement of the productivity efficiency of the employee through training. Additionally, DeSimone, Werner, and Harris (2002, p. 3) claim that training programs aim to "provide its members (of the organization) with the opportunities to learn necessary skills to meet current and future job". This implies training programs do not only aim to enhance the quality of current task and work performance but also support the competence development of trainees in order to meet the demands of the future.

\section{RESEARCH QUESTION AND HYPOTHESES}

This study aims to understand the extent to which the trainee's transfer of what has been learned to the workplace is influenced by motivational perspectives. Moreover, we study the contribution of the trainees' use of transfer strategies. The following research question is addressed: "To what extent do motivational factors, taking into account the role of the participants' transfer strategies, contribute to the transfer of newly acquired knowledge in MBA programs, skills and attitudes on the job?".

Two hypotheses were tested:

H1) "Motivational factors are positively related to the extent of transfer training".

$\mathrm{H} 2)$ "The effects of the motivational factors on the training transfer effects are mediated by trainee's transfer strategies". 


\section{METHODOLOGY AND RESEARCH DESIGN}

\subsection{Participants}

The current study took place in a sample of MBA programs in Vietnam (Appendix A). Data were collected from 305 trainees attending eight different part-time MBA programs in Vietnam. 167 trainees answered the 1st survey. 126 trainees answered the 2 nd one. The majority of the sample was male $(n=102 ; 61 \%)$. The average age was 32 .

\subsection{Setting}

The present study was conducted in the setting of Master of Business Administration (MBA) programs in Vietnam. In Vietnam, education has been considered as top priority by the Vietnamese government in its attempt to develop the economy and join the global arena. After nearly 30 years of economic reform, the country is now facing with more vigorous challenges than ever before. Consequently, the Vietnamese government has established robust educational institutions which include MBA training programs (for instance, the Hanoi National Economics University (NEU), Vietnam National University (VNU), Foreign Trade University (FTU), Solvay Business School (Université Libre de Bruxells, Belgium), Centre FrancoVietnamien de Formation a' la Gestion (CFVG), Maastricht School of Management (MsM) in Vietnam). Although education is highly important in Vietnam, the question how the knowledge and skills obtained by trainees are transferred into work is inadequately verified. Meanwhile, there is a growing market of MBA programs with varying trainees' working conditions. These programs provide opportunity for researchers to examine the different variables incorporated in the transfer process. It also emphasizes a need of the assessments in order to ascertain whether these programs have a positive impact on Vietnamese corporate practice. Thus, providing a comprehensive understanding of real training transfer issue in Vietnam is an urgent necessity. This will help educational organizations in Vietnam effectively and efficiently enhance transfer process by diagnosing the factors that impact on training transfer systems.

The duration of these Vietnamese MBA programs (one up two years) also is a positive element of this study. While almost all other training programs studied in the literature are very short- for example, a three-day course (Lim \& Morris, 2006), one five-and-a-half-day week (Xiao, 1996), 12 days' duration (Kirwan \& Birchall, 2006) or one month program (Velada, Caetano, Michel, Lyons, \& Kavanagh, 2007) - these Vietnamese MBA 
programs have higher probability that trainees will have opportunities to internalize the training and develop a transfer strategy.

\subsection{Measures}

To measure the variables, we used and extended scales which have been validated in similar settings (Appendix $B$ ). We indicated the scale names and their items as they resulted from the factor analyses we conducted.

For measuring the motivational perspective, we used the Nijman, Nijhof, Wognum and Veldkamp (2006) questionnaire, as it comprises motivation to learn, motivation to transfer and self-efficacy. A principal component analysis (PCA) is conducted. The PCA results revealed the following three factors: (1) motivation to learn, Cronbach's alpha $(\mathrm{C \alpha})=.77$; (2) motivation to transfer, $\mathrm{C} \alpha=.68$; and (3) self-efficacy, $\mathrm{C} \alpha=.86$.

For measuring the achievement goal, we used the Elliot and McGregor (2001) questionnaire. This measure comprises mastery-approach, performance-approach, mastery-avoidance and performance-avoidance. The PCA results revealed the following four factors: (1) mastery-approach, $\mathrm{C} \alpha=.82$; (2) performance-approach, $\mathrm{C} \alpha=.91$; (3) mastery-avoidance, $\mathrm{C} \alpha$ $=.79$; and (4) performance-avoidance, $\mathrm{C} \alpha=.76$.

For measuring the transfer strategy, we used questionnaire of Burke and Baldwin (1999). As this instrument has been validated in many studies in comparable settings, amongst which, Pham, Gijselaers and Segers (2010, in press), with this study, we did not conduct a factor analysis on the data for this instrument. The C $\alpha$ is very high for our sample (0.88) and therefore confirms prior validation studies.

For measuring the transfer effects, the questionnaire of Xiao (1996) was used. Moreover, the authors extended the questionnaires with 11 items in order to measure the transfer effects with a more robust instrument. These items were based on an evaluation questionnaire used in Vietnamese training settings. The PCA results revealed three factors: (1) task performance improvement, $\mathrm{C} \alpha=.90$; (2) capacity building, $\mathrm{C} \alpha=.92$ and (3) job performance in general, $\mathrm{Ca}=.86$.

Based on the factors resulting from the factor analyses, the research model of this study can be depicted as follows (figure 3.1). 
Figure 3.1 Research model

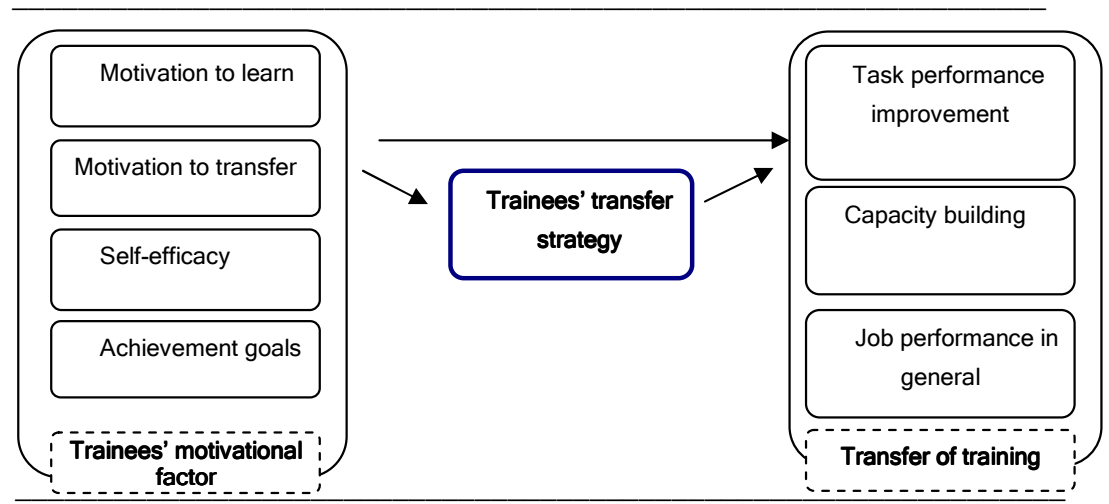

\subsection{Procedures}

Questionnaires were translated into the Vietnamese language. To check the accuracy of the English - Vietnamese translation, the questionnaire was translated back to English to check whether there were any changes in meaning. This was not the case.

We controlled for demographic information: age, gender, years of work experience, job position, reason(s) for pursuing the MBA course, and the source of MBA fees.

The questionnaires were completed by trainees at two points in time: (T1) - at the end of the training program, and (T2) - three months after the end of the training. At time 1, demographic variables, trainees' motivation variables and trainees' perception of using training transfer strategies variables were measured. At time 2, trainees' perception of training transfer effects was measured.

Training transfer effects was measured at time 2, three month after training as literature revealed that transfer of training is changed by time (Awoniyi, Griego, \& Morgan, 2002). Especially, the period after training is considered the most important in facilitating positive transfer (Wexley \& Baldwin, 1986). Nikandrou, Brinia and Bereri (2009, p. 258) suggest that, "to understand the training transfer process we need to understand all the factors affecting trainees as they enter training, during the training process and after training when they return to their work environment". Alliger, Tanenbaum, Bennett, Traver and Shotland (1997, p. 355) also noted: "By gathering reaction data one, three, or six months after training, trainees will have experienced whether the training was in fact useful, and should be in a better position to judge the utility of the training". 


\subsection{Methods of analysis}

The analysis is presented in three parts. According to the theoretical framework, we first test whether motivation variables influence transfer training effects. Next, we analyze whether the trainees' transfer strategies contribute to transfer of training effects. Finally, we analyze whether the complete proposed model of motivational perspective (taking into account the mediating role of the trainees' transfer strategies) is validated.

The first two parts of the analysis are primarily based on regression analyses. The last part of the analysis will use path analyses. The adequacy of the models is assessed by EQS version 6.1 (Bentler, 1985).

\section{RESULTS}

The descriptive statistics, Pearson correlations and reliability coefficient (Cronbach's Alpha) are presented in Table 3.1. The results revealed that:

(1) Self-efficacy and motivation transfer were significantly associated with all three aspects of transfer effects (task performance improvement, capacity building and job performance in general). This is clearly not the case for mastery-avoidance, motivation to learn, performance-approach and performance-avoidance). Mastery-approach has the lowest value $(r=0.23)$ with one aspect of the transfer effects (task performance improvement).

(2) Only self-efficacy and motivation transfer were found significantly associated with both (three aspects of) transfer effects and transfer strategies

(3) All of the motivational variables in this study were found significantly associated with the use of transfer strategies, except mastery-avoidance variable. The strongest correlations are with motivation to transfer $(r=0.55)$ and self-efficacy $(r=0.51)$. The lowest correlations are with motivation to learn $(r=0.19)$ and performance-approach $(r=0.19)$.

(4) The use of transfer strategies was strongly related to all three aspects of the training transfer effects.

(5) Regarding transfer effects, the strongest correlations were transfer strategies $(r=0.51 ; 0.42$ and 0.49 , in order of task performance improvement, capacity building and job performance in general), selfefficacy ( $r=0.37 ; 0.33$ and 0.33 , relatively) and motivation to transfer $(r=0.28 ; 0.24$ and 0.34 relatively). 


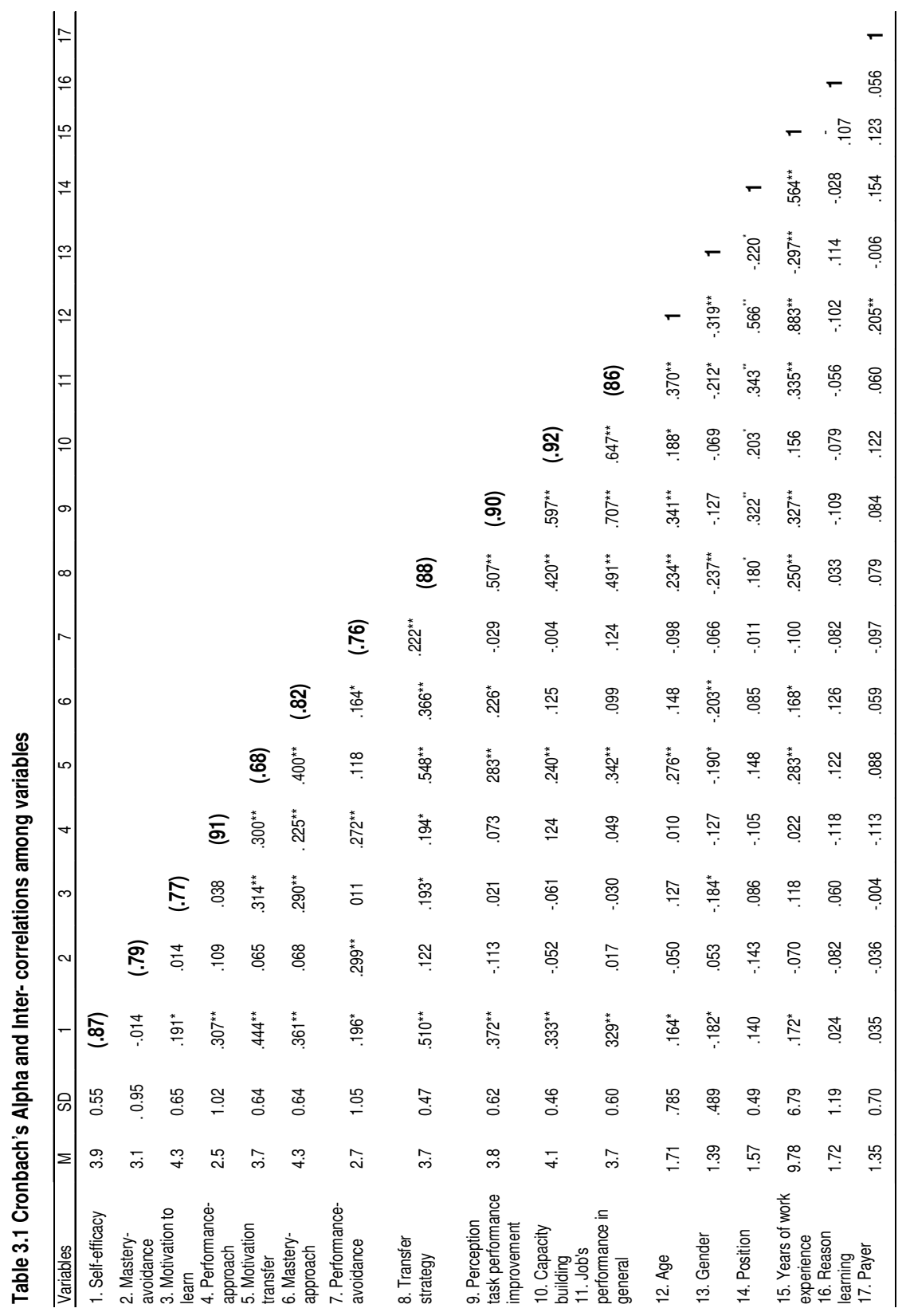




\subsection{Testing hypotheses}

Hypothesis 1: The motivational factors are positively related to the extent of transfer of training

To test this hypothesis, three (stepwise) regression analyses were performed. It was tested if motivational perspectives significantly predict (1) the task performance improvement, (2) the trainees' capacity building and (3) the job performance in general. The results of these computations are presented in Table 3.2. Only statistically significant standardized regression coefficient $\beta_{\mathrm{s}}$ are presented

Table 3.2 Regression analysis for trainees' motivational factors predicting transfer of training

\begin{tabular}{|c|c|c|c|c|c|c|c|c|c|c|}
\hline \multirow{2}{*}{\multicolumn{4}{|c|}{$\begin{array}{l}\text { Variable } \\
\begin{array}{l}\text { Task performance } \\
\text { improvement }\end{array} \\
\end{array}$}} & \multicolumn{4}{|c|}{ Transfer of Training } & & & \\
\hline & & & & & apacity & uilding & & \multicolumn{3}{|c|}{ Job performance general } \\
\hline $\bar{\beta}$ & $\mathrm{t}$ & $\mathrm{p}$ & Adj. $R^{2}$ & $\beta$ & $\mathrm{t}$ & $p$ & Adj. $R^{2}$ & $\beta$ & $\mathrm{t}$ & $\mathrm{p}$ Adj. $\mathrm{R}^{2}$ \\
\hline \multicolumn{11}{|c|}{ 1. Self-efficacy } \\
\hline .37 & .4340 & .000 & .13 & .33 & 3.837 & .000 & .10 & .22 & 2.333 & .021 .14 \\
\hline \multicolumn{8}{|c|}{ 2. Motivation to transfer } & .24 & 2.577 & .011 .110 \\
\hline
\end{tabular}

Note: $\beta=$ standardized coefficients

The statistical results in Table 3.2 show that among trainees' motivational factors (motivation to learn, motivation to transfer, self-efficacy and achievement goals), only self-efficacy and motivation to transfer are predict transfer of training statistically significant. Concretely, self-efficacy independently and significantly predicts all three aspects of transfer of training (the task performance improvement, the trainees' capacity building and the job performance in general): $\beta=.37, \beta=.33$ and $\beta=.22$ respectively. Motivation to transfer significantly predicts transfer of training $(\beta=.24)$ in terms of the job performance in general. This implies that the results (partly) support the first hypothesis.

Other motivational factors such as motivation to learn, masteryapproach, mastery-avoidance, performance-approach and performanceavoidance were not found significantly predict transfer of training. 
Hypothesis 2: The effects of motivational factors on transfer of training are mediated by trainee's transfer strategy

Hypothesis 2 was tested using (enter) regression analysis. To determine whether the transfer strategy is a mediator of the relationship between motivational factors and training transfer, Baron and Kenny (1986) mediation principles have been applied. Firstly we test if the motivational factors predict transfer strategy (block 1 in Table 3.3). Secondly, it was analyzed if the transfer strategy predicts training transfer effects (block 2). Finally, it was analyzed if the transfer strategy mediated the relation between the motivational factors and training transfer effects (block 3 ). We test the effect of the motivational factors on training transfer effects in terms of task performance improvement, capacity building and job performance in general. The results of these computations are presented in Table 3.3.

Table 3.3 shows that, amongst the motivational factors, in terms of task performance improvement, (1) self-efficacy and motivation to transfer significantly predict the transfer strategy $(\beta=.31$ and $\beta=.38$, respectively); (2) training transfer strategy significantly predicts transfer effect $(\beta=.51)$; and (3) transfer strategy mediates the relation between self-efficacy and motivation to transfer and training transfer effects $(\beta=.48)$.

Similarly, in terms of capacity building, (1) self-efficacy and motivation to transfer significantly predict the transfer strategy $(\beta=.31$ and $\beta=.38$, respectively); (2) transfer strategy significantly predicts training transfer effects $(\beta=.42)$; and (3) transfer strategy mediates the relation between selfefficacy and motivation to transfer and training transfer effects $(\beta=.39)$.

Finally, in terms of job performance in general, (1) self-efficacy and motivation to transfer significantly predict the transfer strategy $(\beta=.31$ and $\beta=.38$, respectively); (2) transfer strategy significantly predicts training transfer effects $(\beta=.49)$; and (3) transfer strategy mediates the relation between self-efficacy and motivation to transfer and training transfer effects $(\beta=.41)$.

These results imply that the second hypothesis is (partly) supported. . 
Table 3.3 Regression analysis for trainees' motivational factors and transfer strategy predicting transfer of training

\begin{tabular}{|c|c|c|c|c|c|c|c|c|c|}
\hline \multirow[t]{2}{*}{ Variable } & \multicolumn{3}{|c|}{ Transfer strategy } & \multicolumn{6}{|c|}{$\begin{array}{c}\text { Transfer of training } \\
\text { (Task performance improvement) }\end{array}$} \\
\hline & $\mathrm{B}$ & $\mathrm{t}$ & $\mathrm{p}$ & $\beta$ & $\mathrm{t}$ & $\mathrm{p}$ & $\beta$ & $\mathrm{t}$ & $\mathrm{p}$ \\
\hline $\begin{array}{l}\text { Motivational perspectives } \\
\text { - Self-efficacy } \\
\text { - Motivation to transfer }\end{array}$ & $\begin{array}{l}.31 \\
.38\end{array}$ & $\begin{array}{l}4.368 \\
5.158\end{array}$ & $\begin{array}{l}.000 \\
.000\end{array}$ & & & & .31 & 3.115 & .002 \\
\hline \multirow[t]{3}{*}{ Adj. R2 } & .39 & & & $\begin{array}{l}.51 \\
.25\end{array}$ & 6.356 & .000 & $\begin{array}{l}.48 \\
.28\end{array}$ & 4.650 & .000 \\
\hline & \multicolumn{3}{|c|}{ Transfer strategy } & \multicolumn{6}{|c|}{$\begin{array}{l}\text { Transfer of training } \\
\text { (Capacity building) }\end{array}$} \\
\hline & $\beta$ & $\mathrm{t}$ & $\mathrm{p}$ & $\beta$ & $\mathrm{t}$ & $\mathrm{p}$ & $\beta$ & $\mathrm{t}$ & $\mathrm{p}$ \\
\hline $\begin{array}{l}\text { Motivational perspectives } \\
\text { - Self-efficacy } \\
\text { - Motivation to transfer }\end{array}$ & $\begin{array}{l}.31 \\
.38\end{array}$ & $\begin{array}{l}4.368 \\
5.158\end{array}$ & $\begin{array}{l}.000 \\
.000\end{array}$ & & & & .30 & 2.920 & .004 \\
\hline \multirow[t]{3}{*}{ Adj. R2 } & .39 & & & $\begin{array}{l}.42 \\
.17 \\
\end{array}$ & 5.031 & .000 & $\begin{array}{l}.39 \\
.19 \\
\end{array}$ & 3.575 & .001 \\
\hline & \multicolumn{3}{|c|}{ Transfer strategy } & & (Job & $\begin{array}{l}\text { Transf } \\
\text { erform }\end{array}$ & of $\operatorname{tr}$ & $\begin{array}{l}\text { ining } \\
\text { general }\end{array}$ & \\
\hline & B & $\mathrm{t}$ & $\mathrm{p}$ & $\beta$ & $\mathrm{t}$ & $p$ & $\beta$ & $\mathrm{t}$ & $\mathrm{p}$ \\
\hline $\begin{array}{l}\text { Motivational perspectives } \\
\text { - Self-efficacy } \\
\text { - Motivation to transfer }\end{array}$ & $\begin{array}{l}.31 \\
.38\end{array}$ & $\begin{array}{l}4.368 \\
5.158\end{array}$ & $\begin{array}{l}.000 \\
.000\end{array}$ & & & & $\begin{array}{l}.26 \\
.33\end{array}$ & $\begin{array}{l}2.606 \\
3.269\end{array}$ & $\begin{array}{l}.010 \\
.001\end{array}$ \\
\hline $\begin{array}{l}\text { Transfer strategy } \\
\text { Adj. R2 }\end{array}$ & .33 & & & $\begin{array}{l}.49 \\
.24\end{array}$ & 6.120 & .000 & $\begin{array}{l}.41 \\
.25\end{array}$ & 3.937 & .000 \\
\hline
\end{tabular}

Note: $\beta=$ standardized coefficients

\subsection{Testing the model}

Given the theoretical insights as described above, the originally hypothesized model is composed of paths leading from the constructs measuring motivational variables toward transfer strategy, and three paths from transfer strategy toward transfer training. The study used path analysis to find evidence for the validity of the proposal model.

Based on the exploratory design of the study, and as recommended by Anderson and Gerbing (1988), our proposed model was compared with several other models presenting plausible alternatives. The 'best fitting' model is achieved since it has surpassed all the goodness of fit indices. The goodness of fit indices of this model as presented in figure 3.2 $(\mathrm{X} 2=0.785, \mathrm{df}=3, \mathrm{p}=.853, \mathrm{CFI}=1.000, \mathrm{RMSEA}=0.000)$ indicated that the model fits the data very well. 
Figure 3.2 Path analysis model toward transfer of training

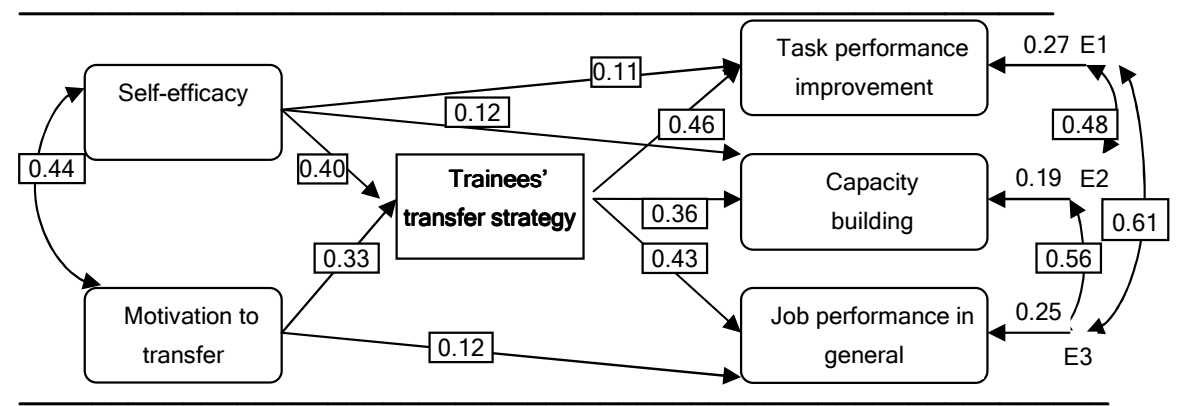

The results of Figure 3.2 partly confirm both hypotheses of this study; concretely:

(1) the extent to which trainees belief in their capabilities to produce effects (self-efficacy) directly influences training transfer effects (the extent to which $\mathrm{s} /$ he improves his/her task performance and the extent to which s/he develops his/her capacities $(\beta=.11$ and $\beta=.12$ respectively). In addition, if trainees poses motivation to transfer, (s)he will directly affects his/her job performance $(\beta=.12)$.

(2) the trainees' use of transfer strategies has a mediating role. In more detail, if trainees are motivated to transfer, this will affect his job performance directly and positively $(\beta=.12)$. This positive effect will be enhanced when $\mathrm{s} /$ he adopt transfer strategies with the indirect effect is $\beta=.33$ * $.43=.14$ : the total effects are $\beta=.12+.14=.26$. Similarly, the relation between self-efficacy and task performance improvement is stronger when trainees use training transfer strategies (the direct effect is $\beta=.11$; the indirect effect is $\beta=.40 * .46=.16$; the total effects are $\beta=.11+.16=.27$ ).

\section{CONCLUSION AND DISCUSSION}

Business schools have tried to bridge the gap between theory and practice and to add value for professionals in the design of MBA programs. This value can be expressed in many ways; among them the capacity to transfer what has been learned into practice. This study focused on the influence of motivational variables on the transfer of what has been learned during MBA programs to the workplace and their implications for pedagogy. The results confirm prior findings that the trainees' self-efficacy and motivation to transfer are positively and directly related to the extent of transfer of training. This implies that if trainees belief that they can 
successfully apply what they have learnt, it will positively affect their task performance and capacity building. In addition, if they are motivated to transfer, their general job performance will be positively influenced. The results support the findings of some earlier studies that self-efficacy predicts transfer of training (e.g. Cheng, 2000; Colquitt, Lepine, \& Noe, 2000; Gist, Stevens, \& Bavetta, 1991; Tannenbaum, Mathieu, Salas, \& Cannon-Bowers, 1991); and that motivation to transfer predicts transfer of training (e.g. Chiaburu \& Lindsay, 2008; Kontoghiorghes, 2002; Tracey, Tannenbaum, \& Kavanagh, 1995).

This study also supports arguments of Pugh and Bergin (2006) and Cheng and Hampson (2008) that studying transfer of training from a motivational perspective contributes to a better understanding of the transfer effects of training.

Additionally, our results indicate the trainees' use of transfer strategies plays a mediating role, strengthening the impact of trainees' self-efficacy on their task performance as well as the effect of trainees' motivation to learn on their general job performance. This implies that the MBA trainees will transfer what they have learned to their jobs and therefore improve their performance as well as develop their competencies if (1) they have the strong self-efficacy (2) if they have the high motivation to transfer and (3) when they make use of strategies to transfer the learned knowledge and skills.

In contradiction with what we expected, the trainees' motivation to learn and their pursuit of achievement goals are not statistically significant predictors of transfer of training. This is probably due to the more general character when compared with motivation to transfer, which is more directly related to the transfer effects measured. Although self-efficacy is also a general factor, its power in predicting learning outcomes and performance has been evidenced in numerous former studies and is confirmed here. Moreover, with regard to the effect of the pursuit of achievement goals, our study confirms prior research of Kozlowski et al (2001) showing that (trait) performance orientation did not predict transfer training (Bell \& Kozlowski, 2002; Ford, Smith, Weissbein, Gully, \& Salas, 1998).

Finally, given that most of the MBA course students in our study have paid their tuition fees themselves (76\%), it can be expected that trainees' motivation to use what they have learned in the program in their job, is suppressing the effect of other more general factors. In addition, given that $62 \%$ of them declare that they participate in the MBA to further develop their competencies, their main concern is how to transfer as much as possible to their job (/ eagerly want to apply what / have learnt in my work). They do not concern about 'appearing' competent (the performance-approach: "/t is important for me to do better than other students"); or show performanceavoidance: "My goal in this course is to avoid performing poorly". 
In conclusion, this study provides indications of the cross-cultural validity of motivational factors for enhancing transfer of training. Also, it adds to the existing knowledge base on training transfer and hopes to stimulate further research in extending the 11 items in the questionnaire to measure the transfer effect. While a number of former studies have used self report questionnaires to measure transfer effects, often with very few items, this addition strengthens the self-report measure. The results highlight why and how specific motivational aspects within MBA programs can influence transfer.

\section{IMPLICATIONS FOR PRACTICE AND RECOMMENDATIONS FOR FUTURE RESEARCH}

Based on this study's results, we suggest several recommendations for stakeholders of MBA training programs to improve training transfer:

Trainees' motivational perspectives:

1) MBA training providers need to ensure that training is designed such that they concentrate on the factors which enhance transfer, such as helping trainees them to pursue their self-efficacy, and motivate them to transfer learning information. Since research has revealed that self-efficacy is trainable (e.g.Karl, O'Leary-Kelly, \& Martocchio, 1993), and in order to maximize transfer of training, faculty should train and regularly monitor trainees' self-efficacy and motivation to transfer in their trainees. Even trainees' self-efficacy can be increased before they attend the training by providing them with training-related information, such as the importance of training, training content, training method or training environment (Tai, 2006).

2) Trainees' line managers are advised to encourage trainees with high self-efficacy and motivation to transfer to become training candidates. In addition, they should work with the employee to choose the best training provider, where training is designed to encourage the particular trainee's self-efficacy. These will help ensure that trainees apply learned knowledge and skills to their workplace both during and after training.

Transfer strategy

3) Trainers should encourage trainees to formulate transfer strategies during the training process. They should collect examples of training transfer strategies from previous trainees, and present these explicitly as part of the training. This helps trainees to be well prepared for applying new knowledge and skills to their work.

4) Line managers should allow, encourage and reward successful trainee graduate to apply learning on the job. Transfer rewards have been 
acknowledged for their effects on motivating employees to achieve certain goals (Cheng, 2000). Along with informing employees that training transfer is valued by the organization; supervisors should identify any organizational reasons behind the failure of application. By doing so, organizations and supervisors will facilitate trainees to transfer their new learning (RichmanHirsch, 2001).

In summary, this study offers evidence for the validity of motivational perspective and the trainees' use of transfer strategies influencing transfer of training in a Vietnamese MBA context. Thus it cannot immediately be transferable to completely different educational form. Future studies in different contexts would strengthen the cross-cultural validity of the findings. Further research should implement ratings from other assessment sources such as supervisors, peers and clients, etc (360 degree assessment) in order to enhance inter-subjecting. Furthermore, we recommend the additional use of qualitative research methods such as interviews for deepening our understanding of the transfer process. 


\section{APPENDIX}

\subsection{Appendix A: Descriptions of MBA programs in Vietnam}

\begin{tabular}{|c|l|l|l|}
\hline No & \multicolumn{1}{|c|}{ Program } & \multicolumn{1}{c|}{ Instructional approach } & \multicolumn{1}{|c|}{ Language } \\
\hline 1 & Vietnam - Belgium ${ }^{1}$ MBA & Lecture; Tutoring & English \\
\hline 2 & NEU ${ }^{2}$ MBA & Lecture & Vietnamese \\
\hline 3 & CFVG $^{3}$ MBA & $\begin{array}{l}\text { Lecture; Consultancy } \\
\text { project; Simulation; } \\
\text { Practical cases; Problem } \\
\text { solving; Conferences } \\
\text { competing }\end{array}$ & English/French \\
\hline 5 & VNU le ${ }^{4}$ MBA5 & $\begin{array}{l}\text { Lecture; Team working; } \\
\text { Seminars; Business } \\
\text { consulting; } \\
\text { Group study; Guest } \\
\text { speakers }\end{array}$ & Vietnamese \\
\hline 5 & VNU Re $^{5}$ MBA & $\begin{array}{l}\text { Lecture; Team working; } \\
\text { Seminars; Business } \\
\text { consulting, } \\
\text { Group study; Guest } \\
\text { speakers }\end{array}$ & English \\
\hline 7 & MsM ${ }^{7}$ MBA & Lecture & Vietnamese \\
\hline 8 & HCMC UT 8MBA & $\begin{array}{l}\text { Lecture; Teaching } \\
\text { assistants; Project } \\
\text { assignments }\end{array}$ & English \\
\hline Lecture & Vietnamese \\
\hline
\end{tabular}

1 Solvay Business School (Universite Libre de Bruxelles, Belgium)

2 Hanoi National Economics University

3 Centre Franco-Vietnamien de Formation a' la Gestion

4 Vietnam National University International Executive

5 Vietnam National University Regular Executive

6 Foreign Trade University

7 Maastricht School of Management in Vietnam

8 Ho Chi Minh City University of Technology 


\subsection{Appendix B: Variables, scales and examples}

\begin{tabular}{|c|c|c|c|}
\hline \multicolumn{2}{|r|}{ Variables } & Scales name & Example items \\
\hline $\begin{array}{l}0 \\
\frac{0}{0} \\
\frac{0}{0} \\
\frac{0}{0} \\
> \\
\frac{0}{0} \\
\frac{0}{0} \\
\frac{0}{0} \\
\frac{0}{0} \\
\frac{0}{0} \\
\underline{0}\end{array}$ & $\begin{array}{l}\text { Trainees' motivation } \\
\text { (Nijman, Nijhof, } \\
\text { Wognum, \& Veldkamp, } \\
\text { 2006) } \\
\text { (Elliot \& McGregor, } \\
\text { 2001) }\end{array}$ & $\begin{array}{l}\text { - Motivation to learn }(n=3) \\
\text { - Motivation to transfer } \\
(n=4) \\
\text { - Self-efficacy }(n=6) \\
\text { - Performance-approach } \\
(n=3) \\
\text { - Mastery-avoidance }(n=3) \\
\text { - Mastery-approach } \\
\text { - Performance avoidance } \\
(n=3)\end{array}$ & $\begin{array}{l}\text { - I was strongly motivated to take part in } \\
\text { it ( } \mathrm{n}=6 \text { ) } \\
\text { - I eagerly want/desired to apply what I } \\
\text { have learnt in my work } \\
\text { - I have the feeling that I am getting } \\
\text { better in my work } \\
\text { - It is important for me to do better than } \\
\text { other students } \\
\text { - I worry that I may not learn all that I } \\
\text { possibly could in this course } \\
\text { - I want to learn as much as possible } \\
\text { from this course } \\
\text { - My goal in this course is to avoid } \\
\text { performing poorly }\end{array}$ \\
\hline 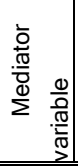 & $\begin{array}{l}\text { Trainees' transfer } \\
\text { strategy (Burke \& } \\
\text { Baldwin, 1999) }\end{array}$ & $\begin{array}{l}\text { Transfer Strategy } \\
(n=19)\end{array}$ & $\begin{array}{l}\text { I identified the appropriate setting for } \\
\text { applying what I have learnt }\end{array}$ \\
\hline 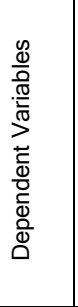 & $\begin{array}{l}\text { Transfer of training } \\
\text { (Xiao, 1996) } \\
\text { - The authors } \\
\text { - The authors }\end{array}$ & $\begin{array}{l}\text { - Task performance } \\
\text { improvement }(n=6) \\
\text { - Capacity building }(n=6) \\
\text { - Job performance in } \\
\text { general }(n=5)\end{array}$ & $\begin{array}{l}\text { - I can accomplish my job task better } \\
\text { than by using new KSA } \\
\text { - My ability to implement work in general } \\
\text { is increased } \\
\text { - In general, I think this training course } \\
\text { has helped me increase my work } \\
\text { performance }\end{array}$ \\
\hline
\end{tabular}

\section{References}

Alliger, G. M., Tannenbaum, S. I., Bennett, W., Traver, J. H., \& Shotland, A. (1997). A metaanalysis of the relations among training criteria. Personnel Psychology, 50(2), 341358.

Ames, C., \& Archer, J. (1988). Achievement goals in the classroom: Student's learning strategies and motivation process. Journal of Educational Psychology, 80, 260-267. 
Anderson, J. C., \& Gerbing, D. W. (1988). Structural equation modeling in practice: A review and recommended two-step approach. Psychological Bulletin 103, 411-423.

Awoniyi, E. A., Griego, O. V., \& Morgan, G. A. (2002). Person-environment fit and transfer of training. International Journal of Training \& Development, 6(1), 25-35.

Axtell, C. M., \& Maitlis, S. (1997). Predicting immediate and longer-term transfer of training. Personnel Review, 26(30), 201-213.

Baldwin, T. T., \& Ford, J. K. (1988). Transfer of training: a review and directions for future research Personnel Psychology, 41(1), 63-105.

Bandura, A. (1982). Self-efficacy mechanism in human agency. American Psychologist, $37(2), 122-147$.

Baron, R. M., \& Kenny, A. A. (1986). The moderator-mediator distinction in social psychological research: Conceptual, strategic, and statistical considerations. Journal of Personality and Social Psychology, 51, 1173-1182.

Bell, B. S., \& Kozlowski, S. W. J. (2002). Goal orientation and ability: interaction effects on self-efficacy, performance, and knowledge. Journal of Applied Psychology, 87(3), 497-505.

Bentler, P. M. (1985). EQS 6. 1: Multivariate Software Inc.

Burke, L. A. (1997). Improving positive transfer: A test of relapse prevention training on transfer outcomes. Human Resource Development Quarterly, 8(2), 115-128.

Burke, L. A., \& Baldwin, T. T. (1999). Workforce training transfer: a study of the effect of relapse prevention training and transfer climate. Human Resource Management, $38(3), 227-241$.

Cameron, S. (2005). The MBA handbook: skills for mastering management (5th ed.): FTPrentice Hall.

Camuffo, A., Gerli, F., \& Chiara, F. (2006). Tracking Careers to Improve Competency-Based Management Education: A longitudinal Study of Italian MBAs. In Charles Wankel \& R. DeFillippi (Eds.). In New Vision of Graduate Management Education. Greenwich, Connecticut: IAP-Information Age Publishing.

Cheng, E. (2000). Test of the MBA knowledge and skills transfer. International Journal of Human Resource Management, 11(4), 837-852.

Cheng, E., \& Hampson, I. (2008). Transfer of training: A review and new insights. International Journal of Management Reviews, 1944), 327-341.

Cheng, E., \& Ho, D. (2001). The influence of job and career attitudes on learning motivation and transfer. Career Development International, 6(1), 20-27.

Chiaburu, D. S., \& Lindsay, D. R. (2008). Can do or will do? The importance of self-efficacy and instrumentality for training transfer. Human Resource Development International, 11(2), 199-206.

Chiaburu, D. S., \& Marinova, S. V. (2005). What predicts skill transfer? An exploratory study of goal orientation, training self-efficacy and organizational supports. . International Journal of Training and Development Journal, 9, 110-123.

Chiaburu, D. S., \& Tekleab, A. G. (2005). Individual and contextual influences on multiple dimensions of training effectiveness. Journal of European Industrial Training, 29(8), 604-626.

Colquitt, J. A., Lepine, J. A., \& Noe, R. A. (2000). Toward an Integrative Theory of Training Motivation: A Meta-Analytic Path Analysis of 20 Years of Research. Journal of Applied Psychology, 85(5), 678-707. 
Coutinho, S. A., \& Neuman, G. (2008). A model of metacognition, achievement goal orientation, learning style and self-efficacy. Learning Environ Res 11, 131-151.

Curry, D. H., Caplan, P., \& Knuppel, L. (1994). Transfer of training and adult learning (TOTAL). Journal of Continuing Social Work Education, 6(1), 8-14.

DeShon, R. P., \& Gillespie, J. Z. (2005). A motivated action theory account of goal orientation. The Journal of Applied Psychology, 90(6).

DeSimone, R. L., Werner, J. M., \& Harris, D. M. (2002). Human resource development. Mason, $\mathrm{OH}$ : South-Western.

Dweck, C. S., \& Leggett, E. S. (1988). A social/cognitive approach to motivation and personality. Psychological Review, 95, 256-273.

Egan, T. M., Yang, B., \& Bartlett, K. R. (2004). The effects of organizational learning culture on motivation to transfer learning and turnover intention. Human Resource Development Quarterly, 5(3), 279-301.

Elangovan, A. R., \& Karakowsky, L. (1999). The role of trainee and environmental factors in transfer of training: an exploratory framework. Leadership \& Organization Development Journal, 20(5), 268-275.

Elliot, A. J. (1999). Approach and avoidance motivation and achievement goals. Educational Psychologist, 34, 169-189.

Elliot, A. J., \& McGregor, H. A. (2001). A $2 \times 2$ achievement goal framework. Journal of Personality and Social Psychology, 80(3), 501-519.

Fleishman, E. A., \& Mumford, M. D. (1989). Individual attributes and training performance. In I. L. Goldstein (Ed.), Training and Development in Organizations (pp. 183-255). Jossey-Bass, San Francisco, CA.

Ford, J. K., Quiñones, M. A., Sego, D. J., \& Speer Sorra, J. (1992). Factors affecting the opportunity to perform trained tasks on the job. Personnel Psychology, 45(3), 511527.

Ford, J. K., Smith, E. M., Weissbein, D. A., Gully, S. M., \& Salas, E. (1998). Relationships of goal orientation, metacognitive activity and practice strategies with learning outcomes and transfer. Journal of Applied Psychology, 83, 218-233.

Ford, J. K., \& Weissbein, D. A. (1997). Transfer of training: An updated review and analysis. Performance Improvement Quarterly, 10, 22-41.

Foxon, M. (1994). A process approach to the transfer of training. Australian Journal of Educational Technology, 10(1), 1-18.

Gaudine, A. P., \& Saks, A. M. (2004). A longitudinal quasi-experiment on the effects of posttraining transfer interventions. Human Resource Development Quarterly, 15(1), 57-76.

Gegenfurtner, A., Veermans, K., Festner, D., \& Gruber, H. (2009). Motivation to Transfer Training: An Integrative Literature Review. Human Resource Development Review OnlineFirst.

Gijselaers, W. H., \& Milter, R. G. (2010, in press). Issues in Accounting / Business Education. Business. In Barry McGaw, Penelope Peterson and Eva Baker (Eds.), The International Encyclopedia of Education, 3rd Edition. Elsevier (in press). International Encyclopedia of Education, Third Edition. Oxford: Elsevier. 
Gist, M. E., \& Steven, C. S. (1998). Effects of Practice Conditions and Supplemental Training Method on Cognitive Learning and Interpersonal Skill Generalization. Organizational Behavior and Human Decision Processes, 75(2), 142-169.

Gollwitzer, P. M. (1999). Implementation intentions: Strong effects of simple plans. American Psychologist, 54, 493-503.

Heyman, G. D., \& Dweck, C. S. (1992). Achievement goals and intrinsic motivation: Their relation and their role in adaptive motivation. . Motivation and Emotion, 16, 231247.

Inderrieden, E. J., Holtom, B. C., \& Bies, R. J. (2006). Do MBA Programs Deliver? In Charles Wankel \& Robert DeFillipi (Eds.), New Vision of Graduate Management Education. Greenwich, Connecticut: IAP-Information Age Publishing.

Karl, K. A., O'Leary-Kelly, A. M., \& Martocchio, J. J. (1993). The impact of feedback and selfefficacy on performance in training. Journal of Organizational Behavior, 14, 379394.

Kaufman, R. (2002). Resolving the (often deserved) attacks on training. Performance Impermanency, 41(6).

Kirkpatrick, D. L. (1998). Evaluating Training Programs: The Four Levels (2nd Ed.): San Francisco: Berrett-Koehler.

Kirwan, C., \& Birchall, D. (2006). Transfer of Learning from Management Development Programmes: Testing the Holton Model. International Journal of Training and Development, 10(4), 252-268.

Kontoghiorghes, C. (2002). Predicting motivation to learn and motivation to transfer learning back to the job in a service organization: A new systemic model for training effectiveness. Performance Improvement Quarterly, 15(3), 114-129.

Kozlowski, S., Gully, S., Brown, K. G., Salas, E., Smith, E. M., \& Nason, E. R. (2001). Effects of training goals and goal orientation traits on multidimentional training outcomes and performance adaptability. Organizational Behavior and Human Decision processes, 85, 1-31.

Latham, G. P. (1997). Overcoming mental models that limit research on transfer of training in organisational settings. Applied Psychology: An International Review, 46, 371375.

Liebermann, S., \& Hoffmann, S. (2008). The impact of practical relevance on training transfer: Evidence from a service quality training program for German bank clerks. International Journal of Training and Development, 12(2), 74-86.

Lim, D. H., \& Morris, M. L. (2006). Influence of Trainee Characteristics, Instructional Satisfaction, and Organizational Climate on Perceived Learning and Training Transfer. Human Resource Development Quarterly, 171), 85-115.

Locke, E. A., Frederick, E., Lee, C., \& Bobko, P. (1984). Effect of self-efficacy, goals, and task strategies on task performance. Journal of Applied Psychology, 69, 241-251.

Machin, M. A., \& Fogarty, G. J. (2003). Perceptions of training-related factors and personal variables as predictors of transfer implementation intentions. Journal of Business and Psychology, 18(1), 51-75.

Machin, M. A., \& Fogarty, G. J. (2004). Assessing the antecedents of transfer interventions in a training context. International Journal of Training and Development, 8(3), 222236. 
Mathieu, J. E., Tannenbaum, S. I., \& Salas, E. (1992). Influences of individual and situational characteristics on measures of training effectiveness. Academy of Management Journal, 35, 828-847.

Mintzberg, H. (2004). Managers not MBAs: a hand look at the soft practice of managing and management development. London: Prentice Education.

Nijman, D., Nijhof, W., Wognum, A., \& Veldkamp, B. (2006). Exploring differential effects of supervisor support on transfer of training. Journal of European Industrial Training, 30(7), 529-549.

Nikandrou, I., Brinia, V., \& Bereri, E. (2009). Perspective on practice. Trainee perceptions of training transfer: an empirical analysis. Journal of European Industrial Training, 33(3), 255-270.

Noe, R. A., \& Schmitt, N. (1986). The influence of trainee attitudes on training effectiveness: the importance of the work environment. Journal of Applied Psychology, 80(1), 239-252.

Noe, R. A., Sears, J., \& Fullenkamp, A. M. (1990). Relapse training: Does it influence trainees' post training behavior and cognitive strategies? Journal of Business and Psychology, 4(3), 317-328.

Olsen, J. H. J. (1998). The evaluation and enhancement of training transfer. International Journal of Training \& Development, 2(1), 61-75.

Orpen, C. (1999). The impact of self-efficacy on the effectiveness of employee training. Journal of Workplace Learning: Employee Counselling Today, 11(4), 119-122.

Pham, N. T. P., Gijselaers, W. H., \& Segers, M. S. R. (2010, in press). The effect of the trainees's perception of the training design on transfer of training: the case of Master of Business Administration (MBA) of Vietnam. In P. V. d. Bossche, W. Gijselaers \& R. Milte (Eds.), Advances in Business Education and Training. Springer.

Pintrich, P. (2000a). An achievement goal theory perspective on issues in motivation terminology, theory, and research. Contemporary Educational Psychology, 25, 92104.

Pintrich, P. (2000b). Multiple goals, multiple pathways: The role of goal orientation in learning and achievement. Journal of Educational Psychology, 92(544-555).

Pugh, K. J., \& Bergin, D. A. (2006). Motivational Influences on Transfer. Educational Psychologist, 41(3), 147-160.

Quinones, M. A. (1997). Contextual influences: on training effectiveness. In M. A. a. E. Quinones, A. (Eds) (Ed.), Training for a Rapidly Changing Workplace: Applications of Psychological Research (pp. 177-199): American Psychological Association, Washington, DC,

Quinones, M. A., Ford, J. K., Sego, D. J., \& Smith, E. M. (1995). The effects of individual and transfer environment characteristics on the opportunity to perform trained tasks. Training Research Journal, 1, 29-48.

Richman-Hirsch, W. L. (2001). Posttraining Interventions to Enhance Transfer: The Moderating Effects of Work Environments. Human Resource Development Quarterly, 12(2), 105-120. 
Roberson, L., Kulik, C. T., \& Pepper, M. B. (2009). Individual and Environmental Factors Influencing the Use of Transfer Strategies After Diversity Training. Group \& Organization Management, 34(1), 67-89.

Saks, A. M. (1995). Longitudinal field investigation of the moderating and mediating effects of self-efficacy on the relationship between training and newcomer adjustment. Journal of Applied Psychology, 80, 211-225.

Stevens, C. K., \& Gist, M. E. (1997). Effects of self-efficacy and goal orientation training on negotiation skill maintenance: What are the mechanisms? Personnel Psychology, 50, 955-978.

Tai, W. T. (2006). Effects of training framing, general self-efficacy and training motivation on trainees' training effectiveness. Personnel Review, 35(1), 51-65.

Taylor, M. (2000). Transfer of learning in workplace literacy programs. Adult Basic Education, 10(1), 3-20.

Tracey, J. B., Tannenbaum, S. I., \& Kavanagh, M. J. (1995). Applying trained skills on the job: the importance of the work environment Journal of Applied Psychology, 80(2), 239-252.

Tziner, A., Haccoun, R. R., \& Kadish, A. (1991). Personal and situational characteristics influencing the effectiveness of transfer of training improvement strategies. Journal of Occupational Psychology, 64(2), 167-177.

Velada, R., Caetano, A., Michel, J., Lyons, B., \& Kavanagh, M. (2007). The effects of training design, individual characteristics and work envoronment on transfer of training. International Journal of Training and Development, 11(4), 282-294.

Wexley, K. N., \& Baldwin, T. T. (1986). Post-training strategies for facilitating positive transfer: An empirical exploration. Academy of Management Journal, 29, 503-520.

Xiao, J. (1996). The relationship between organizational factors and the transfer of training in the electronics industry in Shenzhen, China. Human Resource Development Quarterly, 7, 55-73. 


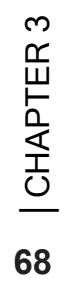




\section{Chapter 4}

\section{EFFECTS OF THE WORK ENVIRONMENT ON TRAINING TRANSFER EFFECTS}

Change the environment; do not try to change man

-R. Buckminster Fuller

One of the most significant current discussions in training issues is how to support trainees' application of newly gained knowledge and skills in their daily work, the so-called training transfer effects. When learning is not applied in the workplace, corporate training is useless, and a waste of money.

Once trainees re-enter the workplace after training, they have to cope with environmental and situational factors which might not only support but also inhibit the use of the newly acquired skills and knowledge. Thus, it has been argued that trainees need to use appropriate strategies, to transfer learned skills and knowledge, i.e. a (training) transfer strategy.

In this empirical study, the influence of the trainees' work environment on his/her transfer of training is focused on, taking into account the mediating role of trainees' transfer strategies.

Data were collected from 305 trainees, who were sampled from eight different MBA programs in Vietnam. The average age was 32 . The analyses are based on regressions and path analyses.

The results of this study show that the work environment factors such as supervisor's support, job autonomy and preferred support (support as needed by the trainee) significantly predict the training transfer effects. Additionally, trainee's use of transfer strategies plays a mediating role.

In order to enhance training transfer effects from MBA programs, it is important and effective to respond to the trainees' preferred support, and to support trainees to formulate and develop their own training transfer strategies

This Chapter is based on Pham, N.T.P., Segers, M.S.R. \& Gijselaers, W.H. (2010). Effects of the Work Environment on Training Transfer Effects: the case of Master of Business Administration (MBA) in Vietnam. In International Journal of Training and Development (Under review). 


\section{INTRODUCTION}

Employee training is one of the important ways to develop employees to the challenges of emerging markets in a globalized economy, and hence, achieve the goals of an organization. Training programs do not only aim to enhance the quality of current task and work performance but also support competence development of trainees in order to meet the demands of the future (DeSimone, Werner, \& Harris, 2002).

There is a concern in industry that training dollars are wasted, since only few of the facts, skills, and attitudes taught in training courses are actually taken back to the workplace and put into use (e.g. Baldwin \& Ford, 1988; Burke \& Hutchins, 2007; Curry, Caplan, \& Knuppel, 1994; Kaufman, 2002). Because many corporate money is spent on training, the so-called training transfer problem has led researchers try to understand the conditions under which trainees effectively apply the training to their work practice (Burke \& Hutchins, 2007; Salas \& Cannon-Bowers, 2001). There is general agreement that the conditions have to do with the training design, the trainee characteristics, and the work environment (Baldwin \& Ford, 1988; Cheng \& Hampson, 2008; Ford \& Weissbein, 1997; Pugh \& Bergin, 2006).

Studies have shown that environmental factors are important for understanding the transfer of training process (e.g. Baldwin \& Ford, 1988; Kirwan \& Birchall, 2006; Rouiller \& Goldstein, 1993; Tracey, Tannenbaum, \& Kavanagh, 1995). Nevertheless, the available literature has revealed that work environment variables have been investigated less often than training design and individual characteristics (Alvarez, Salas, \& Garofano, 2004; Baldwin \& Ford, 1988; Holton, Bates, Seyler, \& Carvalho, 1997; Tannenbaum \& Yukl, 1992). Although it has been proposed that more specific variables, such as social, peer, subordinate and supervisor support, affect transfer behavior (e.g.Burke \& Baldwin, 1999; Tracey, Tannenbaum, \& Kavanagh, 1995), we still lack empirical evidence confirming which aspects of the work environment influence training transfer (Clarke, 2002). Furthermore, Cheng and Hampson (2008) mention some inconsistent findings. For example, on one hand, some studies evidenced the influence of social support of the trainees on their transfer behavior (e.g. Brinkerhoff \& Montesino, 1995; Holton, Bates, \& Ruona, 2000; Olsen, 1998; Xiao, 1996). On the other hand, there is also empirical evidence of non-significant relationships between a supportive environment and transfer outcomes (e.g. Rouiller \& Goldstein, 1993; Tziner, Haccoun, \& Kadish, 1991; Van der Klink, Gielen, \& Nauta, 2001). Therefore, we argue that studying transfer of training from a work environment perspective might contribute to a better understanding of the transfer effects of training. 
Additionally, in their literature review, Cheng and Hampson (2008, p. 335) state that the "inconsistent and unexpected findings alert us that our previous models may not be adequate for studying the transfer process. Perhaps other schools of thought may provide us with plausible answers". They suggest exploring the essential but hidden variables related to the transfer process. Training literature indicates that learning in training does not automatically result in transfer (e.g. Hesketh \& Laidlaw, 1997; Kraiger, Ford, \& Salas, 1993). Trainees, therefore, should have intention to transfer skills and knowledge. Once trainees re-enter the workplace after training, they have to cope with the dynamics of the workplace which might not only support but also inhibit the use of learned knowledge and skills, such as the negative attitudes of their co-workers. Taylor (2000, p. 15) cited a trainee: "When we come from our classes, many of our colleagues tease us about going to school ... These remarks hurt us a bit ... I don't want to show off what l've learned in front of them, because they will tease me even more". Or as a trainee said, organizations "don't even listen to our opinion ... They don't care about applying what we're learning... They don't give us that opportunity in any case ... Just as long as we go to the seminars" (Nikandrou, Brinia, \& Bereri, 2009, p. 264). Given the aforementioned resistance trainees might experience when returning to the workplace, it has been argued that, in order to have opportunities to use acquired trained knowledge and successfully apply it to the job, trainees need to use appropriate strategies, to transfer learned skills and knowledge, i.e. a (training) transfer strategy (Burke \& Baldwin, 1999).

Research revealed that the use of transfer strategies for facilitating the transfer process is a crucial prerequisite for transfer of training (Burke, 1997; Ford \& Weissbein, 1997; Machin \& Fogarty, 2003). Tzinner, Haccoun and Kadish (1991) believed that paying attention to goal-setting and selfmanagement as transfer strategies resulted in a significantly higher level of transfer. Foxon (1994) argued that transfer strategies enhance the transfer probability by simultaneously embracing the impact of organizational system factors and assisting the trainees in practically applying the training into their work. A few studies proposing the importance of transfer strategies as a key mediator of the link between influencing factors and transfer outcomes. Examples include Gollwitzer (1999), Latham (1997) and Noe, Sears, and Fullenkamp (1990). However, it is still unclear to what extent transfer strategies influence the relations between training design and transfer of training. Recently, Pham, Gijselaers, \& Segers (2010, in press) have found the mediating role of transfer strategies play in relation between transfer design and transfer of training. Pham, Segers, \& Gijselaers (2010) have found the mediating role of transfer strategies plays in relation between trainees' motivation and transfer of training. Nevertheless, it is still unclear which role transfer strategies play in the 
relation between work environment and transfer of training. Therefore in addition to direct relationship between work environment and transfer of training, we include the trainee's use of transfer strategies as a mediating variable, proposing it will influences the strength of the relation between the work environment and transfer of training. We hypothesize that work environment affects trainee's use of transfer strategy, which in turn, influences transfer of training.

\section{CONCEPTUAL FRAMEWORK}

\subsection{Work environment factors influencing transfer of training}

Work environment and transfer climate have been used as concepts implying the features of workplace affecting the using on the job what trainees have been acquired during training (Burke \& Saks, 2009; Velada, Caetano, Michel, Lyons, \& Kavanagh, 2007a). In general, research on work environment factors (e.g. Baldwin \& Ford (1988); Richey, (1992)) distinguishes three levels of related (work) environmental factors: (a) general environmental factors , (b) factors generally related to training and (c) factors specifically related to training. According to Richey, these are considered to be related to each other, since general environmental factors influence factors generally related to training which in turn, affect the factors specifically related to training. Nijman, Nijhof, Wognum and Veldkamp (2006) further considered three separate components of the influence of the work environment on transfer: (a) general characteristics of the work environment, (b) the work environment (or transfer climate) which have a specific and intentional role regarding to transfer of training and (c) Supervisor support, meaning the supervisor's behavior to optimize applying training content to trainee's job. It should be emphasized here that Nijman et al. (2006) consider supervisor as a separate component of work environment, while it is seen as one of the features of the transfer climate in other studies (Holton, Bates, \& Ruona, 2000; Holton, Bates, Seyler, \& Carvalho, 1997; Rouiller \& Goldstein, 1993).

In this study, we will make a distinction between general work environment and specific work environment factors (transfer climate) aiming to enhance training transfer. This is consistent with studies of a number of scholars such as Ford, Qiunones, Sego and Speer Sorra (1992), Lim and Johnson (2002), Noe and Schmitt (1986), Russ-Eft (2002) and Seyler, Holton, Bates, Burnett and Carvalho (1998). Examples of the genera/ work environment factors are job autonomy, level of freedom, independence and discretion to employees in planning and in determining the procedures to 
their job (Robbins, 2001), budget restrictions and coordination within organizations, overlapping work assignment, lenience for mistakes, lack of technical assistance (Lim \& Johnson, 2002). Examples of specific work environment factors (transfer climate) factors are opportunity to use training content, peer and supervisor support, supervisor sanctions, positive and negative personal outcomes, and resistance to change (Holton, Bates, \& Ruona, 2000; Holton, Bates, Seyler, \& Carvalho, 1997; Rouiller \& Goldstein, 1993).

General work environment

There are several general characteristics of the workplace that have been described as influential for the transfer of training, although empirical evidence for most of these characteristics is largely missing. One general work environment variable that has received quite some attention in empirical studies is job autonomy. Studies have been supporting its importance role in influencing transfer of training (e.g. Robbins, 2001). According to Robbins, job autonomy refers to the trainees' degree of freedom in scheduling and determining the executing of his/her job. The more autonomous work environments the more effective knowledge transfer occurs (Axtell \& Maitlis, 1997).

Specific work environment (transfer climate)

Burke and Baldwin (1999) mention that characteristics of the work environment are factors that may facilitate or inhibit the use of trained skills, the so-called transfer climate. According to Nijman, Nijhof, Wognum and Veldkamp (2006), the difference between general work environment and specific work environment (transfer climate) is that the latter is "specifically and intentionally directed at the transfer of training" (p. 535). Prior studies have indicated the relevance of different components of the specific work environment factors such as supervisor support, opportunity to use, peer support, supervisor sanctions, positive and negative personal outcomes, and resistance to change (e.g. Holton, Bates, \& Ruona, 2000; Rouiller \& Goldstein, 1993). In addition, other studies have demonstrated that the extent to which trainees prefer support (Nijman, 2004), have sufficient time and resources available also affect transfer outcomes (Noe \& Schmitt, 1986; Russ-Eft, 2002).

Supervisor support generally refers to the extent to which supervisors reinforce and support employees to use knowledge, skills and attitudes gained in training on the job. Literature identified supervisor support as an important work-environment variable influencing transfer of training (e.g. Quinones, Ford, Sego, \& Smith, 1995; Richman-Hirsch, 2001; Salas \& Cannon-Bowers, 2001). For example, Russ-Eft (2002) stated supervisor support such as setting goals with trainees, encouraging learning on the job, facilitating the use of new skills. Baldwin et al. (2000) emphasize the active participation supervisor support, meaning supervisors not only need 
to state the importance of learning, but also should actively participate in training e.g. setting learning goals, offering positive feedback. Moreover, previous studies have confirmed the relationships between positive supervisor support and positive transfer outcomes (Brinkerhoff \& Montesino, 1995; Cromwell \& Kolb, 2004), and opportunities to use training on the job (Ford, Quiñones, Sego, \& Speer Sorra, 1992). Additionally, when trainees perceive supportive supervisors, they also believe that training would be useful and helps them to perform on the job effectively and obtain salary increases, thus suggesting a positive connection between supervisor, the positive outcomes of training, and transfer of training (e.g. Cohen, 1990; P. Taylor, 1992).

Opportunities to use training on the job is "the extent to which a trainee is provided with or actively obtains work experiences relevant to the tasks for which he or she was trained" (Ford, Quiñones, Sego, \& Speer Sorra, 1992 , p. 512). This factor is described as a multidimensional opportunity, suggesting a differentiation between the number of the tasks and the type of tasks to be performed. Former research indicated that when trainees have less opportunities to use training on their working place, transfer is limited (Brinkerhoff \& Montesino, 1995; Lim \& Morris, 2006). Moreover, other studies have shown the important role of these opportunities to transfer in terms of enhancing trainees' motivation to transfer (Mathieu, Martineau, \& Tannenbaum, 1993; Seyler, Holton, Bates, Burnett, \& Carvalho, 1998).

Peer support refers to the level to which peers behave producing reinforcement for trainees' use of learning on the job (Holton, Bates, Seyler, \& Carvalho, 1997; Nijman, Nijhof, Wognum, \& Veldkamp, 2006). It can affect trainees' motivation to transfer and the effect of training transfer (Facteau, Dobbins, Russell, Ladd, \& Kudisch, 1995; Noe \& Schmitt, 1986; Seyler, Holton, Bates, Burnett, \& Carvalho, 1998). Especially, peer support has been reported as factors that related to other characteristics of the work environment (Russ-Eft, 2002). For example, positive peer support predicts the opportunities to use new training content on the job (Quinones, Ford, Sego, \& Smith, 1995). Rouillier and Goldstein (1993) concluded that the work environment including behavior of colleagues was a stronger predictor of training transfer than the trainee's actual learning outcomes at the end of the training program. Also Bates, Holton, Seyler and Carvalho (2000) found that peer support was a significant predictor of training transfer. Holton, Chen and Naquin (2003) compared and contrasted learning transfer systems across organizations and found that peer support scales varied among different types of organizations and may promote or prohibit learning transfer.

Preferred support relates to "the level of support that can best be given, to achieve intended transfer outcomes" (Nijman, 2004, p. 95). According to 
him, transfer of training might be influenced by preferred support because it relates to trainee's motivation to transfer. In this study, preferred support was interpreted as a work environment factor that may facilitate the use of trained knowledge and skills. Our argument is that the need of the trainee for support from supervisor and peers (beside the actual support given by them), is a work environment relevant predictor of transfer effects. In fact, it is logical that one will transfer most when he/she gets the specific help which he/she is looking for.

Personal Outcomes-Positive is "the degree to which application of training on the job leads to positive outcomes or payoffs for the individual" (Holton, Bates, Seyler, \& Carvalho, 1997, p. 110). Trainees who perceive positive personal outcomes of the training will receive higher salary, higher positions (Holton et al., 1997) and also positive performance evaluations (Facteau, Dobbins, Russell, Ladd, \& Kudisch, 1995). Concretely, verbal praise and promotion chances increase training transfer outcomes (Xiao, 1996), and transfer rewards enhance the trainees' motivation to learn (Cheng, 2000).

Personal Outcomes-Negative refers to the negative consequences for trainees if they are not using learned knowledge and skills on the job after training (Holton, Bates, \& Ruona, 2000). According to them, when not using new knowledge or skills on-the-job, they are under pressure of the negative outcomes such as being overlooked for raises and being reprimanded. However, Ruona, Leimbach, Holton, and Bates (2002) have drawn attention to the fact that perceiving personal outcomes-negative in turn, leads to increased trainee motivation to transfer training. Nevertheless, research on these negative consequences has hardly been examined (Nijman, Nijhof, Wognum, \& Veldkamp, 2006).

Sanctioning of transfer is defined as the extent to which individuals perceive negative responses from others when transferring training (Holton, Bates, \& Ruona, 2000; Holton, Bates, Seyler, \& Carvalho, 1997). For example, it can be punishment (Rouiller \& Goldstein, 1993), or experiencing supervisors' indifference and active opposition, even being seen as outrageous by others (Russ-Eft, 2002) when transferring training on the job. As a result, sanctions lead to reduced trainee motivation to transfer (Facteau, Dobbins, Russell, Ladd, \& Kudisch, 1995; Seyler, Holton, Bates, Burnett, \& Carvalho, 1998).

Resistance to change at the workplace is the extent to which individuals resist or discourage the applying of the training content on the job (Holton, Bates, \& Ruona, 2000). Nijman, Njihof, Wogum and Veldkamp (2006) see resistance is opposite to openness when trainees use new training content at work. Previous studies concretely indicated that for example, coworker's openness will increase trainee motivation to transfer (Ruona, Leimbach, Holton, \& Bates, 2002), and transfer outcomes (Cheng, 2000). 
In summary, given the results of the aforementioned studies and following Nijman, Njihof, Wogum and Veldkamp (2006) empirical study, the present study will focus on the following variables. For specific work environment factors (transfer climate), we will address the role of trainees' opportunities to use training on the job; supervisor and peer support; by the trainee preferred supervisor support; perceived positive and negative personal outcomes; sanctioning of transfer; and resistance to change. For general work environment factor, we will address the influence of job autonomy on transfer of training.

\section{$2.2 \quad$ Use of transfer strategy}

According to Noe, Sears and Fullenkamp (1990) (cited in Roberson, Kulik, and Pepper (2009), transfer strategies are cognitive and behavioral techniques, that include setting goals, analyzing work situations, preparing to deal with difficulties, identifying and using the necessary supports, and recognizing and monitoring opportunities to use acquired knowledge and skills on the job.

Foxon $(1994$, p. 3) has argued that transfer strategies have to be formulated, and "implemented during the design, development and delivery of instruction". She believes that such strategies tend to increase the possibility of transfer through organizational system factors that simultaneously assist the individual to focus on potential applications of the learning. Olsen (1998) emphasizes the need of understanding how to develop trainee's intention to use the new knowledge and skills.

There are several transfer strategies outlined in the literature which can be incorporated into training courses such as (1) the trainees' situation (e.g. identifying situations at work to apply the trained skills), (2) the trainees' thoughts/feelings (e.g. thoughts about the necessary support needed in order to use the trained skills; retaining self-confidence when experiencing resistance or burdens), (3) the trainees' behavior (e.g. creating and maintaining a social network), and (4) consequences of the trainees' behavior (e.g. being prepared to deal with skepticism of colleagues) (Burke \& Baldwin, 1999). Researchers have consistently emphasized the need for better understanding of the role of use of transfer strategies by trainees (e.g. Ford \& Weissbein, 1997; Machin \& Fogarty, 2004).

\subsection{Training transfer effects}

Many practitioners and researchers refer to Kirkpatrick's taxonomy (1998) to evaluate training effects. Kirkpatrick discerns four 'levels': (1) how 
trainees felt about the training; (2) whether they have learned anything, (3) whether the learning was transferred to the job or the extent of behavior and capability improvement and implementation/application and (4) the effects on the business or environment. In this study we focus on the third level by questioning if the application of the trained knowledge, skills and attitudes in the workplace improves the performance of the job tasks as well as the work performance in general. In this respect, Xiao (1996) refers to the improvement of the productivity efficiency of the employee through training. Additionally, DeSimone, Werner, and Harris (2002, p. 3) claim that training programs aim to "provide its members (of the organization) with the opportunities to learn necessary skills to meet current and future job". This implies training programs do not only aim to enhance the quality of current task and work performance but also support the competence development of trainees to meet the demands of the future.

\section{RESEARCH QUESTION AND HYPOTHESES}

The present study aims to understand to what extent the trainee's transfer of learning to workplace is influenced by work environment factors. Moreover, we study the contribution of the trainees' use of transfer strategies.

The following research question is addressed: "To what extent do work environment factors, taking into account the role of the trainees' transfer strategies, contribute to transfer newly acquired knowledge, skills and attitudes on the job?". Two hypotheses were tested:

$\mathrm{H} 1$ : "Work environment factors are positively related to the extent of transfer training".

$\mathrm{H}$ 2: "The effect of work environment factors on the training transfer effects is mediated by trainee's transfer strategies ".

\section{METHODOLOGY AND RESEARCH DESIGN}

\subsection{Participants}

Data were collected from 305 trainees attending eight different part-time MBA programs in Vietnam (Appendix A). All trainees combined a job with an MBA study. 167 trainees answered the first survey. 126 trainees answered the second one. The majority of the sample was male $(n=102$; $61 \%)$. The average age is 32 . Moreover, 33 trainees' supervisors of the trainees answered the second survey in terms of transfer effects. 


\subsection{Setting}

The present study was conducted in the setting of Master of Business Administration (MBA) programs. The first MBAs were offered by Harvard University about 100 years ago, in a two-year, full-time format. To date, MBA degree programs have spread around the world, with a diversity of master's degree in management-related subject. "Master's qualification is becoming almost a prerequisite for success as a senior manager" (Cameron, 2005, p. 4). The MBA setting provides a good opportunity to study transfer of training for the following reasons. First, the MBA degree is a higher education product in demand, with about 75,000 MBAS graduating each year in the US in the 1990s (Gijselaers \& Milter, 2010, in press). The numbers of MBA programs and students has continued to grow since then across the globe. Second, MBA programs are professionally oriented and focus on the development of professional competence (Mintzberg, 2004). They aim to improve the functional and managerial competencies of trainees (Camuffo, Gerli, \& Chiara, 2006), since most MBA participants are professionals with a considerable amount of experience, and they perceive the training as a competitive advantage for their professional development (Cheng \& Ho, 2001). Therefore, the possibilities training programs offer trainees to transfer the competencies they have been practicing during the training to the workplace, are of utmost importance for the trainees. Third, MBA programs provide trainees with "a highly analytical approach to managerial problem solving, and the ability to approach new problem in a structured fashion" (Cameron, 2005, p. 14). The question is if and under what conditions, MBA programs really reach these high ambitions. Finally, MBA programs produce economic benefits and career success to MBA trainees, to the extent that MBA graduates receive more promotions than those who did not receive an MBA degree (Inderrieden, Holtom, \& Bies, 2006). Given these benefits, studying MBA programs in order to contribute to optimizing their transfer effects, is appropriate.

In Vietnam, education has been considered as top priority by the Vietnamese government in its attempt to develop the economy and join the global arena. After nearly 30 years of economic reform, the country is now facing with more vigorous challenges than ever before. Consequently, the Vietnamese government has established robust educational institutions which include MBA training programs (for instance, the Hanoi National Economics University (NEU), Vietnam National University (VNU), Foreign Trade University (FTU), Solvay Business School (Université Libre de Bruxells, Belgium), Centre Franco-Vietnamien de Formation a' la Gestion (CFVG), Maastricht School of Management (MsM) in Vietnam). Although education is highly important in Vietnam, the question how the knowledge 
and skills obtained by trainees are transferred into work is inadequately verified. Meanwhile, there is a growing market of MBA programs with varying trainees' working conditions. These programs provide opportunity for researchers to examine the different variables incorporated in the transfer process. It also emphasizes a need of the assessments in order to ascertain whether these programs have a positive impact on Vietnamese corporate practice. Thus, providing a comprehensive understanding of real training transfer issue in Vietnam is an urgent necessity. This will help educational organizations in Vietnam effectively and efficiently enhance transfer process by diagnosing the factors that impact on training transfer systems.

The duration of these Vietnamese MBA programs (one up two years) also is a positive element of this study. While almost all other training programs studied in the literature are very short- for example, a three-day course (Lim \& Morris, 2006), one five-and-a-half-day week (Xiao, 1996), 12 days' duration (Kirwan \& Birchall, 2006) or one month program (Velada, Caetano, Michel, Lyons, \& Kavanagh, 2007b) - these Vietnamese MBA programs have higher probability that trainees will have opportunities to internalize the training and develop a transfer strategy.

\subsection{Measures}

All measures were based on instruments validated in previous studies. In some cases they were adapted for the specific purpose of data collection in MBA programs (see Appendix B).

To measure work environment factors, we used (1) the Nijman, Nijhof, Wogum and Veldkamp (2006) questionnaires which contain 17 items for measuring specific work environment factors (transfer climate); (2) 4 items for measuring general work environment (job autonomy) and (3), the Xiao (1996) questionnaire comprises 6 items for measuring supervisor support.

To explain correlations among observed variables with hypothetical variables, and to examine the structure of the data in the Vietnamese MBA context, a confirm factor analysis (CFA) was conducted. The adequacy of the models was assessed by EQS version 6.0 (Bentler, 2002). Models were all tested with standardized coefficients obtained from the maximum likelihood method of estimation. The values of the fit indices indicate a good fit to the data (Chi-square/df = 2.6; $\mathrm{TLI}=0.87 ; \mathrm{CFI}=0.90 ; \mathrm{RMSEA}=0.09$ ). The results of CFA revealed that work environment can be explained by five factors: Sanctioning transfer, Peer support, Preferred support, Supervisor support and Job autonomy (item-examples of these factors are presented in Appendix B). These five factors are consistent with studies of Colquitt, Lepine and Noe (2000), Holton, Bates and Ruona (2000) and Rouiller and 
Goldstein(1993). Ca of each factor is high (minimum is 0.73 , see Table 4.1). Based on the results from the CFA, we used these 5 factors to test the aforementioned hypotheses.

For measuring the transfer strategy, we used questionnaire of Burke and Baldwin (1999). As this instrument has been validated in many studies in comparable settings, amongst which, Pham, Gijselaers and Segers (2010, in press) and (Pham, Segers, \& Gijselaers, 2010), with this study, we did not conduct a factor analysis on the data for this instrument. The Ca is very high for our sample (0.88) and therefore confirms prior validation studies.

For measuring the transfer effects, the questionnaire of Xiao (1996) was used. Moreover, the authors extended the questionnaire with 11 items in order to measure the transfer effects with a more robust instrument. These items were based on an evaluation questionnaire used in Vietnamese training settings. The PCA results revealed three factors: (1) task performance improvement, $\mathrm{C} \alpha=.90$; (2) capacity building, $\mathrm{C} \alpha=.92$ and (3) job performance in general, $\mathrm{C} \alpha=.86$.

The research model of this study can be depicted as follows (figure 4.1). In this model, we schematized the research model that will be investigate in this study, including work environment factors as independent variables and transfer of training as dependent variables and transfer strategy as mediation variable.

\section{Figure 4.1 Research model}

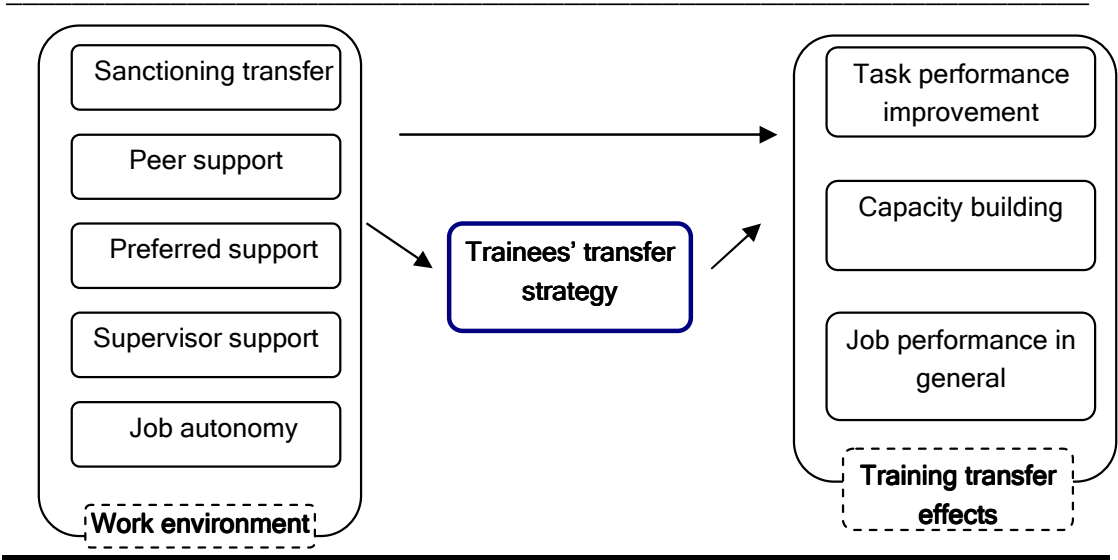




\subsection{Procedure}

The original questionnaires were translated into Vietnamese language. Then the Vietnamese versions were translated back to English to assure the consistency of meaning.

We controlled for demographic information: age, gender, years of work experience, job position, reasons for pursuing the MBA course and the source of MBA fees.

The questionnaires were completed by trainees at two points in time: (T1) - at the end of the training program, and (T2) - three months after the end of the training. At time 1, we measured (a) demographic variables, (b) trainee's perception of work environment variables, and (c) trainee's use of training transfer strategies. At time 2, we measured again (d) trainee's perception of the work environment, (e) trainee's perception of the transfer of training and ( $f$ ) trainee's supervisor perception of transfer of training.

It is worth explaining why we measure trainee's perception of the work environment both at T1 and T2. Generally, when entering training, most trainees already have knowledge and skills, expectations, and motivations, especially perceptions about their work environment. Moreover, as mentioned above, in our MBA setting, the trainees are employees working while following the program. Thus, they experience the support or the hindrance of the work environment already during the training. However, in the training process, the influences of content of training, the training methods and training design as well as interactions between the trainers and the trainees, and between trainees will influence these trainees' characteristics and perceptions. As a result, these interactions can influence their perception of work environment. After the training period, trainees' perceptions of work environment might have changed. They might use acquired knowledge and skills to influence the organization directly or/and indirectly by demanding more autonomy, task variety, and job involvement (Kontoghiorghes, 2004; Nikandrou, Brinia, \& Bereri, 2009). Thus, the period after training is considered the most important in facilitating positive transfer (Wexley \& Baldwin, 1986). In other words, it is relevant to measure trainee's perception of work environment not only during the training but also some period after the training (e.g.Tannenbaum $\&$ Yukl, 1992), as we have done here.

Training transfer effects was measured at time 2, three month after training as literature revealed that transfer of training is changed by time (Awoniyi, Griego, \& Morgan, 2002). Especially, the period after training is considered the most important in facilitating positive transfer (Wexley \& Baldwin, 1986). Nikandrou, Brinia and Bereri (2009, p. 258) suggest that, "to understand the training transfer process we need to understand all the 
factors affecting trainees as they enter training, during the training process and after training when they return to their work environment". Alliger, Tanenbaum, Bennett, Traver and Shotland (1997, p. 355) also noted: "By gathering reaction data one, three, or six months after training, trainees will have experienced whether the training was in fact useful, and should be in a better position to judge the utility of the training". According to Vermeulen (2002, p. 369), at the end of the training, trainees usually do not fully master the newly learned knowledge and skills because "They need to practice and learn more in their job context to internalize what they have learned".

While most earlier research is based on trainees' self-report (e.g. Kontoghiorghes, 2004; Machin \& Fogarty, 2004; Velada, Caetano, Michel, Lyons, \& Kavanagh, 2007a), we used both trainees' self reports and supervisor ratings. The reason is that, especially when measuring effects, self-reports have been argued as being flawed measures (e.g. Velada \& Caetano, 2007). The supervisor's transfer assessments sharpen understanding of influencing factors and assure the findings.

\subsection{Methods of analysis}

To tests whether work environment variables influence transfer training effects, and whether the participants' transfer strategies contribute to transfer of training effects, we use path analysis to identify effects of potentially important theoretical relations. The adequacy of the models was assessed by EQS version 6.1 (Bentler, 1985).

\section{RESULTS}

The descriptive statistics, Pearson correlations and internal consistencies of the variables are presented in Table 4.1. The results reveal that:

(1) Most of the work environment variables (both at the end of the training and three months after the training) are significantly associated with the transfer effects, but this is not the case for the variable peer support and job autonomy at the end of training.

(2) The strong significant correlations of these work environment factors with transfer of training do not only appear at the end of training, but also three months after the training. Especially, work environment factors three month of the training are even stronger than at the end of the training.

(3) Most of the work environment variables are significantly associated with the use of transfer strategies. This is clearly not the case for both the variable sanctioning transfer and job autonomy after training three months. 
(4) The use of (training) transfer strategies is strongly related to the transfer of training.

In addition, the results of regression showed that the control variables such as age, gender, years of work experience, job position, reason (s) for pursuing the MBA course and the source of MBA fees have no significant effects on transfer of training. Therefore we did not include these control variables in the path analysis

Moreover, as mentioned above, this study measure transfer of training effects by both trainees' own evaluation and their supervisors' evaluations, to avoid bias and achieve comparability. An independent-sample t-test was conducted to compare the training transfer score for trainees and their supervisors. The results reveal that there is no significant difference in scores between trainees and their supervisors in terms of three perspectives training transfer (task performance improvement, capacity building and general job performance): $t(150)=1.58, p=12, t(151)=1.71$, $p=.09, t(151)=1.81, p=.07$ respectively). Also, in terms of the effect size for independent-sample t-test (Cohen, 1988), the magnitude of the differences in means (in terms of task performance improvement; capacity building and job performance in general) is very small $\left(\theta^{2}=.016 ; .019\right.$ and .021 respectively). In summary, the similarity of mean transfer effect scores for trainees and their supervisor can be interpreted as an indication of interrater reliability. 


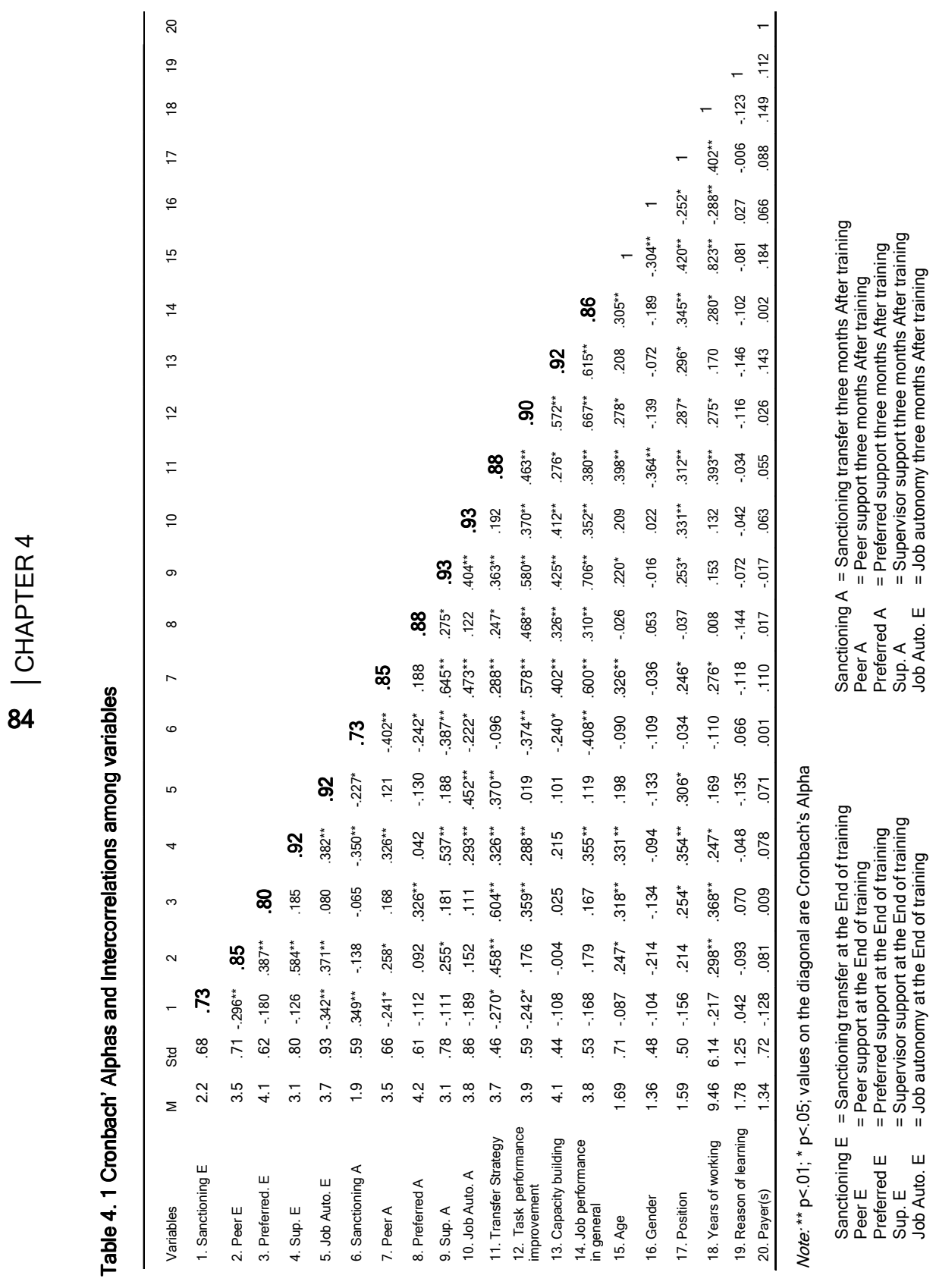




\section{$5.1 \quad$ Testing the model}

Given the theoretical insights as described above, the originally hypothesized model is composed of paths leading from the constructs measuring work environment (sanctioning transfer, peer support, preferred support, supervisor support and job autonomy) both directly toward transfer training and indirectly toward transfer training through transfer strategy (mediation variable), and three paths from transfer strategy toward transfer training. Moreover, trainee's perception of work environment in the end of training $(E)$ influences their perception of work environment three months after the training $(A)$.

Based on the exploratory design of the study, and as recommended by Anderson and Gerbing (1988), the present model was compared with several other models presenting plausible alternatives. The 'best fitting' is achieved since it has surpassed all the goodness of fit indices. The goodness of fit indices of this model (Chi-square $=47 ; \mathrm{df}=25 ; \mathrm{p}=.005$; $\mathrm{TLI}=.87$; RMSEA=.10) indicated the appropriateness of the model structure and theoretically acceptable. The results are as presented in figure 4.2.

Figure 4.2 Path analysis model toward training transfer effects

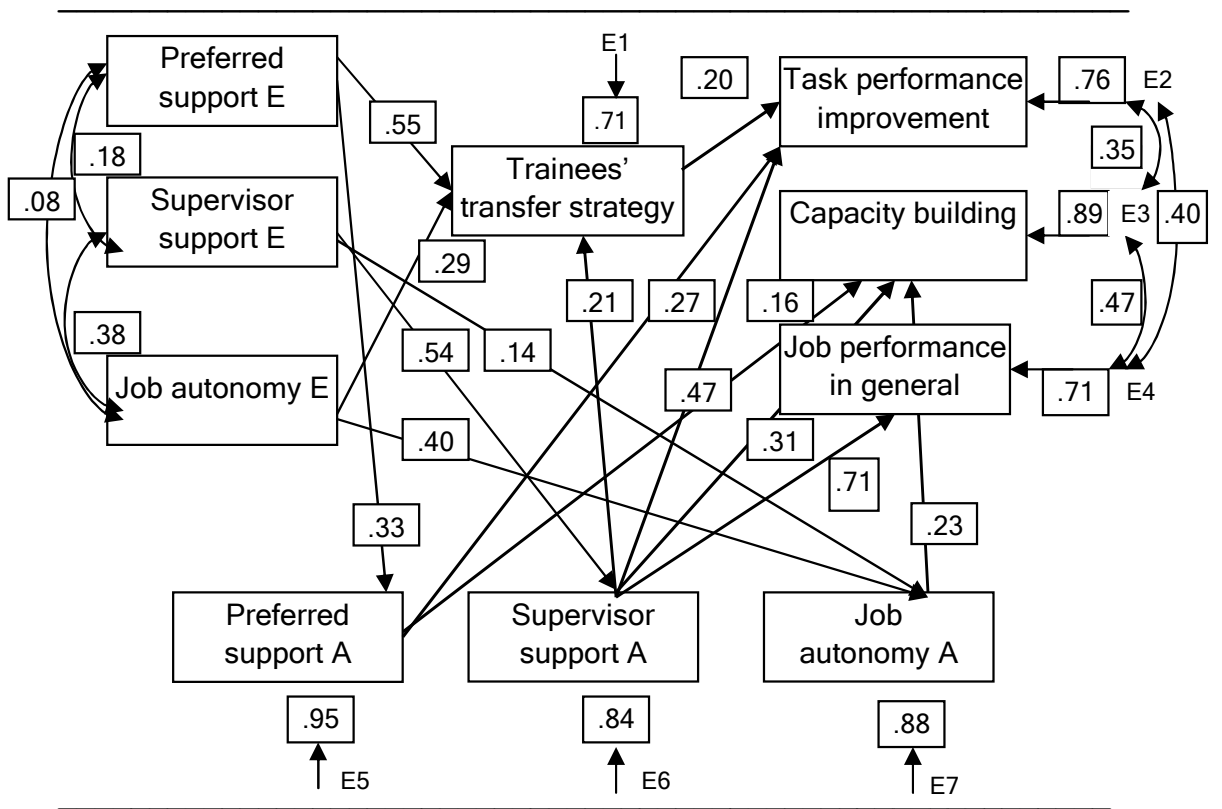

Note: $\mathrm{E}=$ End of training; $\mathrm{A}=$ After three months of training 
Figure 4.2 indicate some interesting results that:

1) Trainees' perceptions of work environment (including preferred support, supervisor support and job autonomy) at the end of the course (E) are significantly related to their perceptions three months later $(A)(\beta=.33$; .29 and .40 , relatively).

2) All of trainee's perceptions of work environment variables after training: preferred support $A$, job autonomy $A$ and especially supervisor support $A$ are powerful variables in affecting transfer of training directly and indirectly. For example, job performance in general (item example is "In general, I think this training course has helped me increase my work performance") were directly predicted by supervisor support $A(\beta=.71)$. Task performance improvement ("I can accomplish my job task better than by using new knowledge and skills") was directly predicted by (a) supervisor support $A$ directly $(\beta=.47)$ (and also indirectly, $\beta=.21^{*} .20=.04$ ); (b) preferred support $A(\beta=.27)$, and (c) trainees' transfer strategy $(\beta=.20)$. Similarly, capacity building ("My ability to implement work in general is increased") were directly predicted by supervisor support $A(\beta=.31)$, job autonomy $A$ $(\beta=.23)$ and preferred support $A(\beta=.16)$.

3) None of preferred support $E$, supervisor support $E$ and job autonomy $E$ directly influencestransfer of training. Instead, they only directly influence preferred support $A$, supervisor support $A$ and job autonomy $A$ or transfer strategies. In turn, preferred support $A$, supervisor support $A$, job autonomy $A$ and transfer strategies directly influence transfer of training. For example, supervisor support $E$ influences supervisor support $A(\beta=.54)$. In turn, supervisor support $A$ directly influence transfer of training $(\beta=.47 ; 31$; and 71 in terms of task performance improvement, capacity building and job performance in general, relatively).

4) Job autonomy A directly influences capacity building and job autonomy $E$ influences performance improvement through transfer strategy

These results imply that the results partly support the first hypothesis.

5) Transfer strategy is directly influenced (in order of importance) by preferred support $E(\beta=.55)$, job autonomy $E(\beta=.29)$ and supervisor support A $(\beta=.21)$. In addition, transfer strategy influences directly the training transfer effects in terms of Task performance improvement $(\beta=.20)$. Moreover, the relation between supervisor support $A$ and task performance improvement is strengthened when trainees use transfer strategies.

Therefore, the second hypothesis is partly supported. 


\section{CONCLUSION AND DISCUSSION}

The purpose of this study is to increase our understanding of how the extent work environment factors affect training transfer process. Furthermore, while there has traditionally been a focus on the relation between either work environment or transfer training effects with training transfer effects, this study includes simultaneously incorporated of work environment and the participants' transfer strategies influence transfer training. The findings support that such major work environment factors (i.e. preferred support, supervisor support and job autonomy) affect transfer outcomes in different ways. Especially these effects were shown to be different when tested at two points in time: at the end of the training program (E) and three months after the end of the training (A). In addition, the participants' transfer strategies, playing the role of mediator, contribute to the relation between work environment and transfer of training.

The results of the path analysis confirm prior research indicating that work environment variables influence transfer training effects (Axtell \& Maitlis, 1997; Baldwin \& Ford, 1988; Ford \& Weissbein, 1997; Holton, Bates, \& Ruona, 2000; Nijman, Nijhof, Wognum, \& Veldkamp, 2006; Robbins, 2001) with supervisor support as a powerful variable (e.g. Brinkerhoff \& Montesino, 1995; Campbell \& Cheek, 1989; Cohen, 1990; Cromwell \& Kolb, 2004). Based on the above conclusions, there are a number of issues that are worth discussing.

First, a significant finding of this study is the results indicate that how trainees perceive the work environment three months after training $(A)$ is a stronger indicator of transfer of training than trainees' perceptions of supervisor support at the end the training (E). For example, we found that none of preferred support $E$, supervisor support $E$ and job autonomy $E$ directly influence transfer of training with supervisor support $E$ was not related to either transfer strategy nor to training transfer. Given the fact that MBA trainees work during the training, it can be explained by the possibility that perhaps during training, the trainees depend less on their supervisors in the workplace than they do when they return to their job (after training). It became apparent that to for the trainee to transfer the knowledge and skills acquired through training, (s)he must have supervisor support after the training period. Consequently, how they experience the support by the work environment when return to their workplace will influence the extent to which they transfer what they have learned to the workplace. Similarly, none of preferred support, supervisor support and job autonomy at the end the training directly influence transfer of training, whereas preferred support, supervisor support and job autonomy after training do. The power of trainee's perceptions three months after the training might be explained 
by the various interactions during as well as after the training that shape trainees' perception of work environment. The results confirm the importance of what happens at the workplace after the training (Kontoghiorghes, 2004; Tannenbaum \& Yukl, 1992; Vermeulen, 2002; Wexley \& Baldwin, 1986) and support the suggestions by Alliger, Tannenbau, Bennett, Traver and Shotland (1997) and Nikandrou, Brinia and Bereri (2009) that repeated measures of trainees' perceptions are relevant in order to better understand transfer of training.

The role of preferred supports, directly affect training transfer effects (task performance improvement) after the training and indirectly at the end the training through transfer strategy, demonstrate the practical implications: managers should recognize that trainees who believe and know in advance that they would have needed support, and who have transfer strategy will apply their learned knowledge and skills to work.

Second, finding the impact of the trainee's job autonomy on training transfer implies that the more the trainees' degree of freedom in executing of his/her job), the more ability of them to organize and execute their work, result in effectively transfer occurs. This confirms prior research that mentioned the role of job autonomy (e.g. Axtell \& Maitlis, 1997; Nijman, 2004).

We found it interesting that supervisor support $E$ influences job autonomy $A(\beta=.14)$. This can be explained by the possibility that when an employee is allowed autonomy, it means (a) the supervisor trusts the employee. Trust is seen as 'support' by the employee; and (b) the supervisor 'covers for' the employee and defends the employee when the employee takes unauthorized initiatives. This is also support.

Third, trainees' transfer strategy plays a significant role. It directly influences transfer in terms of task performance improvement $(\beta=.20)$. It also plays an indirect effect in the relationships between supervisor support after training and training transfer. In other words, transfer strategy strengthens the relationships between supervisor support after training and training transfer.

Finally, the study has several following contributions.

(1) it adds to the existing knowledge base and might stimulate further research in using a complete conceptualization of work environment to predict training transfer, both at the end and three months after the training. The present findings provide empirical study that the more comprehensive the characteristics assessment, the better.

(2) this study indicates the use of transfer strategies strengthens transfer of training. The result supports the outcomes of the previous studies such as Machin and Fogarty (2004), Pham, Gijselaers, and Seger (2010, in press) and (Pham, Segers, \& Gijselaers, 2010) studies, which found the 
use of transfer strategies is a strong predictor of training transfer. More precisely, this finding emphasizes the importance of transfer strategies as the mediation, interacting with other factors resulting in an effective transfer practice.

(3) the study extends 11 items for questionnaire measuring the transfer effect. While a number of previous studies have used a few items to measure transfer effects, our study goes beyond that by extending the Xiao (1996) questionnaire. This evaluative addition presents a milestone and adding a more robust self-report measure.

(4) the study adds a preferred support construct in the set of work environment components, adding an additional tool for measuring work environment influencing training transfer.

(5) different from previous studies uses self-report questionnaires to measure training transfer, we have measured transfer by (33) trainees' supervisor as well (it was not feasible to get access to these kinds of data for a whole group of trainees involved in the study because of the Vietnamese context of this study). It helped to reduce the possibility of common method bias and to increase the reliability and validity of the relationships examined.

\section{RECOMMENDATIONS FOR FUTURE RESEARCH}

Based on the results, we suggest several recommendations to enhance transfer of training for educational practice of MBA programs:

\section{Work environment}

1) Training providers/trainers should train supervisors about how to (a) support trainees during and after training; and (b) allow successful trainee "graduates" to exercise more autonomy on the job.

2) Training providers, as part of the negotiation on the content and targets of the training program, should focus on the role of the work environment in enhancing transfer effects. They should make organizations aware of their responsibility in making transfer happen. At the same time, supporting trainees in overcoming resistance should be on the agenda of the training program.

3) Line managers are advised to maintain facilitating trainees during and after training, and respond to their need for support (preferred support). Concurrently, allow them to exercise more autonomy on the job. It is also important for organizations to be aware of their responsibility in making transfer happen by letting trainees know that they will receive the support from the organization (preferred support), supervisor as well as having job autonomy to successfully transfer the training. It influences the trainees' 
perception that their need for support is relevant and of high value. It influences the trainees' perception that their supervisors trust them in their ability to transfer training to improve job performance.

Trainees' transfer strategy

4) Trainers should encourage trainees to formulate transfer strategies during the training process. They should collect examples of training transfer strategies from previous trainees, and present these explicitly as part of the training. This helps trainees to be well prepared for applying new knowledge and skills to their work

5) Line managers should allow, encourage and reward successful trainee graduate to apply learning on the job. Transfer rewards have been acknowledged for their effects on motivating employees to achieve certain goals (Cheng, 2000). Along with informing employees that training transfer is valued by the organization; supervisors should identify any organizational reasons behind the failure of application. By doing so, organizations and supervisors will facilitate trainees to transfer their new learning (RichmanHirsch, 2001).

The results of this study indicate some direction for future research.

First, this study offers evidence for the validity of work environment and the trainees' use of transfer strategies influencing transfer of training in a Vietnamese MBA context. Therefore, it may not immediately be generalized to different educational contexts. For further research, replication studies in MBA programs in different countries can confirm cross-national validity of our findings.

Second, with respect to transfer of training, we included the ratings of 33 supervisors in this study. However for future research, we suggest the use of not only supervisor evaluation, but also additional measures based on multiple sources (e.g. peers, subordinates, customers), especially adding qualitative measures (e.g. interview) to confirm results.

Finally, although our sample provided statistical power for our hypotheses testing, larger sample is suggested for getting a greater sophistication in statistical analysis, in turn having stronger evidence for the validation of the measure. 


\section{APPENDIX}

\subsection{Appendix A: Descriptions of MBA programs in Vietnam}

\begin{tabular}{|c|c|c|c|}
\hline No & Program & Instructional approach & Language \\
\hline 1 & $\begin{array}{l}\text { Vietnam }^{1} \\
\text { Belgium }^{1} \mathrm{MBA}\end{array}$ & Lecture; Tutoring & English \\
\hline 2 & NEU ${ }^{2}$ MBA & Lecture & Vietnamese \\
\hline 3 & $\mathrm{CFVG}^{3} \mathrm{MBA}$ & $\begin{array}{l}\text { Lecture; Consultancy project; } \\
\text { Simulation; } \\
\text { Practical cases; Problem } \\
\text { solving; Conferences } \\
\text { competing }\end{array}$ & English/French \\
\hline 4 & VNU le ${ }^{4}$ MBA5 & $\begin{array}{l}\text { Lecture; Team working; } \\
\text { Seminars; Business consulting; } \\
\text { Group study; Guest speakers }\end{array}$ & Vietnamese \\
\hline 5 & VNU $\operatorname{Re}^{5} \mathrm{MBA}$ & $\begin{array}{l}\text { Lecture; Team working; } \\
\text { Seminars; Business consulting, } \\
\text { Group study; Guest speakers }\end{array}$ & English \\
\hline 6 & $\mathrm{FTU}^{6} \mathrm{MBA}$ & Lecture & Vietnamese \\
\hline 7 & $\mathrm{MsM}^{7} \mathrm{MBA}$ & $\begin{array}{l}\text { Lecture; Teaching assistants; } \\
\text { Project assignments }\end{array}$ & English \\
\hline 8 & $\mathrm{HCMC} \cup \mathrm{T}^{8} \mathrm{MBA}$ & Lecture & Vietnamese \\
\hline
\end{tabular}

1 Solvay Business School (Univ. Libre de Bruxelles, Belgium)

2 Hanoi National Economics University

3 Centre Franco-Vietnamien de Formation a' la Gestion

4 Vietnam National University International Executive

5 Vietnam National University Regular Executive

6 Foreign Trade University

7 Maastricht School of Management in Vietnam

8 Ho Chi Minh City University of Technology 


\subsection{Appendix B: Variables, scales and examples}

\begin{tabular}{|c|c|c|c|}
\hline & Variables & Scales name & Example items \\
\hline 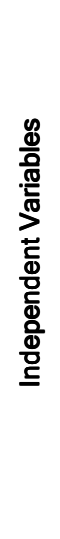 & $\begin{array}{l}\text { Work environment } \\
\text { (Nijman, Nijhof, } \\
\text { Wognum, \& } \\
\text { Veldkamp, 2006) } \\
\text { Transfer Climate } \\
\\
\text { (Xiao, 1996) } \\
\text { Job autonomy } \\
\text { (Nijman et al, } \\
2006 \text { ) }\end{array}$ & $\begin{array}{l}\text { - Sanctioning transfer } \\
(n=3) \\
\text { - Peer support } \\
(n=4) \\
\text { - Preferred support } \\
(n=2) \\
\text { - Supervisor support } \\
(n=6) \\
\text { - Job autonomy } \\
(n=4)\end{array}$ & $\begin{array}{l}\text { - My colleagues/supervisor are } \\
\text { against my applying what has been } \\
\text { learnt } \\
\text { - My colleagues seems to trust in my } \\
\text { application of what has been learnt } \\
\text { - I would rather have more support } \\
\text { and help from others with my training } \\
\text { - My supervisor help me set goals for } \\
\text { applying new KSA to my job } \\
\text { - I can determine by myself how I } \\
\text { can execute my work }\end{array}$ \\
\hline 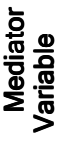 & $\begin{array}{l}\text { Trainees' transfer } \\
\text { strategy } \\
\text { (Burke \& Baldwin, } \\
\text { 1999) }\end{array}$ & $\begin{array}{l}\text { Transfer Strategy } \\
(n=19)\end{array}$ & $\begin{array}{l}\text { I identified the appropriate setting } \\
\text { for applying what I have learnt }(n=19)\end{array}$ \\
\hline 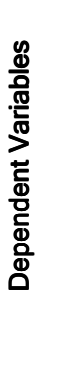 & $\begin{array}{l}\text { Training transfer } \\
\text { effect } \\
\text { (Xiao, 1996) } \\
\text { - The authors } \\
\text { - The authors }\end{array}$ & $\begin{array}{l}\text { - Task performance } \\
\text { improvement }(n=6) \\
\text { - Capacity building } \\
(n=6) \\
\text { - Job performance in } \\
\text { general }(n=5)\end{array}$ & $\begin{array}{l}\text { - I can accomplish my job task better } \\
\text { than by using new KSA } \\
\text { - My ability to implement work in } \\
\text { general is increased) } \\
\text { - In general, I think this training course } \\
\text { has helped me increase my work } \\
\text { performance }\end{array}$ \\
\hline
\end{tabular}

Note: The scale names and their items are indicated as they resulted from the factor analyses.

\section{References}

Alliger, G. M., Tannenbaum, S. I., Bennett, W., Traver, J. H., \& Shotland, A. (1997). A metaanalysis of the relations among training criteria. Personnel Psychology, 50(2), 341358. 
Alvarez, K., Salas, E., \& Garofano, C. M. (2004). An integrated model of training evaluation and effectiveness. Human Resource Development Review 3, 385-416.

Anderson, J. C., \& Gerbing, D. W. (1988). Structural equation modeling in practice: A review and recommended two-step approach. Psychological Bulletin 103, 411-423.

Awoniyi, E. A., Griego, O. V., \& Morgan, G. A. (2002). Person-environment fit and transfer of training. International Journal of Training \& Development, 6(1), 25-35.

Axtell, C. M., \& Maitlis, S. (1997). Predicting immediate and longer-term transfer of training. Personnel Review, 26(30), 201-213.

Baldwin, T. T., \& Ford, J. K. (1988). Transfer of training: a review and directions for future research. Personnel Psychology, 41(1), 63-105.

Bates, R. A., Holton, E. F., Seyler, D. L., \& Carvalho, M. A. (2000). The role of interpersonal factors in the application of computer-based training in an industrial setting. Human Resource Development International, 3, 19-42.

Bentler, P. M. (1985). EQS 6. 1: Multivariate Software Inc.

Brinkerhoff, R. O., \& Montesino, M. U. (1995). Partnerships for training transfer: lessons from a corporate study. Human Resource Development Quarterly, 6, 263-274.

Burke, L. A. (1997). Improving positive transfer: A test of relapse prevention training on transfer outcomes. Human Resource Development Quarterly, 8(2), 115-128.

Burke, L. A., \& Baldwin, T. T. (1999). Workforce training transfer: a study of the effect of relapse prevention training and transfer climate. Human Resource Management, 38(3), 227-241.

Burke, L. A., \& Hutchins, H. (2007). Training Transfer: An Integrative Literature Review. Human Resource Development Review, 6, 263-296.

Burke, L. A., \& Saks, A. M. (2009). Accountability in Training Transfer: Adapting Schlenker's Model of Responsibility to a Persistent but Solvable Problem. Human Resource Development Review, 8(3), 382-402.

Cameron, S. (2005). The MBA handbook: skills for mastering management (5th ed.): FTPrentice Hall.

Campbell, C. P., \& Cheek, G. D. (1989). Putting training to work. Journal of European Industrial Training, 13(4), 32-36.

Camuffo, A., Gerli, F., \& Chiara, F. (2006). Tracking Careers to Improve Competency-Based Management Education: A longitudinal Study of Italian MBAs. In Charles Wankel \& R. DeFillippi (Eds.). In New Vision of Graduate Management Education. Greenwich, Connecticut: IAP-Information Age Publishing.

Cheng, E. (2000). Test of the MBA knowledge and skills transfer. International Journal of Human Resource Management, 11(4), 837-852.

Cheng, E., \& Hampson, I. (2008). Transfer of training: A review and new insights. International Journal of Management Reviews, 10(4), 327-341.

Cheng, E., \& Ho, D. (2001). The influence of job and career attitudes on learning motivation and transfer. Career Development International, 6(1), 20-27.

Clarke, N. (2002). Job/work environment factors influencing training transfer within a human service agency: some indicative support for Baldwin and Ford's transfer climate construct. International Journal of Training \& Development, 6(3), 146-162.

Cohen, D. J. (1988). Statistical power analysis for the behavior science: Huillsdale, NJ: Erlbaum. 
Cohen, D. J. (1990). What motivates trainees? Training and Development Journal, 36(1), 9193.

Colquitt, J. A., Lepine, J. A., \& Noe, R. A. (2000). Toward an Integrative Theory of Training Motivation: A Meta-Analytic Path Analysis of 20 Years of Research. Journal of Applied Psychology, 85(5), 678-707.

Cromwell, S. E., \& Kolb, J. A. (2004). An Examination of Work-Environment Support Factors Affecting Transfer of Supervisory Skills Training to the Workplace. Human Resource Development Quarterly, 15(4), 449 - 470.

Curry, D. H., Caplan, P., \& Knuppel, L. (1994). Transfer of training and adult learning (TOTAL). Journal of Continuing Social Work Education, 6(1), 8-14.

DeSimone, R. L., Werner, J. M., \& Harris, D. M. (2002). Human resource development. Mason, $\mathrm{OH}$ : South-Western.

Facteau, J. D., Dobbins, G. H., Russell, J. E. A., Ladd, R. T., \& Kudisch, J. D. (1995). The influence of general perceptions of the training environment on pre-training motivation and perceived transfer of training. Journal of Management, 21, 1-25.

Ford, J. K., Quiñones, M. A., Sego, D. J., \& Speer Sorra, J. (1992). Factors affecting the opportunity to perform trained tasks on the job. Personnel Psychology, 45(3), 511527.

Ford, J. K., \& Weissbein, D. A. (1997). Transfer of training: An updated review and analysis. Performance Improvement Quarterly, 10, 22-41.

Foxon, M. (1994). A process approach to the transfer of training. Australian Journal of Educational Technology, 10(1), 1-18.

Gijselaers, W. H., \& Milter, R. G. (2010, in press). Issues in Accounting / Business Education. Business. In Barry McGaw, Penelope Peterson and Eva Baker (Eds.), The International Encyclopedia of Education, 3rd Edition. Elsevier (in press). International Encyclopedia of Education, Third Edition. Oxford: Elsevier.

Gollwitzer, P. M. (1999). Implementation intentions: Strong effects of simple plans. American Psychologist, 54, 493-503.

Hesketh, E. A., \& Laidlaw, J. M. (1997). 'Selling' educational events to healthcare professionals: Twelve tips on the function and design of trigger leaflets. Medical Teacher, 19(4), 250-256.

Holton, E. F., Bates, R. A., \& Ruona, W. E. A. (2000). Development of a Generalized Learning Transfer System Inventory. Human Resource Development Quarterly, 11(4), 333-360.

Holton, E. F., Bates, R. A., Seyler, D. L., \& Carvalho, M. B. (1997). Toward construct validation of a transfer climate instrument. Human Resource Development Quarterly, 8(2), 95-113.

Holton, E. F., Chen, H. C., \& Naquin, S. S. (2003). An Examination of Learning Transfer System Characteristics across Organizational Settings. Human Resource Development Quarterly, 14(4), 459-482.

Inderrieden, E. J., Holtom, B. C., \& Bies, R. J. (2006). Do MBA Programs Deliver? In Charles Wankel \& Robert DeFillipi (Eds.), New Vision of Graduate Management Education. Greenwich, Connecticut: IAP-Information Age Publishing.

Kaufman, R. (2002). Resolving the (often deserved) attacks on training. Performance Impermanency, 41(6). 
Kirkpatrick, D. L. (1998). Evaluating Training Programs: The Four Levels (2nd Ed.): San Francisco: Berrett-Koehler.

Kirwan, C., \& Birchall, D. (2006). Transfer of Learning from Management Development Programmes: Testing the Holton Model. International Journal of Training and Development, 10(4), 252-268.

Kontoghiorghes, C. (2004). Reconceptualizing the learning transfer conceptual framework: empirical validation of a new systemic model. International Journal of Training and Development, 8(3), 1-25.

Kraiger, K., Ford, J. K., \& Salas, E. (1993). Application of cognitive, skill-based, and affective theories of learning outcomes to new methods of training evaluation. Journal of Applied Psychology, 78, 311-328.

Latham, G. P. (1997). Overcoming mental models that limit research on transfer of training in organisational settings. Applied Psychology: An International Review, 46, 371-375.

Lim, D. H., \& Johnson, S. D. (2002). Trainee perceptions of factors that influence learning transfer. International Journal of Training and Development, 6(1), 36-48.

Lim, D. H., \& Morris, M. L. (2006). Influence of Trainee Characteristics, Instructional Satisfaction, and Organizational Climate on Perceived Learning and Training Transfer. Human Resource Development Quarterly, 171), 85-115.

Machin, M. A., \& Fogarty, G. J. (2003). Perceptions of training-related factors and personal variables as predictors of transfer implementation intentions. Journal of Business and Psychology, 18(1), 51-75.

Machin, M. A., \& Fogarty, G. J. (2004). Assessing the antecedents of transfer interventions in a training context. International Journal of Training and Development, 8(3), 222236.

Mathieu, J. E., Martineau, J. W., \& Tannenbaum, S. I. (1993). Individual and situational influences on the development of self-efficacy: implications for training effectiveness. Personnel Psychology, 46(125-147).

Mintzberg, H. (2004). Managers not MBAs: a hand look at the soft practice of managing and management development. London: Prentice Education.

Nijman, D. (2004). Supporting transfer of training: effects of the supervisor. Unpublished Doctoral dissertation, University of Twente, Enschende.

Nijman, D., Nijhof, W., Wognum, A., \& Veldkamp, B. (2006). Exploring differential effects of supervisor support on transfer of training. Journal of European Industrial Training, 30(7), 529-549.

Nikandrou, I., Brinia, V., \& Bereri, E. (2009). Perspective on practice. Trainee perceptions of training transfer: an empirical analysis. Journal of European Industrial Training, 33(3), 255-270.

Noe, R. A., \& Schmitt, N. (1986). The influence of trainee attitudes on training effectiveness: the importance of the work environment. Journal of Applied Psychology, 80(1), 239252.

Noe, R. A., Sears, J., \& Fullenkamp, A. M. (1990). Relapse training: Does it influence trainees' post training behavior and cognitive strategies? Journal of Business and Psychology, 4(3), 317-328.

Olsen, J. H. J. (1998). The evaluation and enhancement of training transfer. International Journal of Training \& Development, 2(1), 61-75. 
Pham, N. T. P., Gijselaers, W. H., \& Segers, M. S. R. (2010, in press). The effect of the trainees's perception of the training design on transfer of training: the case of Master of Business Administration (MBA) of Vietnam. In P. V. d. Bossche, W. Gijselaers \& R. Milte (Eds.), Advances in Business Education and Training. Springer.

Pham, N. T. P., Segers, M. S. R., \& Gijselaers, W. H. (2010). Understanding transfer of training effects from a motivational perspectives: A test of MBA programs. Business Leadership Review, 7(3), 1-25.

Pugh, K. J., \& Bergin, D. A. (2006). Motivational Influences on Transfer. Educational Psychologist, 41(3), 147-160.

Quinones, M. A., Ford, J. K., Sego, D. J., \& Smith, E. M. (1995). The effects of individual and transfer environment characteristics on the opportunity to perform trained tasks. Training Research Journal, 1, 29-48.

Richey, R. C. (1992). Designing Instruction for the Adult Learner. Kogan Page: London.

Richman-Hirsch, W. L. (2001). Posttraining Interventions to Enhance Transfer: The Moderating Effects of Work Environments. Human Resource Development Quarterly, 12(2), 105-120.

Robbins, S. P. (Ed.). (2001). Organizational Behavior (9th ed.): Prentice-Hall, Upper Saddle River, NJ.

Roberson, L., Kulik, C. T., \& Pepper, M. B. (2009). Individual and Environmental Factors Influencing the Use of Transfer Strategies After Diversity Training. Group \& Organization Management, 34(1), 67-89.

Rouiller, J. Z., \& Goldstein, I. L. (1993). The relationship between organizational transfer climate and positive transfer training. Human Resource Development Quarterly, 4(4), 377-390.

Ruona, W. E. A., Leimbach, M., Holton, E. F. I., \& Bates, R. A. (2002). The relationship between learner utility reactions and predicted learning transfer among trainees. International Journal of Training and Development, 6(4), 218-228.

Russ-Eft, D. (2002). A typology of training transfer design and work environment factors affecting workplace learning and transfer. Human Resource Development Review, 1(1), 45-65.

Salas, E., \& Cannon-Bowers, J. A. (2001). The science of training: A decade of progress. Annual Review of Psychology, 52, 471-499.

Seyler, D. L., Holton, E. F. I., Bates, R. A., Burnett, M. F., \& Carvalho, M. A. (1998). Factors affecting motivation to transfer training. International Journal of Training \& Development, 2(1), 2-16.

Tannenbaum, S. I., \& Yukl, G. (1992). Training and development in work organizations. Annual Review of Psychology, 43, 399-441.

Taylor, M. (2000). Transfer of learning in workplace literacy programs. Adult Basic Education, 101), 3-20.

Taylor, P. (1992). Training directors' perceptions about the successful implementation of supervisory training. Human Resource Development Quarterly, 3, 243-259.

Tracey, J. B., Tannenbaum, S. I., \& Kavanagh, M. J. (1995). Applying trained skills on the job: the importance of the work environment Journal of Applied Psychology, 80(2), 239-252. 
Tziner, A., Haccoun, R. R., \& Kadish, A. (1991). Personal and situational characteristics influencing the effectiveness of transfer of training improvement strategies. Journal of Occupational Psychology, 64(2), 167-177.

Van der Klink, M., Gielen, E., \& Nauta, C. (2001). Supervisory support as a major condition to enhance transfer. Human Resource Development Quarterly, 5, 52-63.

Velada, R., \& Caetano, A. (2007). Training transfer: the mediating role of perception of learning. Journal of European Industrial Training, 31(4), 283-296.

Velada, R., Caetano, A., Michel, J., Lyons, B., \& Kavanagh, M. (2007a). The effects fo training design, individual characteristics and work environment on transfer of training. International Journal of Training and Development, 11(4), 282-294.

Velada, R., Caetano, A., Michel, J., Lyons, B., \& Kavanagh, M. (2007b). The effects of training design, individual characteristics and work envoronment on transfer of training. International Journal of Training and Development, 11(4), 282-294.

Vermeulen, R. C. M. (2002). Narrowing the transfer gap: the advantages of "as if" situations in training. Journal of European Industrial Training, 26(8), 366-374.

Wexley, K. N., \& Baldwin, T. T. (1986). Post-training strategies for facilitating positive transfer: An empirical exploration. Academy of Management Journal, 29, 503-520.

Xiao, J. (1996). The relationship between organizational factors and the transfer of training in the electronics industry in Shenzhen, China. Human Resource Development Quarterly, 7, 55-73. 


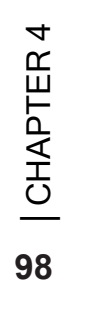




\section{Chapter 5}

\section{FACILITATING TRAINING TRANSFER EFFECTS BASED ON SIMULTANEOUS INFLUENCES OF TRAINING DESIGN, TRAINEES' MOTIVATION AND WORK ENVIRONMENT}

Training is effective only if trainees successfully apply (transfer) the trained knowledge, skills and attitudes to their job. There is increasing concern that in order to fully understand the transfer of training issue, a system approach is needed, looking at the simultaneous effects of the factors influence transfer process.

This study presents the empirical validation of a model of transfer of training, incorporating three groups of factors that predict transfer of training: training design, trainees' motivation and work environment.

The study is conducted in MBA programs in Vietnam. The results indicate that different variables of the three types of predictors simultaneously influence the transfer of training. Additionally, trainees' transfer strategy demonstrates a high level impact on transfer.

The results suggest that in order to optimize transfer of training, MBA programs should take into account the joint role of the training design, trainees' motivation and work environment in enhancing transfer effects. Moreover, supporting trainees in using transfer strategies will strengthens training transfer.

This Chapter is based on Pham, N.T.P., Gijselaers, W.H. \& Segers, M.S.R. (2010). Facilitating training transfer effects based on simultaneous influences of training design, trainees' motivation and work environment: the case of Master of Business Administration (MBA) in Vietnam (submitted). 


\section{INTRODUCTION}

The literature shows only a small amount of acquired training is transferred to trainees' job performance (e.g. Baldwin \& Ford, 1988; Curry, Caplan, \& Knuppel, 1994). When learning is not applied in the workplace, corporate training is useless, and a waste of money. Therefore, transfer of training is critical concern for the field of Human Resource Development (HRD) (e.g. Burke \& Hutchins, 2007; Salas \& Cannon-Bowers, 2001). In recent years, there has been an increasing interest in understanding the conditions for transfer of training to take place. The most cited transfer of training model is Baldwin and Ford's in which three components influence transfer: training design, trainees' characteristics and work environment. Based on this theoretical model, a number of studies has been conducted (Cheng \& Hampson, 2008; Cheng \& Ho, 2001; Ford \& Weissbein, 1997; Holton, Bates, \& Ruona, 2000; Lim \& Morris, 2006; Velada, Caetano, Michel, Lyons, \& Kavanagh, 2007a). Two strands of literature can be discerned. First, studies have been addressing the separate influence of the above components. For example, concerning training design, Alvarez, Salas, and Garofano (2004) focus on instructional techniques and learning principles; Tziner, Haccoun, and Kadish (1991) Wexley and Nemeroff (1975) emphasized self-management and relapse prevention strategies; and Gist, Bavetta, and Stevens (1990) and Brown (2005) stressed goal setting affecting transfer of training. The trainee characteristics such as self-efficacy, motivation to learn, motivation to transfer and achievement goal influencing transfer of training are indicated by a number of studies e.g. Colquitt, Lepine, and Noe (2000); Mathieu, Tannenbaum, and Salas (1992); and Velada and Caetano (2007). The work environment factors related to transfer of training such as supervisor support, supervisor sanctions, peer support, and performance feedback are highlight in research of Baldwin and Ford (1988); Colquitt, Lepine, and Noe (2000); Holton, Bates, and Ruona (2000); Tracey and Tews (2005). Second, it has been stressed that in order to fully understand the transfer of training issue, a system approach is needed, looking at the simultaneous effects of the training design, trainee characteristics and work environment. This is because of training transfer is a complex phenomenon which is influenced by a group of variables and the interaction of these variables (e.g. Merriam \& Leahy, 2005). The extant literature argue that research should assess training transfer as a multidimensional phenomenon (e.g. Burke \& Hutchins, 2007; Kontoghiorghes, 2004). New approaches studying the issue of transfer of training focus more on multidimensional models. Attention has shifted to organizational factors which are assumed to have an impact on successful training transfer. Holton, Bates and Ruona (2000) 
provide a case in point. They challenged current expectations about how the factors having an impact on training transfer may be captured and assessed. They developed a broad conceptual transfer model addressing trainee characteristics, motivation, work environment, and ability. An instrument (including 16 constructs) was designed capturing these factors in the so-called learning transfer system inventory (LTSI). However, Holton et al admit the needs to strengthen the reliabilities of several of the scales, and to examine the convergent and divergent validity of the constructs. Since then, LTSI has been used in several studies. Kirwan and Birchall (2006) examined the LTSI in Ireland, Yamnill and McLean (2005) in Thailand and Khasawneh, Bates and Holton (2004) in Jordan. Kirwan and Birchal (2006) found - amongst others - that increased levels of self-efficacy were positively related to motivation to transfer. In general, research on LTSI indicates that peer support in the work environment, and feedback and coaching, independently and positively affect the motivation to transfer. In addition, the managers' support facilitated transfer of training. Especially, organizational support affects trainees' desire and ability to transfer. Yamnill and McLean (2005) indicated that peer support is a strong factor for enhancing transfer. Moreover, according to them, a reward system is a promising key to enhancing employees' motivation to transfer.

Yamnill and McLean (2005) conducted a study in Thailand and identified some weaknesses of the LTSI. They pointed out that LTSI demonstrates several psychometric problems such as different number of items across factors, and low reliability (internal consistency) in some factors. This calls for revision of LTSI (Yamnill \& McLean, 2005). Burke and Hutchins (2007) indicated that no published work links the use of the LTSI to concrete enhancement in transfer outcomes. Also, the authors argue that there is not yet empirical evidence as to what extent the factors, identified in the Holton, Bates and Ruona (2000) model, jointly affect transfer in terms of improved performance.

Recently, a study of Velada, Caetano, Michel and Kavanagh (2007b) related training design, trainee characteristics and work environment to transfer of training. It found that transfer design, self-efficacy and training retention and the environmental variables significantly predicted transfer of training. Their results suggest the need to examine more aspects of the training process when conducting research on transfer of training.

Cheng and Hampson (2008, p. 335) note the "inconsistent and unexpected findings alert us that our previous models may not be adequate for studying the transfer process. Perhaps other schools of thought may provide us with plausible answers. Therefore, in order to contribute to a better understanding of transfer of training, more research 
taking a system approach is needed. We address the joint influence of training design, trainee characteristics (motivations) and work environment on transfer of training. It builds on our previous studies in which we focused on the separate influence of the three aforementioned groups of variables.

In addition, learning in training does not automatically result in transfer (e.g. Hesketh \& Laidlaw, 1997; Kraiger, Ford, \& Salas, 1993). Trainees, therefore, should have intention to transfer skills and knowledge. Once trainees re-enter the workplace after training, they have to cope with the dynamics of the workplace which might support or inhibit the use of learned knowledge and skills, such as the negative attitudes of their co-workers (Nikandrou, Brinia, \& Bereri, 2009; M. Taylor, 2000). Therefore, it has been argued that, in order to have opportunities to use acquired trained knowledge and successfully apply them to the job, trainees need to use appropriate strategies i.e. a (training) transfer strategy (Burke \& Baldwin, 1999).

Machin \& Fogarty (2003) and Burk (Burke, 1997) revealed that the use of transfer strategies for facilitating the transfer process is a crucial prerequisite for transfer of training. Tzinner, Haccoun and Kadish (1991) believed that paying attention to goal-setting and self-management as transfer strategies resulted in a significantly higher level of transfer. Foxon (1994) argued that transfer strategies enhance the transfer probability by simultaneously embracing the impact of organizational system factors and assisting the trainees in practically applying the training into their work. A few studies proposing the importance of transfer strategies as a key mediator of the link between influencing factors and transfer outcomes. Examples include Gollwitzer (1999), Latham (1997) and Noe, Sears, and Fullenkamp (1990). Recently, a series of studies of Pham, Gijselaers and Segers (2010, in press), Pham, Segers, \& Gijselaers (2010b) and Pham, Segers, \& Gijselaers (2010a) have found the mediating role that transfer strategy play in the singular relationship between (a) training design and transfer of training; (b) trainees' motivations and transfer of training; and (c) work environment and transfer of training. It is still unclear to what extent transfer strategies influence the simultaneous relations among training design, trainees' motivation and trainees' work environment with transfer of training. Therefore in addition to the directly simultaneous relationship between training design, trainees' motivation and work environment and transfer of training, we include the trainee's use of transfer strategies as a mediating variable, proposing it will influences the strength of the relation between the aforementioned factors and transfer of training. We hypothesize that training design, trainees' motivation and work environment affect trainee's use of transfer strategy, which in turn, influence transfer of training. 
In short, while transfer of training has been studied by analyzing singular effects of training design, trainee characteristics and work environment with transfer of training, or the relation between transfer strategies transfer of training, very few studies exist following a more comprehensive approach examining joint effects of these variables. This study, therefore, explores the separate as well as the joint role of training design, trainees' motivations and work environment factors and its effects on transfer strategy as a systematic approach towards training transfer.

While many studies rely on trainee's self report of transfer of training (e.g. Kontoghiorghes, 2004; Machin \& Fogarty, 2004; Velada, Caetano, Michel, Lyons, \& Kavanagh, 2007a), we used self reports as well as supervisor ratings, an independent source. The reason is that, especially when measuring effects, self-reports have been argued as being flawed measures (e.g. Richman-Hirsch, 2001; Velada \& Caetano, 2007). Thus, the collection of transfer measures from both trainees and their supervisor can avoid the common method variance problem and assure the findings. Moreover, while a number of former studies have used questionnaires often with very few items to measure transfer effects, we extended 11 items for questionnaires for a more robust instrument.

\section{CONCEPTUAL FRAMEWORK}

\subsection{Training design factors influencing transfer of training}

From a learning perspective, the training principles that have been applied in previous transfer of training research have their origin mainly in behaviorist and cognitivist teaching theories, addressing training design characteristics such as identical elements, over-learning, relapse prevention and goal-setting.

In behaviorist approach, the stimulus response idea within the identical elements principle or over-learning, provide trainees abilities to respond automatically to the specific goal. This instructional design emphasizes the role of feedback and reinforcement, not self-interpretations and selfreflections (Tenenbaum, Naidu, Jegede, \& Austin, 2001). It is clear that this approach is not considering the possibility of thought process occurring inside the mind. It results in trainees cannot respond in a novel situation.

Cognitivist learning theories based on the trainees' process information behind the behavior (e.g. relapse prevention or goal-setting). This instructional design has been aimed at encouraging problem solving in 
order to develop cognitive capacities, enable the trainees to make this memory-based interaction and stimulates their cognitive development (Tenenbaum et al, 2001).

The effectiveness of the design of training programs implementing the aforementioned principles has been under debate during the past ten years. In the new global economy, an important challenge for higher education is how to develop and implement instructional practice that promote trainees' competencies such as skill communication, critical thinking, problem solving, team working, making meaning of learned information (Pellegrino et al 2001). This creates challenge not only for topics and goals of the training programs but also for the educational approach employed (Cho \& Schmeizer, 2000). Since the early 1990's the interest in constructivism as a learning theory has intensified. "The basic and most fundamental assumption of constructivism is that knowledge does not exist independent of the learner, knowledge is constructed" (Vrasidas, 2000 , p. 6). Learning, therefore, is a process of constructing trainees' own knowledge, not the passive transmission information. Constructivism refers to situated in authentic activities (J. S. Brown, Collins, \& Duguid, 1989). Constructivist approach provides opportunities to trainees to interpret the world with a multiple perspective, based on their own experiences, interpretations, and (internal and social) negotiation (Jonassen, 1994). Thus, trainees can apply their knowledge to a new situation (Wagner \& McCombs, 1995).

In one of our previous studies the effect of the aforementioned training design variables on transfer of training was tested. The results indicated that transfer of training is significantly predicted by the trainee's perception that (a) the course was personal benefit (the item example: "The course took into consideration my needs and concerns"); (b) interactive teaching approaches ("The course allowed for arguments, discussion and debates") and real-life events were used during the training ("The course addressed real-life events") and (c) transfer enhancing instructional methods are included in the training design (use of identical elements "/ found the contents of the training in agreement with my daily work'), relapse prevention ("I am prepared for the possibility of setbacks of my work in applying what has been learnt") and goal setting ("I have intended to apply what has been learnt in my work"). Personal benefits factors and interactive teaching approaches and real-life events factors represent constructivist pedagogy. In all, the results imply that, in terms of training design, trainees involved in our study will only transfer what they have learned to their jobs and therefore improve their performance as well as develop their competencies if (1) they perceive the MBA course is beneficial for them; (2) the course supports interactions among participants and makes use of real 
life events; (3) if transfer enhancing instructional methods are applied in the training design and (4) when they make use of strategies to transfer the learned knowledge and skills.

\subsection{Trainees' motivation influencing transfer of training}

Cheng and Hampson (2008) strongly recommend more investigating on the decision role of trainees in transfer process is strongly recommended. According to them, trainees play an important role in transfer since they are the agents who decide either to transfer or not to transfer, even how much knowledge gained they want to transfer. In a meta-analysis study, Colquitt, Lepine, and Noe (2000) found that research must examine how personal characteristics relate to training effectiveness. Moreover, trainees' motivation is considered plays more important role to training achievement than are course-content elements (Fleishman \& Mumford, 1989; Quinones, 1997). Many authors have stressed the relevance to motivation to learn and to transfer, self-efficacy, and goal orientation when study transfer of training (e.g. (Cheng \& Hampson, 2008; Colquitt, Lepine, \& Noe, 2000; Holton, Bates, \& Ruona, 2000; Velada, Caetano, Michel, Lyons, \& Kavanagh, 2007a). This is confirmed in a study by Pugh and Bergin's (2006) indicating a group of four prevalent and strong motivational factors which affect transfer of training: (1) trainees' motivation (of two different types: trainees' motivation to learn and motivation to transfer); (2) their perceived selfefficacy; and (3) the extent to which they set achievement goals. They argued that trainees' motivation have a significant impact on transfer because of the influence that they have on cognitive engagement which in turn, influences transfer of training. They conclude that "there is enough evidence from various sources to view motivation as a promising lens for future research on transfer, and we encourage others to pursue this intersection of fields" (p. 157). Therefore, we argue that studying transfer of training from a motivational perspective might contribute to a better understanding of such effects.

Pham, Segers, \& Gijselaers (2010b) measured the direct as well as indirect simultaneous effects of these motivational variables on the transfer of training in an MBA setting. The results indicated that self-efficacy and motivation to transfer are positively related to the extent of transfer of training; and the influence of the motivational variables on transfer of training was mediated by the trainee's use of transfer of training strategies. In other words, self-efficacy and motivation to transfer turned out to be crucial motivational factors, which give rise to trainees' transfer strategies, and in turn leading to higher transfer of training. The results mean that the 
MBA trainees will transfer what they have learned to their jobs (1) if they have the strong self-efficacy; (2) if they have the high motivation to transfer and (3) when they make use of strategies to transfer the learned knowledge and skills.

\subsection{Work environment factors influencing training transfer effects}

In general, literature on transfer of training makes a distinction between general work environment factors and specific work environment factors (or transfer climate) aiming to enhance training transfer (Ford, Quiñones, Sego, \& Speer Sorra, 1992; Lim \& Johnson, 2002; Noe \& Schmitt, 1986; Russ-Eft, 2002; Seyler, Holton, Bates, Burnett, \& Carvalho, 1988). Examples of the general work environment factors are job autonomy, level of freedom, independence, and discretion to employees in planning and in determining the procedures to their job (Robbins, 2001). Examples of specific work environment factors are opportunity to use training content, peer and supervisor support, supervisor sanctions, personal outcomespositive, personal outcomes-negative, and resistance to change (Holton, Bates, \& Ruona, 2000; Holton, Bates, Seyler, \& Carvalho, 1997; Rouiller \& Goldstein, 1993). Prior studies have indicated the relevance of different components of specific work environment factors affecting transfer of training (e.g. Holton, Bates, \& Ruona, 2000; Rouiller \& Goldstein, 1993). Other studies have demonstrated that the extent to which trainees prefer support (Nijman, Nijhof, Wognum, \& Veldkamp, 2006), have sufficient time and resources available also affect transfer outcomes (Noe \& Schmitt, 1986; Russ-Eft, 2002).

Our previous study (Pham, Segers, \& Gijselaers, 2010a) focused on the influence of (a) general work environment factors: job autonomy (the degree of freedom in scheduling and determining the execution of the job by the trainee him/herself); and (b) specific work environment factors such as (1) the opportunities the trainees have to use what they have learned during the training on the job; (2) peer support; (3) positive personal outcomes (application of training on the job leads to positive outcomes for the trainees; (4) negative personal outcomes; (5) sanctioning of transfer (the extent to which individuals perceive negative responses from others); (6) resistance to change (the extent to which individuals resist or discourage the applying training content on the job); (7) supervisor support and (8) preferred support (the level of support that the trainee needs in order to achieve intended transfer outcomes). We measure trainees' perception of the work environment at the end of the training as well as 
three months after the training. The results indicated interesting findings. First, transfer of training is influenced by work environment factors (preferred support, supervisor support, and job autonomy), both at the end of the training as well as three months after the training, directly and in directly. Second, the work environment three months after the training has a stronger influence on transfer than such at the end of the training. Third, the work environment at the end of the course significantly related to their perceptions three months later. These results indicate that how trainees perceive the work environment three months after training is a stronger indicator of transfer of training than trainees' perceptions of supervisor support at the end the training. Finally, the trainees' use of transfer strategies plays a mediating role. Transfer strategy influences directly the training transfer effects (task performance improvement). Furthermore, the relation between supervisor support after the training and task performance improvement is strengthened when trainees use transfer strategies.

\section{$2.4 \quad$ Use of transfer strategy}

According to Noe, Sears and Fullenkamp (1990) (cited in Roberson, Kulik, and Pepper (2009), transfer strategies include setting goals, analyzing work situations, preparing to deal with difficulties, identifying and using the necessary supports, and recognizing and monitoring opportunities to use acquired knowledge and skills on the job.

Foxon (1994, p. 3) has argued that transfer strategies have to be formulated, and "implemented during the design, development and delivery of instruction". She believes such strategies tend to increase the possibility of transfer through organizational system factors that assist the individual to focus on potential applications of the learning. Olsen (1998) emphasizes the need of understanding how to develop trainee's intention to use the new knowledge and skills.

There are several transfer strategies which can be incorporated into training courses such as (1) the trainees' situation (e.g. identifying situations at work to apply the trained skills), (2) the trainees' thoughts/feelings (e.g. thoughts about the necessary support needed in order to use the trained skills; retaining self-confidence when experiencing resistance or burdens), (3) the trainees' behavior (e.g. creating and maintaining a social network), and (4) consequences of the trainees' behavior (e.g. being prepared to deal with skepticism of colleagues) (Burke $\&$ Baldwin, 1999). Researchers have consistently emphasized the need for better understanding of the role of use of transfer strategies by trainees (e.g. Ford \& Weissbein, 1997; Machin \& Fogarty, 2004). 


\subsection{Training transfer effects}

Many practitioners and researchers refer to Kirkpatrick's taxonomy (1998) to evaluate training effects. Kirkpatrick discerns four 'levels': (1) how trainees felt about the training; (2) whether they have learned anything; (3) whether the learning was transferred to the job or the extent of behavior and capability improvement and implementation/application; and (4) the effects on the business or environment. In this study we focus on the third level by questioning if the application of the trained knowledge, skills and attitudes in the workplace improves the performance of the job tasks as well as the work performance in general. In this respect, Xiao (1996) refers to the improvement of the productivity efficiency of the employee through training. Additionally, DeSimone, Werner, and Harris (2002, p. 3) claim that training programs aim to "provide its members (of the organization) with the opportunities to learn necessary skills to meet current and future job". This implies training programs do not only aim to enhance the quality of current task and work performance but also support the competence development of trainees in order to meet the demands of the future.

\section{RESEARCH QUESTION AND HYPOTHESES}

This study aims to understand the extent to which the trainee's transfer of learning to workplace is simultaneously influenced by training design, trainees' motivation and work environment factors that appeared to be significant influential in our previous work (see Figure 5.1). We include the mediating role of the trainees' use of transfer strategies. The following research question is addressed: "To what extent do training design, the trainees' motivation and work environment factors, taking into account the role of the trainees' transfer strategies, simultaneously contribute to the transfer of newly acquired knowledge, skills and attitudes on the job?" Two hypotheses were tested. First, "Training design (personal course benefits, training transfer design characteristics and interactions and using real-life events), the trainees' motivational factors (self-efficacy and motivation to transfer), and work environment (preferred support, supervisor support and job autonomy) are positively related to the extent of transfer training" . Second, "The effects of training design (personal course benefits, training transfer design characteristics and interactions and using real-life events), the trainees' motivational factors (self-efficacy and motivation to transfer), and work environment (preferred support, supervisor support and job autonomy) are mediated by trainee's transfer strategies". 
Figure 5.1 Research model

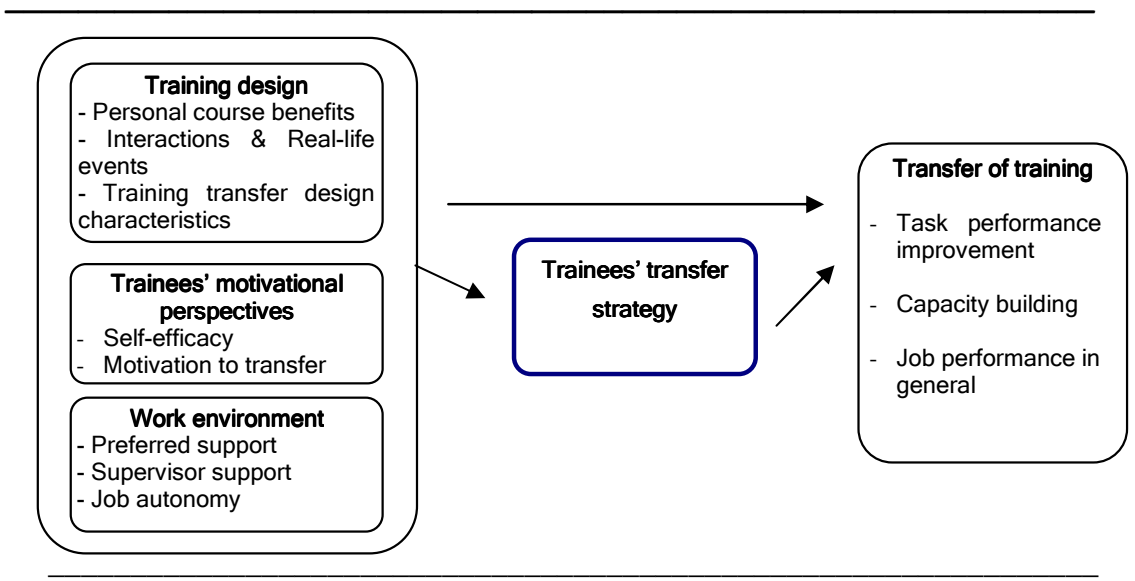

\section{METHODOLOGY AND RESEARCH DESIGN}

\subsection{Participants}

Data were collected from 305 trainees who were sampled from eight different part-time MBA programs in Vietnam. All trainees combined a job with an MBA study (for a description of the programs, see Appendix). 167 trainees answered the 1st survey, while 126 trainees answered the $2 \mathrm{dn}$ one. The majority of the sample was male $(n=102 ; 61 \%)$. The average age is 32. Moreover, 33 supervisors of the trainees answered the second survey. We controlled for age, gender, years of work experience, job position, reason(s) for pursuing the MBA course, and the source of MBA fees.

\subsection{Setting}

The present study was conducted in the setting of Master of Business Administration (MBA) programs. This setting provides a good opportunity to study transfer of training for the following reasons. First, the MBA degree is a higher education product in demand, with about 75,000 MBAS graduating each year in the US in the 1990s (Gijselaers \& Milter, 2010, in press). The numbers of MBA programs and students has continued to grow since then 
across the globe. Second, MBA programs are professionally oriented and focus on the development of professional competence (Mintzberg, 2004). They aim to improve the functional and managerial competencies of trainees (Camuffo, Gerli, \& Chiara, 2006), since most MBA participants are professionals with a considerable amount of experience, and they perceive the training as a competitive advantage for their professional development (Cheng \& Ho, 2001). Therefore, the possibilities training programs offer trainees to transfer the competencies they have been practicing during the training to the workplace, are of utmost importance for the trainees. Third, MBA programs provide trainees with "a highly analytical approach to managerial problem solving, and the ability to approach new problem in a structured fashion" (Cameron, 2005, p. 14). The question is if and under what conditions, MBA programs really reach these high ambitions. Finally, MBA programs produce economic benefits and career success to MBA trainees, to the extent that MBA graduates receive more promotions than those who did not receive an MBA degree (Inderrieden, Holtom, \& Bies, 2006). Given these benefits, studying MBA programs in order to contribute to optimizing their transfer effects, is appropriate.

In Vietnam, education has been considered as top priority by the Vietnamese government in its attempt to develop the economy and join the global arena. After nearly 30 years of economic reform, the country is now facing with more vigorous challenges than ever before. Consequently, the Vietnamese government has established robust educational institutions which include MBA training programs (for instance, the Hanoi National Economics University (NEU), Vietnam National University (VNU), Foreign Trade University (FTU), Solvay Business School (Université Libre de Bruxells, Belgium), Centre Franco-Vietnamien de Formation a' la Gestion (CFVG), Maastricht School of Management (MsM) in Vietnam). Although education is highly important in Vietnam, the question how the knowledge and skills obtained by trainees are transferred into work is inadequately verified. Meanwhile, there is a growing market of MBA programs with varying trainees' working conditions. These programs provide opportunity for researchers to examine the different variables incorporated in the transfer process. It also emphasizes a need of the assessments to ascertain whether these programs have a positive impact on Vietnamese corporate practice. Thus, providing a comprehensive understanding of real training transfer issue in Vietnam is an urgent necessity. This will help educational organizations in Vietnam effectively and efficiently enhance transfer process by diagnosing the factors that impact on training transfer systems.

The duration of these Vietnamese MBA programs (one to two years) also is a positive element of this study. While almost all other training 
programs studied in the literature are very short- for example, a three-day course (Lim \& Morris, 2006), one five-and-a-half-day week (Xiao, 1996), 12 days' duration (Kirwan \& Birchall, 2006) or one month program (Velada, Caetano, Michel, Lyons, \& Kavanagh, 2007b) - these Vietnamese MBA programs have higher probability that trainees will have opportunities to internalize the training and develop a transfer strategy.

\subsection{Measures}

To measure the variables we adapted and extended questionnaires which have been validated in similar settings. We indicated the scale names and their items as they resulted from the factor analysis in our previous studies (Table 5.1). 
Table 5.1 Variables, scales and examples

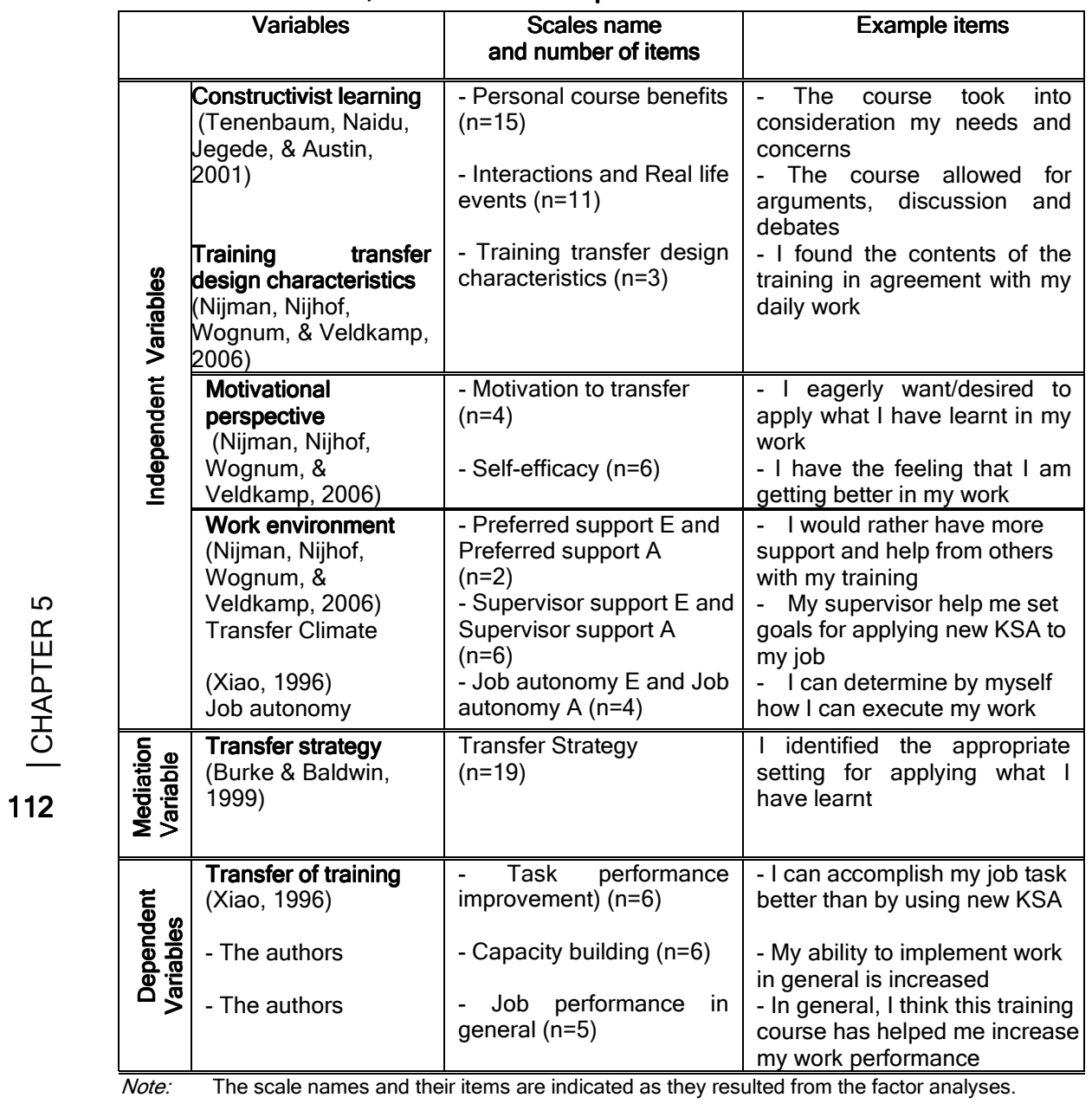

\subsection{Procedures}

Questionnaires were translated into the Vietnamese language and translated back to English to check whether changes would occur. This was not the case. Questionnaires were pilot-tested before final fielding.

The questionnaires were completed by trainees at two points in time: (T1) - at the end of the training program, and (T2) - three months after the 
end of the training. At T1, demographic variables, training design, trainees' motivation, work environment and transfer strategies were measured. At T2, we measured again work environment, training transfer effects and supervisor support.

It is worth explaining why we measure trainee's perception of the work environment both at T1 and T2. Generally, when entering training, most trainees already have knowledge and skills, expectations, and motivations, especially perceptions about their work environment. In our MBA setting, the trainees are employees working while following the program. Thus, they experience the support or the hindrance of the work environment already during the training. However, in the training process, the influences of content of training, the training methods and training design as well as interactions between the trainers and the trainees, and between trainees will influence these trainees' characteristics and perceptions. As a result, these interactions can influence their perception of work environment. After the training period, trainees' perceptions of work environment might have changed. They might use acquired knowledge and skills to influence the organization directly or/and indirectly by demanding more autonomy, task variety, and job involvement (Kontoghiorghes, 2004; Nikandrou, Brinia, \& Bereri, 2009). Thus, the period after training is considered the most important in facilitating positive transfer (Wexley \& Baldwin, 1986). In other words, it is relevant to measure trainee's perception of work environment not only during the training but also some period after the training (e.g. Tannenbaum \& Yukl, 1992), as we have done here.

Training transfer effects were measured at T2, three month after training as literature revealed that transfer of training is changed by time (Awoniyi, Griego, \& Morgan, 2002). The period after training is considered the most important in facilitating positive transfer (Wexley \& Baldwin, 1986). Alliger, Tanenbaum, Bennett, Traver and Shotland (1997, p. 355) also noted: "By gathering reaction data one, three, or six months after training, trainees will have experienced whether the training was in fact useful, and should be in a better position to judge the utility of the training".

\subsection{Methods of analysis}

In order to test these simultaneous effects, and whether the participants' transfer strategies contribute to transfer of training effects, we use path analysis. The adequacy of the models was assessed by EQS version 6.1 (Bentler, 1985). 


\section{RESULTS}

The descriptive statistics, Pearson correlations and reliability Cronbach's Alpha are presented in Table 5.2. Table 5.2 reveals that most of (a) the training design; (b) trainee's motivational variables and (c) work environment variables (both at the end of training and three months after the training) are positive and significantly associated with the use of transfer strategies and with the transfer effects measured. Moreover, (d) the use of transfer strategies is strongly related to the transfer of training.

Aside from trainees' own evaluations and, in order to achieve comparability, their supervisors' evaluations are measured as well. An independent-sample t-test was conducted to compare the training transfer score for trainees and their supervisors. The results reveal that there is no significant difference in scores in terms of three aspect of training transfer (performance improvement, capacity building and general job performance) for trainees and for supervisors $(t(150)=1.58, p=.12, t(151)=1.71, p=.09$, $t(151)=1.81, p=.07$ respectively). Additionally, the magnitude of the differences in mean of transfer effects between trainees and their supervisors (in terms of perception task performance improvement; capacity building and Job performance in general) is very small (eta squared $=.016$; .019 and .021 respectively) (Cohen, 1988). The similarity of mean transfer effect scores for trainees and their supervisor can be seen as an indication of high inter-rater reliability.

Furthermore, the result of regression shows the control variables (age, gender, years of work experience, job position, reason(s) for pursuing the MBA course and the source of MBA fees) have no significant effects on transfer of training. 


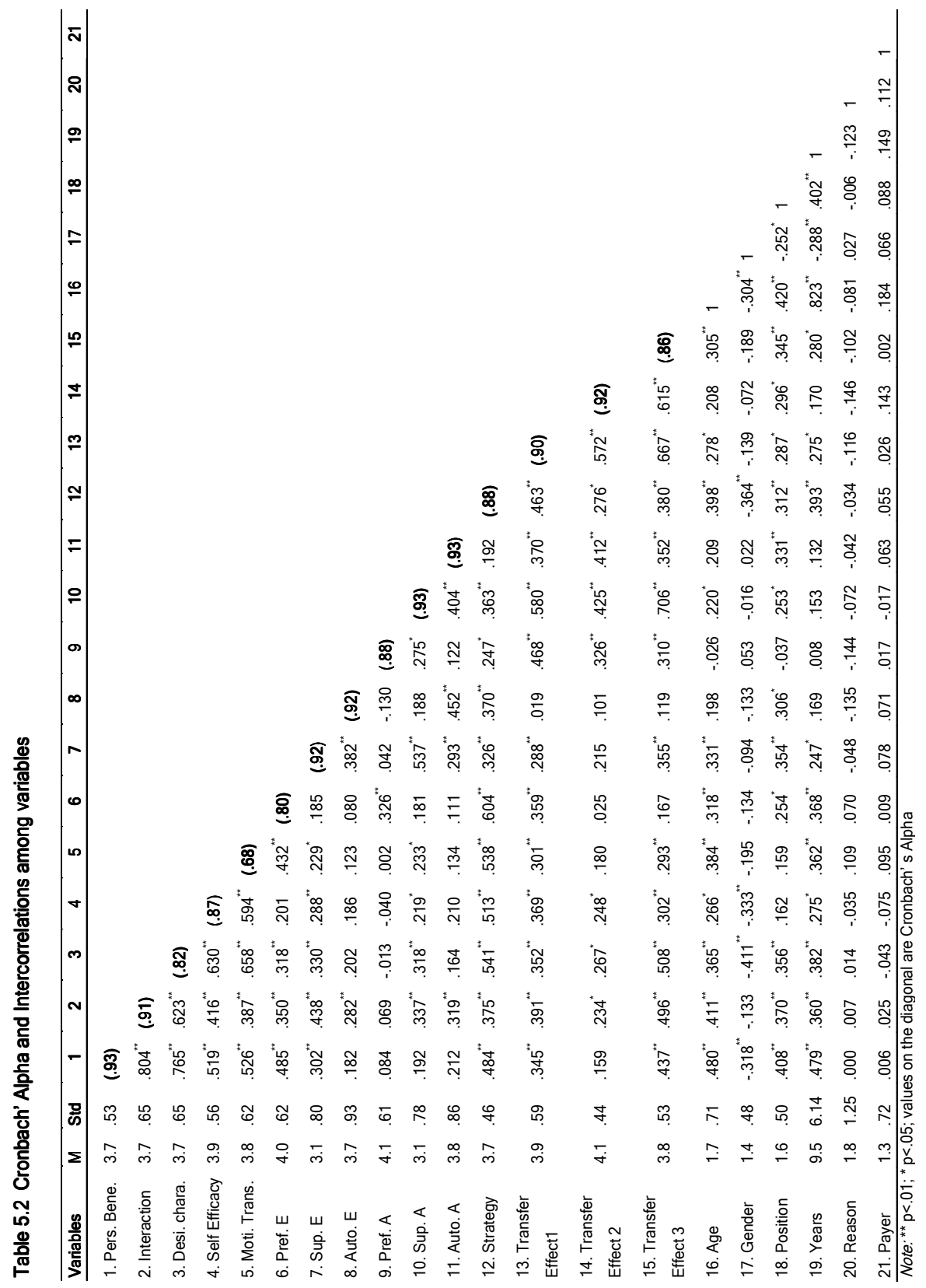


Variable Definition:

Variable definition:

$\begin{array}{ll}\text { Pers. Bene. } & =\text { Personal course benefits } \\ \text { Interaction } & =\text { Interaction and Real-life events } \\ \text { Desi. chara. } & \text { = Training design characteristics } \\ \text { Self efficacy } & \text { = Self efficacy } \\ \text { Moti. Trans. } & =\text { Motivation to transfer } \\ \text { Pref. E } & =\text { Preferred support at the End of training } \\ \text { Sup. E } & =\text { Supervisor support at the End of training } \\ \text { Auto. E } & \text { = Job autonomy at the End of training } \\ \text { Pref. A } & \text { = Preferred support three months After training } \\ \text { Sup. A } & \text { = Supervisor support three months After training } \\ \text { Auto. A } & =\text { Job autonomy three months After training } \\ \text { Strategy } & =\text { Trainees' Transfer strategy } \\ \text { Transfer Effect1 } & =\text { Task performance improvement } \\ \text { Transfer Effect2 } & =\text { Capacity building } \\ \text { Transfer Effect3 } & =\text { Job performance in general }\end{array}$

\section{$5.1 \quad$ Testing the model}

Based on the exploratory design of the study and as recommended by Anderson and Gerbing (1988), the present model was compared with several other models presenting plausible alternatives. The 'best fitting' model is achieved since it has surpassed all the goodness of fit indices. The goodness of fit indices presented in figure 5.2 indicated the appropriateness of the model structure and its theoretically acceptability (Chi-square $=50 ; \mathrm{df}=34 ; \mathrm{p}=.038 ; \mathrm{NFI}=.89 ; \mathrm{CFI}=.96 ; \mathrm{RMSEA}=.076$ ). The results are as presented in figure 5.2 (only significant relations are shown). 
Figure 5.2 Path analysis model toward training transfer effects

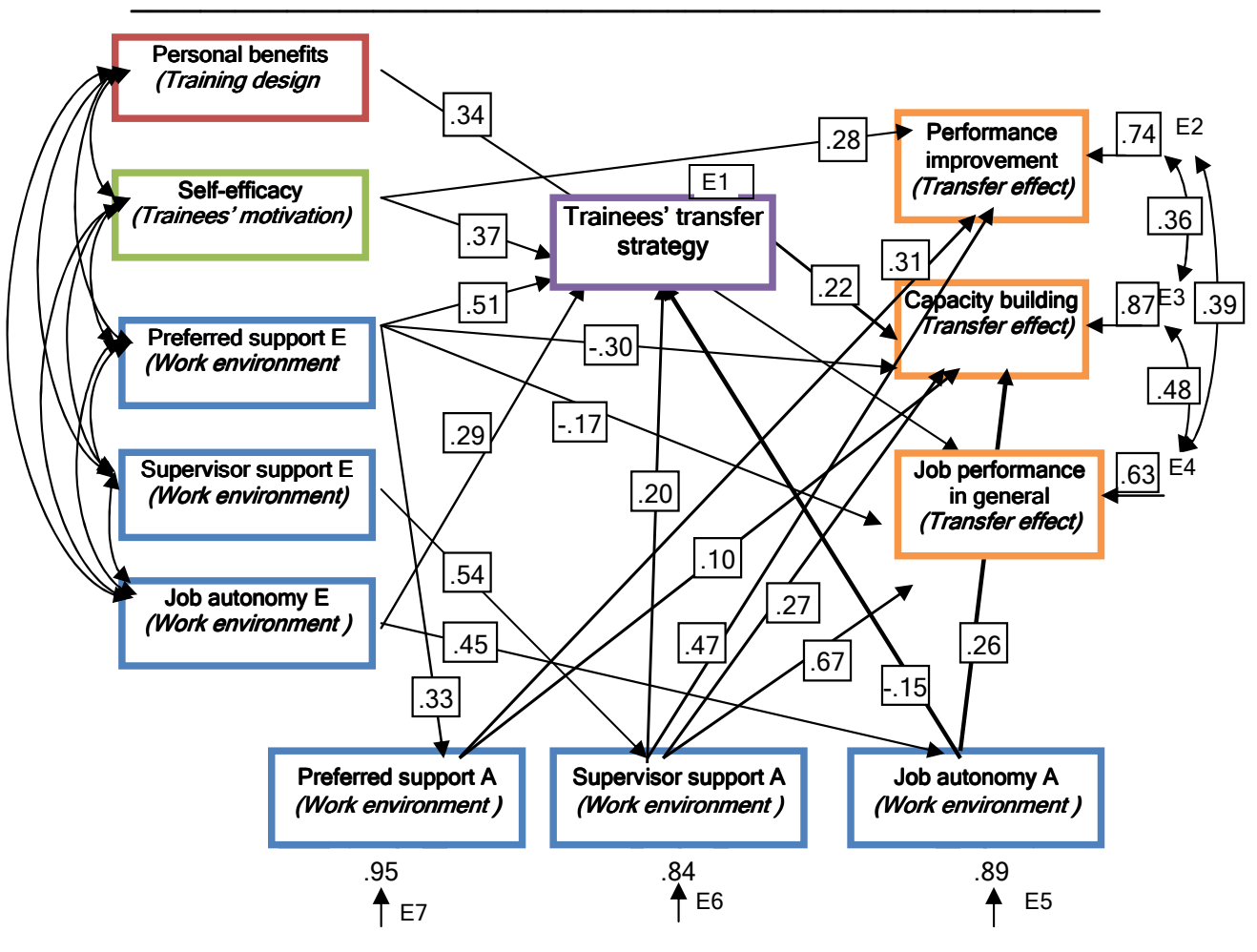

Note: $\mathrm{E}=\mathrm{End}$ of training; $\mathrm{A}=$ After three months of training

\subsection{Results}

This empirical study indicates the validity of a model presenting the joint influence of trainees' perception of training design (represented by personal course benefits); trainees' motivational variables (represented by trainees' self-efficacy) and work environment (represented by preferred support, supervisor support and job autonomy) on transfer of training. Path analysis results indicate that the above combined factors predict transfer training effects directly and indirectly, supporting (partly) the first hypothesis.

Additionally, the model shows direct as well as indirect effects of trainees' use of transfer strategies. It indicates the important role of trainees' use of transfer strategies on transfer of training. The impacts (of 
self efficacy, preferred support $E$, supervisor support $A$ and job autonomy A) on transfer are strengthened when the trainee uses transfer strategies. The results support (partly) the second hypothesis.

Regarding training design, the results revealed that personal course benefits directly and positively predict sixty percent of the variance in Job performance $(\beta=.34)$. Personal course benefits refers to what the valueadded of the training is for the trainees in terms of motivating them toward reflections and concept investigation; encouraging them making meaning of the learning content; taking into account their need and providing materials and resources to support learning. They all are principles of constructivist pedagogy.

Trainees' motivation (self-efficacy) directly influence the extent of transfer of training in terms of performance improvement $(\beta=.28)$ and directly influence transfer strategy $(\beta=.37)$.

In terms of work environment, we found that preferred support, supervisor support and job autonomy, both at the end of training (E) and three months after the training $(A)$ affects transfer of training, directly and indirectly. The work environment $A$ play a significant role in influencing transfer even more than the work environment $E$, with supervisor support $A$ is a powerful variable predict transfer of training. For example, supervisor support A directly predicts Job performance in general $(\beta=.67)$; Performance improvement $(\beta=.47)$ and Capacity building $(\beta=.27)$. This relation is strengthened when the trainee adopt transfer strategies. Specially, supervisor support A directly predicts Capacity building $(\beta=.27)$ and indirectly predicted through transfer strategy $\left(\beta=.20{ }^{*} .22=.04\right)$.

Preferred support $A$ positively and directly affect Performance improvement and Capacity building $(\beta=.31$ and $\beta=10$ respectively), preferred support $E$ negatively and directly affect Capacity building and Job performance $(\beta=-.30$ and $\beta=-.17$ respectively).

Job autonomy $E$ does not directly affect transfer of training, but indirectly affect Capacity building through transfer strategy, and directly affects Job autonomy $A(\beta=.45)$. Job autonomy $A$ positively and directly affects Capacity building $(\beta=.26)$, and negatively affects transfer strategy $(\beta=-15)$.

Transfer strategy is directly influenced Capacity building $(\beta=.22)$. In addition, the relation between supervisor support $A$ and Capacity building is strengthened when trainees use transfer strategies. 


\section{CONCLUSION AND DISCUSSION}

The aim of this study is to explore the join role of training design, trainees' motivations and work environment factors as a systematic approach towards training transfer. In addition, we investigate the extent to which the mediating role of the trainee's use of transfer strategies to clarify how the impact of these factors in the transfer process.

It was found that (i) training design, trainees' motivation characteristics and work environment jointly affect training transfer, and (ii), trainees' transfer strategies play a significant role in the relationships between the above factors and training transfer.

Previous transfer of training models such as the pivotal Holton, Bates and Ruona (2000) model have been presenting a large set of influential variables. Nevertheless, our study shows a limited set of variables significantly affects transfer.

First, the results confirm prior researchers' arguments for applying characteristics of the constructivist learning environments (Lea, Stephenson, \& Troy, 2003; Pham, Gijselaers, \& Segers, 2010, in press; Tenenbaum, Naidu, Jegede, \& Austin, 2001). Training design should concentrate on the factors which meet trainees' personal benefits, referring to what the value-added of the training is for the trainee in terms of motivating them toward reflections and concept investigation; encouraging them making meaning of the learning content; taking into account their need and providing materials and resources to support learning.

Additionally, the results confirm the role of self-efficacy in transfer of training (Cheng \& Hampson, 2008; Colquitt, Lepine, \& Noe, 2000; Elangovan \& Karakowsky, 1999; Pham, Segers, \& Gijselaers, 2010b; Pugh \& Bergin, 2006; Velada, Caetano, Michel, Lyons, \& Kavanagh, 2007a). This means that the trainee's who possess a strong self-efficacy will transfer what they have learned to their workplace.

Finally, the results confirm prior research indicating that work environment variables including preferred support, supervisor support and job autonomy influence transfer training effects, directly and in directly, with supervisor support after the training is a powerful variable (Bates, Holton, \& Seyler, 1996; Brinkerhoff \& Montesino, 1995; Cohen, 1990; Cromwell \& Kolb, 2004; Pham, Segers, \& Gijselaers, 2010a; P. Taylor, 1992). The results support the suggestions by Alliger, Tannenbaum, Bennett, Traver, and Shotland (1997) and Nikandrou, Brinia and Bereri (2009) that repeated measures of trainees' perceptions are relevant in order to better understand transfer of training. 
One of the most striking findings of the present study indicates the importance of what happens at the workplace after the training. For example, it is surprising that supervisor support as perceived at the end of the training was not found to be related to either transfer strategy nor to training transfer, whereas supervisor support three months later is a powerful variables directly affect transfer strategy $(\beta=.20)$ and transfer of training as well $(\beta=.67, \beta=.47$ and $\beta=.27$ in terms of job general improvement, performance improvement and capacity building respectively) and indirectly $\left(\beta=.20^{*} .22=.04\right)$ in terms of capacity building). Given the fact that MBA trainees work during the training, this effect might be explained by the possibility that during training, the trainees depend less on their supervisors in the workplace than they do when they return to their jobs (after training). Moreover, the power of trainees' perception three month after the training might be explained by various interactions during as well as after the training shape trainees' perception of work environment.

The results also indicated that trainees who believe and know in advance that they would need support (preferred support) will apply their learned knowledge and skills to work (in terms of performance improvement and capacity building).

We found the impact of the trainee's job autonomy three months after on capacity building significant $(\beta=.26)$, implying that the more the trainees' degree of freedom in executing of his/her job), the more (s)he develop his/her ability to organize and execute the work. This confirms prior research (e.g. Axtell \& Maitlis, 1997; Nijman, Nijhof, Wognum, \& Veldkamp, 2006).

Job autonomy A negatively affects transfer strategy $(\beta=-15)$. This could be explained in terms of the nature of transfer strategy, which includes analyzing work situations, preparing to deal with difficulties, and recognizing and monitoring opportunities to use acquired knowledge and skills on the job. The more job autonomy the trainee had before the training, the more freedom (s)he knows (s)he will have following the training, so less transfer strategy is needed.

Preferred support $\mathrm{E}$ negatively affect Capacity building and Job performance ( $\beta=-.30$ and $\beta=-.17$ respectively). Reasons remain to be elucidated, but there are several reasonable hypotheses. In terms of Capacity building, preferred support $E$ directly and significantly influences preferred support $A(\beta=.33)$. Based on the correlation between preferred support $A$ and $E(r=.33)$, preferred support $A$ directly predicts Capacity building, so it could be said that preferred support $E$ is suppressed by preferred support A. Again, the results confirm the importance of what happens at the workplace after the training (Kontoghiorghes, 2004; Tannenbaum \& Yukl, 1992; Vermeulen, 2002; Wexley \& Baldwin, 1986) 
and support the suggestions by Alliger, Tannenbau, Bennett, Traver and Shotland (1997) and Nikandrou, Brinia and Bereri (2009) that repeated measures of trainees' perceptions are relevant in order to better understand transfer of training.

Similarly, preferred support $E$ negatively affecting job performance ( $\beta=-$ 17) might be explained by the nature of preferred support. Trainees need to have support to apply their learned knowledge and skills. Given the fact that most MBA trainees work during the training, they may (as part of their transfer strategy) ask for the needed support at work, and this might conflict with a supervisor's notion that, on the contrary, training will result in a need for less support.

In conclusion, for MBA training programs aimed at developing professional competencies and practical experience, our results indicate it is essential to consider simultaneously (a) applying constructivist pedagogy in training design (i.e. trainees' personal benefits), (b) trainees' motivational factors (i.e. self-efficacy), (c) work environment factors (i.e. preferred support, supervisor support and job autonomy), both at the end of training and three months after the training and (d) support trainees in the development and use of transfer strategies.

\section{IMPLICATIONS FOR PRACTICE AND RECOMMENDATIONS FOR FUTURE RESEARCH}

Based on the results, we recommend MBA stakeholders focus on the following joint factors:

1) Training design

Trainers should ensure that training is designed according to constructivist pedagogy. i.e. meet trainees' needs, help them to pursue their personal goals, allow them for negotiation of the instructional goals and objectives of the course, motivate them to think reflectively and (further) investigate concepts and ensure that the course resources effectively convey learning information, to enhance transfer. This helps ensure that trainees have the positive reactions to learn, that maximize their learning, in turn, facilitate application/transfer their acquired learning to the workplace.

Moreover, while both trainers and trainees should be open to negotiating the instructional goals and objectives, trainees' supervisors should also participate in these negotiations. By doing so, supervisors can show trainees that they are believed having the ability to successfully learn training and utilize such new knowledge on the job. 


\section{2) Trainees' motivation}

MBA training providers need to ensure that training is designed such that concentrate on these factors which enhance transfer, such as help them to pursue their self-efficacy to transfer learning information. Specifically, it also indicates that to maximize return on training, trainers should regularly monitor trainees' self-efficacy. Research has revealed that self-efficacy is trainable (e.g.Karl, O'Leary-Kelly, \& Martocchio, 1993), therefore, in order to maximize transfer of training, faculty should train and regularly monitor trainees' self-efficacy and motivation to transfer in their trainees. Trainees' self-efficacy can be increased before they attend the training by providing them with training-related information, such as the importance of training, training content, training method or training environment (Tai, 2006)

Also, trainees' supervisors should encourage trainees with high selfefficacy to become training candidates. Furthermore, they should work with the employee to choose the best training provider where training is designed to encourage the particular trainee's self-efficacy.

\section{3) Work environment}

Trainers should train supervisors about how to (a) support trainees during and after training; (b) respond to their needed support and (c) allow them to exercise more autonomy on the job.

Line managers should maintain facilitating trainees during and after training, and respond to their need for support (preferred support). Concurrently, allow them to exercise more autonomy on the job. It is also important for organizations to be aware of their responsibility in making transfer happen by letting trainees know that they will receive the support from the organization (preferred support and supervisor support) as well as having job autonomy to successfully transfer the training. It influences the trainees' perception that their need for support is relevant and of high value, and that their supervisor trusts them in their ability to transfer training to improve job performance.

\section{4) Transfer strategy}

Trainers should encourage trainees to formulate transfer strategies during the training process. They should collect examples of training transfer strategies from previous trainees, and present these explicitly as part of the training. This helps trainees to be well prepared for applying new knowledge and skills to their work

Line managers should allow, encourage and reward successful trainee graduate to apply learning on the job. Transfer rewards have been acknowledged for their effects on motivating employees to achieve certain goals (Cheng, 2000). Along with informing employees that training transfer is valued by the organization; supervisors should identify any organizational reasons behind the failure of application. By doing so, organizations and 
supervisors will facilitate trainees to transfer their new learning (RichmanHirsch, 2001).

The results of this study indicate some direction for future research.

First, this study offers evidence for the validity of training design characteristics and the trainees' use of transfer strategies in a Vietnamese MBA context. Thus it cannot immediately transferable to completely different educational form. Future studies in different countries contexts and different training contexts could strengthen the cross-cultural validity of the findings.

Second, we suggest looking for possibilities to implement ratings from supervisors, peers, clients and other sources (360 degree assessment) in order to enhance inter-subjecting;

Third, we recommend the additional use of qualitative research methods such as interviews in order to deepen our understanding of the transfer process.

Finally, although our final sample of 167 participants provided statistical power to conduct our hypotheses testing, the larger sample is suggested for getting a greater sophistication in statistical analysis, in turn having more in-depth discussion. 


\section{APPENDIX OF DESCRIPTION OF MBA PROGRAMS IN VIETNAM}

\begin{tabular}{|c|c|c|c|}
\hline No & Program & Instructional approach * & Language \\
\hline 1 & $\begin{array}{l}\text { Vietnam - }^{-} \\
\text {Belgium }^{1} \mathrm{MBA}\end{array}$ & Lecture; Tutoring & English \\
\hline 2 & $\mathrm{NEU}^{2} \mathrm{MBA}$ & Lecture & Vietnamese \\
\hline 3 & $\mathrm{CFVG}^{3} \mathrm{MBA}$ & $\begin{array}{l}\text { Lecture; Consultancy project; } \\
\text { Simulation; } \\
\text { Practical cases; Problem solving; } \\
\text { Conferences competing }\end{array}$ & English/French \\
\hline 4 & VNU le ${ }^{4}$ MBA5 & $\begin{array}{l}\text { Lecture; Team working; } \\
\text { Seminars; Business consulting; } \\
\text { Group study; Guest speakers }\end{array}$ & Vietnamese \\
\hline 5 & VNU $\operatorname{Re}^{5} \mathrm{MBA}$ & $\begin{array}{l}\text { Lecture; Team working; } \\
\text { Seminars; Business consulting, } \\
\text { Group study; Guest speakers }\end{array}$ & English \\
\hline 6 & FTU $^{6}$ MBA & Lecture & Vietnamese \\
\hline 7 & $\mathrm{MsM}^{7} \mathrm{MBA}$ & $\begin{array}{l}\text { Lecture; Teaching assistants; } \\
\text { Project assignments }\end{array}$ & English \\
\hline 8 & HCMC UT ${ }^{8} \mathrm{MBA}$ & Lecture & Vietnamese \\
\hline
\end{tabular}

* As described in the information in the program brochures. It can be questioned whether the practice in the classrooms is perfectly matching these information. Therefore we decided not to divide our sample in traditional vs constructivist approach.

1 Solvay Business School (Universite Libre de Bruxelles, Belgium)

2 Hanoi National Economics University

3 Centre Franco-Vietnamien de Formation a' la Gestion

4 Vietnam National University International Executive

5 Vietnam National University Regular Executive

6 Foreign Trade University

7 Maastricht School of Management in Vietnam

8 Ho Chi Minh City University of Technology 


\section{References}

Alliger, G. M., Tannenbaum, S. I., Bennett, W., Traver, J. H., \& Shotland, A. (1997). A metaanalysis of the relations among training criteria. Personnel Psychology, 50(2), 341358.

Alvarez, K., Salas, E., \& Garofano, C. M. (2004). An integrated model of training evaluation and effectiveness. Human Resource Development Review 3, 385-416.

Anderson, J. C., \& Gerbing, D. W. (1988). Structural equation modeling in practice: A review and recommended two-step approach. Psychological Bulletin 103, 411-423.

Awoniyi, E. A., Griego, O. V., \& Morgan, G. A. (2002). Person-environment fit and transfer of training. International Journal of Training \& Development, 6(1), 25-35.

Axtell, C. M., \& Maitlis, S. (1997). Predicting immediate and longer-term transfer of training. Personnel Review, 26(30), 201-213.

Baldwin, T. T., \& Ford, J. K. (1988). Transfer of training: a review and directions for future research. Personnel Psychology, 41(1), 63-105.

Bates, R. A., Holton, E. F., \& Seyler, D. L. (1996). Validation of a transfer climate instrument. Paper presented at the Academy of Human Resource Development.

Bentler, P. M. (1985). EQS 6. 1: Multivariate Software Inc.

Brinkerhoff, R. O., \& Montesino, M. U. (1995). Partnerships for training transfer: lessons from a corporate study. Human Resource Development Quarterly, 6, 263-274.

Brown, J. S., Collins, A., \& Duguid, P. (1989). Situated cognition and the culture of learning. Educational Researcher, 18, 32-42.

Brown, T. C. (2005). Effectiveness of distal and proximal goals as transfer-of-training interventions: a field experiment. Human Resource Development Quarterly, 16(3), 369-387.

Burke, L. A. (1997). Improving positive transfer: A test of relapse prevention training on transfer outcomes. Human Resource Development Quarterly, 8(2), 115-128.

Burke, L. A., \& Baldwin, T. T. (1999). Workforce training transfer: a study of the effect of relapse prevention training and transfer climate. Human Resource Management, $38(3), 227-241$.

Burke, L. A., \& Hutchins, H. (2007). Training Transfer: An Integrative Literature Review. Human Resource Development Review, 6, 263-296.

Cameron, S. (2005). The MBA handbook: skills for mastering management (5th ed.): FTPrentice Hall.

Camuffo, A., Gerli, F., \& Chiara, F. (2006). Tracking Careers to Improve Competency-Based Management Education: A longitudinal Study of Italian MBAs. In Charles Wankel \& R. DeFillippi (Eds.). In New Vision of Graduate Management Education. Greenwich, Connecticut: IAP-Information Age Publishing.

Cheng, E. (2000). Test of the MBA knowledge and skills transfer. International Journal of Human Resource Management, 11(4), 837-852.

Cheng, E., \& Hampson, I. (2008). Transfer of training: A review and new insights. International Journal of Management Reviews, 10(4), 327-341.

Cheng, E., \& Ho, D. (2001). The influence of job and career attitudes on learning motivation and transfer. Career Development International, 6(1), 20-27. 
Cohen, D. J. (1988). Statistical power analysis for the behavior science: Huillsdale, NJ: Erlbaum.

Cohen, D. J. (1990). What motivates trainees? Training and Development Journal, 36(1), 91-93.

Colquitt, J. A., Lepine, J. A., \& Noe, R. A. (2000). Toward an Integrative Theory of Training Motivation: A Meta-Analytic Path Analysis of 20 Years of Research. Journal of Applied Psychology, 85(5), 678-707.

Cromwell, S. E., \& Kolb, J. A. (2004). An Examination of Work-Environment Support Factors Affecting Transfer of Supervisory Skills Training to the Workplace. Human Resource Development Quarterly, 15(4), 449 - 470.

Curry, D. H., Caplan, P., \& Knuppel, L. (1994). Transfer of training and adult learning (TOTAL). Journal of Continuing Social Work Education, 6(1), 8-14.

DeSimone, R. L., Werner, J. M., \& Harris, D. M. (2002). Human resource development. Mason, $\mathrm{OH}$ : South-Western.

Elangovan, A. R., \& Karakowsky, L. (1999). The role of trainee and environmental factors in transfer of training: an exploratory framework. Leadership \& Organization Development Journal, 20(5), 268-275.

Fleishman, E. A., \& Mumford, M. D. (1989). Individual attributes and training performance. In I. L. Goldstein (Ed.), Training and Development in Organizations (pp. 183-255). Jossey-Bass, San Francisco, CA.

Ford, J. K., Quiñones, M. A., Sego, D. J., \& Speer Sorra, J. (1992). Factors affecting the opportunity to perform trained tasks on the job. Personnel Psychology, 45(3), 511527.

Ford, J. K., \& Weissbein, D. A. (1997). Transfer of training: An updated review and analysis. Performance Improvement Quarterly, 10, 22-41.

Foxon, M. (1994). A process approach to the transfer of training. Australian Journal of Educational Technology, 10(1), 1-18.

Gijselaers, W. H., \& Milter, R. G. (2010, in press). Issues in Accounting / Business Education. Business. In Barry McGaw, Penelope Peterson and Eva Baker (Eds.), The International Encyclopedia of Education, 3rd Edition. Elsevier (in press). International Encyclopedia of Education, Third Edition. Oxford: Elsevier.

Gist, M. E., Bavetta, A. G., \& Stevens, C. K. (1990). Transfer training method: Its influence on skill generalization, skill reflection, and performance level. Personne/ Psychology, 43, 501-523.

Gollwitzer, P. M. (1999). Implementation intentions: Strong effects of simple plans. American Psychologist, 54, 493-503.

Hesketh, E. A., \& Laidlaw, J. M. (1997). 'Selling' educational events to healthcare professionals: Twelve tips on the function and design of trigger leaflets. Medical Teacher, 19(4), 250-256.

Holton, E. F., Bates, R. A., \& Ruona, W. E. A. (2000). Development of a Generalized Learning Transfer System Inventory. Human Resource Development Quarterly, 11(4), 333-360.

Holton, E. F., Bates, R. A., Seyler, D. L., \& Carvalho, M. B. (1997). Toward construct validation of a transfer climate instrument. Human Resource Development Quarterly, 8(2), 95-113. 
Inderrieden, E. J., Holtom, B. C., \& Bies, R. J. (2006). Do MBA Programs Deliver? In Charles Wankel \& Robert DeFillipi (Eds.), New Vision of Graduate Management Education. Greenwich, Connecticut: IAP-Information Age Publishing.

Jonassen, D. H. (1994). Thinking Technology: Toward a Constructivist Design Model. Educational Technology, 34(4), 34-37.

Karl, K. A., O'Leary-Kelly, A. M., \& Martocchio, J. J. (1993). The impact of feedback and selfefficacy on performance in training. Journal of Organizational Behavior, 14, 379394.

Khasawneh, S., Bates, R. A., \& Holton, E. F., III. . (2004). Construct validation of an Arabic version of the Learning Transfer System Inventory (LTSI) for use in Jordan. Paper presented at the Proceedings of AHRD conference Bowling Green, $\mathrm{OH}$ : Academy of Human Resource Development.

Kirkpatrick, D. L. (1998). Evaluating Training Programs: The Four Levels (2nd Ed.): San Francisco: Berrett-Koehler.

Kirwan, C., \& Birchall, D. (2006). Transfer of Learning from Management Development Programmes: Testing the Holton Model. International Journal of Training and Development, 10(4), 252-268.

Kontoghiorghes, C. (2004). Reconceptualizing the learning transfer conceptual framework: empirical validation of a new systemic model. International Journal of Training and Development, 8(3), 1-25.

Kraiger, K., Ford, J. K., \& Salas, E. (1993). Application of cognitive, skill-based, and affective theories of learning outcomes to new methods of training evaluation. Journal of Applied Psychology, 78, 311-328.

Latham, G. P. (1997). Overcoming mental models that limit research on transfer of training in organisational settings. Applied Psychology: An International Review, 46, 371375.

Lea, S. J., Stephenson, D., \& Troy, J. (2003). Higher education students' attitudes toward student-centred learning: Beyond 'educational bulimia'? Studies in Higher Education, 28, 321-334.

Lim, D. H., \& Johnson, S. D. (2002). Trainee perceptions of factors that influence learning transfer. International Journal of Training and Development, 6(1), 36-48.

Lim, D. H., \& Morris, M. L. (2006). Influence of Trainee Characteristics, Instructional Satisfaction, and Organizational Climate on Perceived Learning and Training Transfer. Human Resource Development Quarterly, 171), 85-115.

Machin, M. A., \& Fogarty, G. J. (2003). Perceptions of training-related factors and personal variables as predictors of transfer implementation intentions. Journal of Business and Psychology, 18(1), 51-75.

Machin, M. A., \& Fogarty, G. J. (2004). Assessing the antecedents of transfer interventions in a training context. International Journal of Training and Development, 8(3), 222236.

Mathieu, J. E., Tannenbaum, S. I., \& Salas, E. (1992). Influences of individual and situational characteristics on measures of training effectiveness. Academy of Management Journal, 35, 828-847. 
Merriam, B. S., \& Leahy, B. (2005). Learning Transfer: A Review of the Research in Adult Education and Training. PAACE Journal of Lifelong Learning, 14, 1-24.

Mintzberg, H. (2004). Managers not MBAs: a hand look at the soft practice of managing and management development. London: Prentice Education.

Nijman, D., Nijhof, W., Wognum, A., \& Veldkamp, B. (2006). Exploring differential effects of supervisor support on transfer of training. Journal of European Industrial Training, 30(7), 529-549.

Nikandrou, I., Brinia, V., \& Bereri, E. (2009). Perspective on practice. Trainee perceptions of training transfer: an empirical analysis. Journal of European Industrial Training, 33(3), 255-270.

Noe, R. A., \& Schmitt, N. (1986). The influence of trainee attitudes on training effectiveness: the importance of the work environment. Journal of Applied Psychology, 80(1), 239-252.

Noe, R. A., Sears, J., \& Fullenkamp, A. M. (1990). Relapse training: Does it influence trainees' post training behavior and cognitive strategies? Journal of Business and Psychology, 4(3), 317-328.

Olsen, J. H. J. (1998). The evaluation and enhancement of training transfer. International Journal of Training \& Development, 2(1), 61-75.

Pham, N. T. P., Gijselaers, W. H., \& Segers, M. S. R. (2010, in press). The effect of the trainees's perception of the training design on transfer of training: the case of Master of Business Administration (MBA) of Vietnam. In P. V. d. Bossche, W. Gijselaers \& R. Milte (Eds.), Advances in Business Education and Training. Springer.

Pham, N. T. P., Segers, M. S. R., \& Gijselaers, W. H. (2010a). Effects of the work environment on transfer of Master of Business Administration (MBA) training on the mediating role of the trainees' transfer strategies. International Journal of Training \& Development.

Pham, N. T. P., Segers, M. S. R., \& Gijselaers, W. H. (2010b). Understanding transfer of training effects from a motivational perspectives: A test of MBA programs. Business Leadership Review, 7(3), 1-25.

Pugh, K. J., \& Bergin, D. A. (2006). Motivational Influences on Transfer. Educational Psychologist, 41(3), 147-160.

Quinones, M. A. (1997). Contextual influences: on training effectiveness. In M. A. a. E. Quinones, A. (Eds) (Ed.), Training for a Rapidly Changing Workplace: Applications of Psychological Research (pp. 177-199): American Psychological Association, Washington, DC,

Richman-Hirsch, W. L. (2001). Posttraining Interventions to Enhance Transfer: The Moderating Effects of Work Environments. Human Resource Development Quarterly, 12(2), 105-120.

Roberson, L., Kulik, C. T., \& Pepper, M. B. (2009). Individual and Environmental Factors Influencing the Use of Transfer Strategies After Diversity Training. Group \& Organization Management, 34(1), 67-89.

Rouiller, J. Z., \& Goldstein, I. L. (1993). The relationship between organizational transfer climate and positive transfer training. Human Resource Development Quarterly, 4(4), 377-390. 
Russ-Eft, D. (2002). A typology of training transfer design and work environment factors affecting workplace learning and transfer. Human Resource Development Review, 1(1), 45-65.

Salas, E., \& Cannon-Bowers, J. A. (2001). The science of training: A decade of progress. Annual Review of Psychology, 52, 471-499.

Seyler, D. L., Holton, E. F. I., Bates, R. A., Burnett, M. F., \& Carvalho, M. A. (1988). Factors affecting motivation to transfer training. International Journal of Training \& Development, 2(1), 2-16.

Tai, W. T. (2006). Effects of training framing, general self-efficacy and training motivation on trainees' training effectiveness. Personnel Review, 35(1), 51-65.

Tannenbaum, S. I., \& Yukl, G. (1992). Training and development in work organizations. Annual Review of Psychology, 43, 399-441.

Taylor, M. (2000). Transfer of learning in workplace literacy programs. Adult Basic Education, 10(1), 3-20.

Taylor, P. (1992). Training directors' perceptions about the successful implementation of supervisory training. Human Resource Development Quarterly, 3, 243-259.

Tenenbaum, G., Naidu, S., Jegede, O., \& Austin, J. (2001). Constructivist pedagogy in conventional on-campus and distance learning practice: an exploratory investigation. Learning and Instruction, 11(2), 87-111.

Tracey, J. B., \& Tews, M. J. (2005). Construct validity of a general training climate scale. Organizational Research Methods, 8( 353-74).

Tziner, A., Haccoun, R. R., \& Kadish, A. (1991). Personal and situational characteristics influencing the effectiveness of transfer of training improvement strategies. Journal of Occupational Psychology, 64(2), 167-177.

Velada, R., \& Caetano, A. (2007). Training transfer: the mediating role of perception of learning. Journal of European Industrial Training, 31(4), 283-296.

Velada, R., Caetano, A., Michel, J., Lyons, B., \& Kavanagh, M. (2007a). The effects fo training design, individual characteristics and work environment on transfer of training. International Journal of Training and Development, 11(4), 282-294.

Velada, R., Caetano, A., Michel, J., Lyons, B., \& Kavanagh, M. (2007b). The effects of training design, individual characteristics and work envoronment on transfer of training. International Journal of Training and Development, 11(4), 282-294.

Vrasidas, C. (2000). Constructivism versus objectivism: Implications for interaction, course design, and evaluation in distance education. International Journal of Educational Telecommunications, 6(4), 339-362.

Wagner, E. D., \& McCombs, B. L. (1995). Learner centre psychological principles in practice: designs for distance education. Educational Technology 35(32-35).

Wexley, K. N., \& Baldwin, T. T. (1986). Post-training strategies for facilitating positive transfer: An empirical exploration. Academy of Management Journal, 29, 503-520.

Wexley, K. N., \& Nemeroff, W. (1975). Effectiveness of positive reinforcement and goal setting as methods of management development. Journal of Applied Psychology, 64, 239-246. 
Xiao, J. (1996). The relationship between organizational factors and the transfer of training in the electronics industry in Shenzhen, China. Human Resource Development Quarterly, 7, 55-73.

Yamnill, S., \& McLean, G. N. (2005). Factors affecting transfer of training in Thailand. Human Resource Development Quarterly, 16(3), 323-344. 


\section{Chapter 6}

\section{SUMMARY AND GENERAL CONCLUSIONS \& DISCUSSION}

"Education is a kind of continuing dialogue, and a dialogue assumes, in the nature of the case, different point of view". Robert Hutchins (1899-1997)

\section{THESIS OVERVIEW}

The challenges of emerging markets in a globalized economy require well trained employees. Therefore, employee training plays a critical role in developing employees to be able to adapt to new challenges and hence to achieve the goals of an organization. However, training is effective only if trainees successfully apply/transfer the newly gained knowledge, skills and attitudes to their job. Otherwise, corporate training is useless and a waste of money. This Thesis develops and tests a series of models identifying the factors influencing training transfer, aiming to enhance the application of training in job settings, the so-called transfer of training (Baldwin \& Ford, 1988; Burke \& Hutchins, 2007; Cheng \& Ho, 2001; Ford \& Weissbein, 1997; Pidd, 2004).

The literature has identified three groups of variables that influence training transfer: training design, trainees' characteristics, and work environment (Cheng \& Hampson, 2008; Ford \& Weissbein, 1997; Pugh \& Bergin, 2006). Nevertheless, compared to traditional transfer of training research (analyzing singular effects of training design, trainee characteristics and work environment with transfer of training), the Thesis 
takes different perspectives. First of all, we address the joint influence of the aforementioned factors on transfer of training. In addition to the system approach, we extend the above three variables commonly measured with the variable transfer strategies. Transfer strategies are cognitive and behavioral techniques, that include setting goals, analyzing work situations, preparing to deal with difficulties, identifying and using the necessary supports, and recognizing and monitoring opportunities to use acquired knowledge and skills on the job (Noe, Sears, \& Fullenkamp, 1990). Learning in training does not automatically result in transfer (e.g. Hesketh \& Laidlaw, 1997). Once trainees re-enter the workplace after training, they have to cope with the dynamics of the workplace which might support or inhibit the use of learned knowledge and skills, such as the negative attitudes of their co-workers (e.g. Nikandrou, Brinia, \& Bereri, 2009; M. C. Taylor, 2000). Therefore, we argue that trainees need to use appropriate strategies, to transfer learned skills and knowledge, i.e a transfer training strategy (Burke \& Baldwin, 1999).

The literature confirms the relations between using transfer strategies and transfer (Burke, 1997; Burke \& Baldwin, 1999; Tziner, Haccoun, \& Kadish, 1991). For example, Tzinner et al (1991) believed that paying attention to goal-setting and self-management as transfer strategies resulted in a significantly higher level of transfer. Machin and Fogarty (2003) and Ford and Weissbein (1997) revealed that the use of transfer strategies for facilitating the transfer process is a crucial prerequisite for transfer of training. A few studies proposing the importance of transfer strategies as a key mediator of the link between influencing factors and transfer outcomes. Examples include Gollwitzer (1999), Latham (1997) and Noe, Sears, and Fullenkamp (1990). Therefore in addition to the direct (separate as well as simultaneous) relationship between training design, trainees' motivation and work environment and transfer of training, we include the trainee's use of transfer strategies as a mediating variable, proposing it will influences the strength of the relation between the aforementioned factors and transfer of training. We hypothesize that training design, trainees' motivation and work environment affect trainee's use of transfer strategy, which in turn, influence transfer of training.

Second, before building the comprehensive model, a series of three studies is presented, each dealing with one factor (training design, trainee characteristics and trainees work environment), taking into account the mediating role of the trainee's use transfer strategy, that influence transfer of training. This deepens our understanding of the unique impact of each factor, and of how the results affect the main theories in the training field.

Finally, a comprehensive model including the joint effects of training design, trainees' characteristics and work environment is built based on a 
series of our studies in which we have been focusing on the separate influence of the three aforementioned variables. It has been stressed that in order to fully understand the transfer of training issue, a system approach is needed, looking at the simultaneous effects of the training design, trainees' motivation and work environment. This suggests the need to extend the research base to a better understanding of whether and how different these factors jointly influence training transfer. In other words, we study transfer process not only by analyzing the separate influence of training design, trainees' motivational characteristics and work environment, but also by positioning transfer of training as a multidimensional model. This helps to better understand the transfer process. .

For studying the influence of training design (chapter 2), we add a constructivist learning theory approach, along with the traditional training design approach. Given the current training practices where to a minor or major extent constructivist pedagogy is implemented, it can be questioned if the traditional training design characteristics are sufficient to capture the design training programs. Therefore we argue the necessity of an extension of the traditionally measured design characteristics with characteristics that reflect the constructivist learning environments in current training programs. According to Vrasidas (2000, p. 6) "the basic and most fundamental assumption of constructivism is that knowledge does not exist independent of the learner, knowledge is constructed". The core idea of constructivist pedagogy considers learning as meaning making, and the negotiation of meaning.

In addition, we address the trainees' characteristics influence transfer of training from a motivational perspective (chapter 3 ). Pugh and Bergin (2006, p. 156) argued that "motivational factors seem likely to have a significant impact on transfer because of the influence that they have on cognitive engagement" which in turn, influences the transfer of training. They conclude that "there is enough evidence from various sources to view motivation as a promising lens for future research on transfer, and we encourage others to pursue this intersection of fields" (p. 157). This study investigates how different motivational factors influence the extent to which trainees apply in their workplace what they have learned.

With regards to the influence of the work environment on transfer effect (chapter 4), we take into account not only trainees' perception of the work environment at the end of the training (T1) but also three months after the training (T2). It is worth noting why we measure trainee's perception of the work environment both at T1 and T2. Generally, when entering training, most trainees already have their own characteristics such as specific acquired knowledge and skills, expectations, and motivations, especially perceptions about their work environment. In our MBA setting, the trainees 
are employees working while following the program. Thus, they experience the support or the hindrance of the work environment already during the training. However, in the training process, the influences of content of training, the training methods and training design as well as interactions between the trainers and the trainees, and between trainees will influence these trainees' characteristics and perceptions. As a result, these interactions can shape their perception of work environment. When return to their workplace after the training period, trainees' perceptions of work environment might have changed. They might use acquired knowledge and skills to influence the organization directly or/and indirectly by demanding more autonomy, task variety, and job involvement (Kontoghiorghes, 2004). Thus, the period after training is considered the most important in facilitating positive transfer (Wexley \& Baldwin, 1986). In other words, it is relevant to measure trainee's perception of work environment not only during the training but also some period after the training (Tannenbaum \& Yukl, 1992). Figure 6.1 shows the empirical model of Thesis.

Figure 6.1 Thesis Model

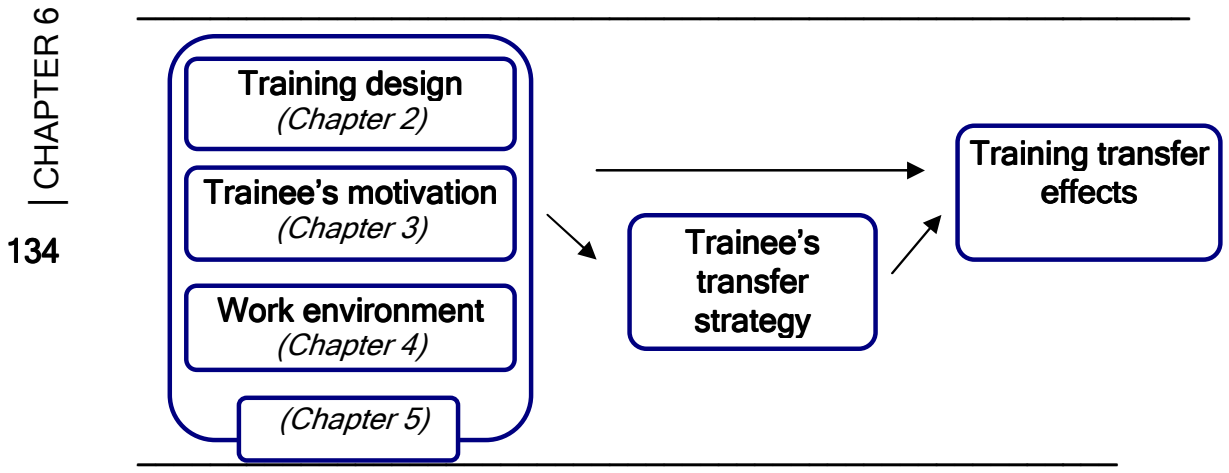

All measures were based on questionnaires validated in previous studies. In some cases they were adapted for the specific purpose of data collection in MBA programs. All measures were assessed by the closedended questions in a 5-point Likert scale.

The questionnaires were completed by trainees at two points in time: (T1) - at the end of the training program, and (T2) - three months after the end of the training. At time 1, we have measured (a) demographic variables, (b) training design, trainees' motivational characteristics and work environment and (c) trainee's use of training transfer strategies. At time 2, we have measured again (d) trainee's perception of the work environment, 
(e) trainee's perception of the transfer of training and (f) trainee's supervisor perception of transfer of training. It helped to avoid bias and achieve comparability in the overall evaluation.

Data were collected from 305 trainees who were sampled from eight different part-time MBA programs in Vietnam. All trainees combined a job with an MBA study (for a description of the programs, see Appendix). 167 trainees answered the 1 st survey, while 126 trainees answered the $2^{\text {nd }}$ one. The majority of the sample was male ( $n=102 ; 61 \%)$. The average age is 32. Moreover, 33 supervisors of the trainees answered the second survey.

\section{RESULTS}

Chapter 2 explores the impact of training design, focusing on the influence of constructivist features of the design of the training programs as well as the mediating role of trainee's transfer strategy, on training transfer (figure 6.2). The results show that (i) the training transfer design characteristics, specially the presence of constructivist perspective, are positively related to transfer of training; (ii) the association between training design and transfer of training was mediated through the trainees' use of transfer strategies. Concretely:

- The effects of training design on transfer of training represented by three factors: (1) personal benefits of the training; (2) the use of interactions and real life events during the training directly affect the transfer of training and (3) training transfer design characteristics. Personal benefits refers to what the value-added of the course is for the trainees and represents constructivist principles: motivating them toward reflections and concept investigation; encouraging them making meaning of the learning content; taking into account their need; and providing materials and resources to support learning. This factor, together with interactions among participants and use of real life events factors represent constructivist principles.

- The relation between personal benefits and transfer of training is stronger when the trainee uses strategies to improve transfer. In other words, the trainee's use strategies play a mediating role in the relationship of training design with training transfer. 
Figure 6.2 The effects of training design on training transfer effects

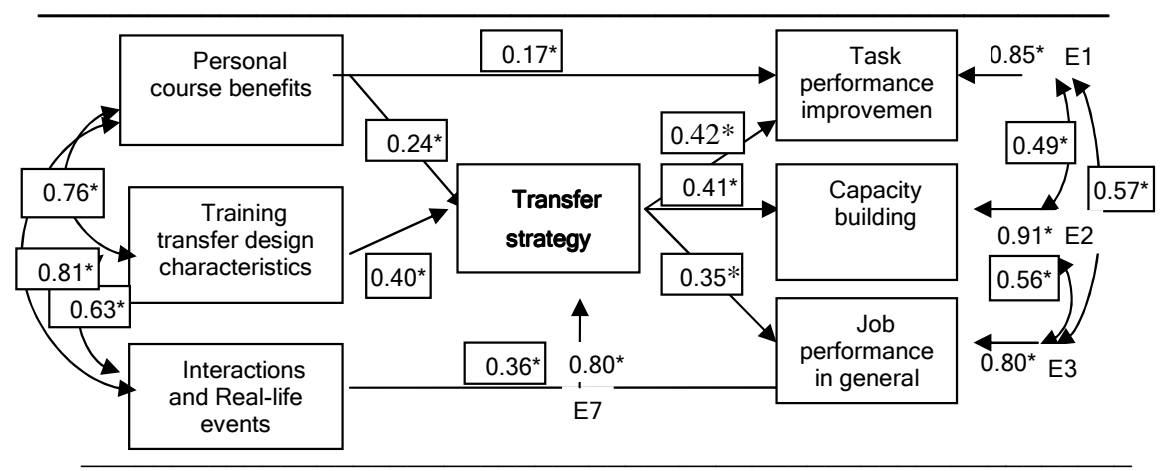

Chapter 3, concerning the trainees' motivation, highlights motivational aspects within MBA programs can influence transfer (figure 6.3).

Figure 6.3 The effects of trainee's motivation on training transfer effects

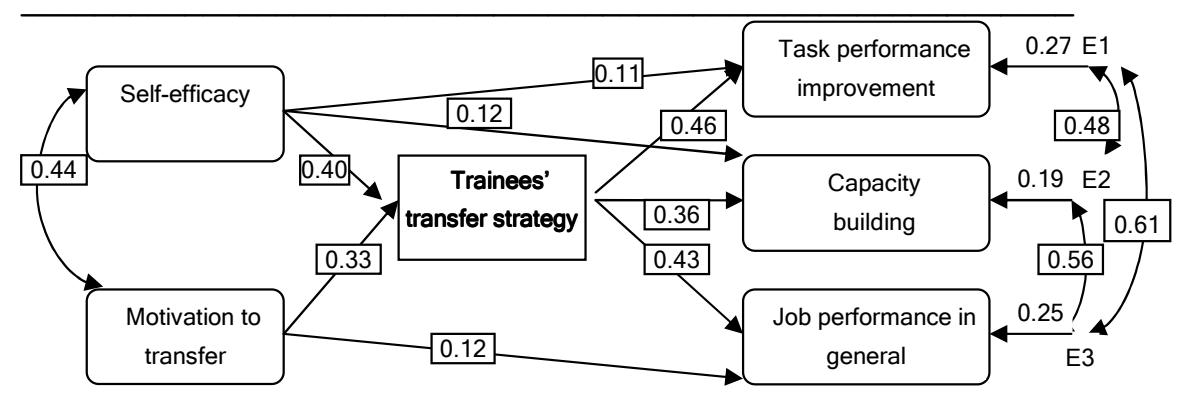

The results show that the trainees' motivation, concretely self-efficacy and motivation to transfer, are directly related to the extent of transfer of training in terms of task performance improvement, job performance in general and capacity building $(\beta=.11 ; \beta=.12$; and $\beta=.12$ respectively). This study supports Pugh and Bergin (2006) and Cheng and Hampson (2008) argument that studying transfer of training from a motivational perspective, contributes to a better understanding of the transfer effects of training.

Moreover, transfer strategy strongly and directly related to the extent of transfer of training in terms of task performance improvement, capacity building and job performance in general $(\beta=.46 ; \beta=.36 ;$ and $\beta=.43$ 
respectively). The relations between self-efficacy and motivation to transfer are strengthened when trainees use transfer strategies

Chapter 4 explores the effects of work environment on transfer of training (figure 6.4). The results indicate that work environment (preferred support, supervisor support and job autonomy), both at the end of training and three months after the training, affect transfer of training, directly and indirectly with supervisor support as a powerful variable. Furthermore, the effect of work environment factors on the training transfer effects is mediated by trainee's transfer strategies.

\section{Figure 6.4 The effects of work environment on training transfer effects}

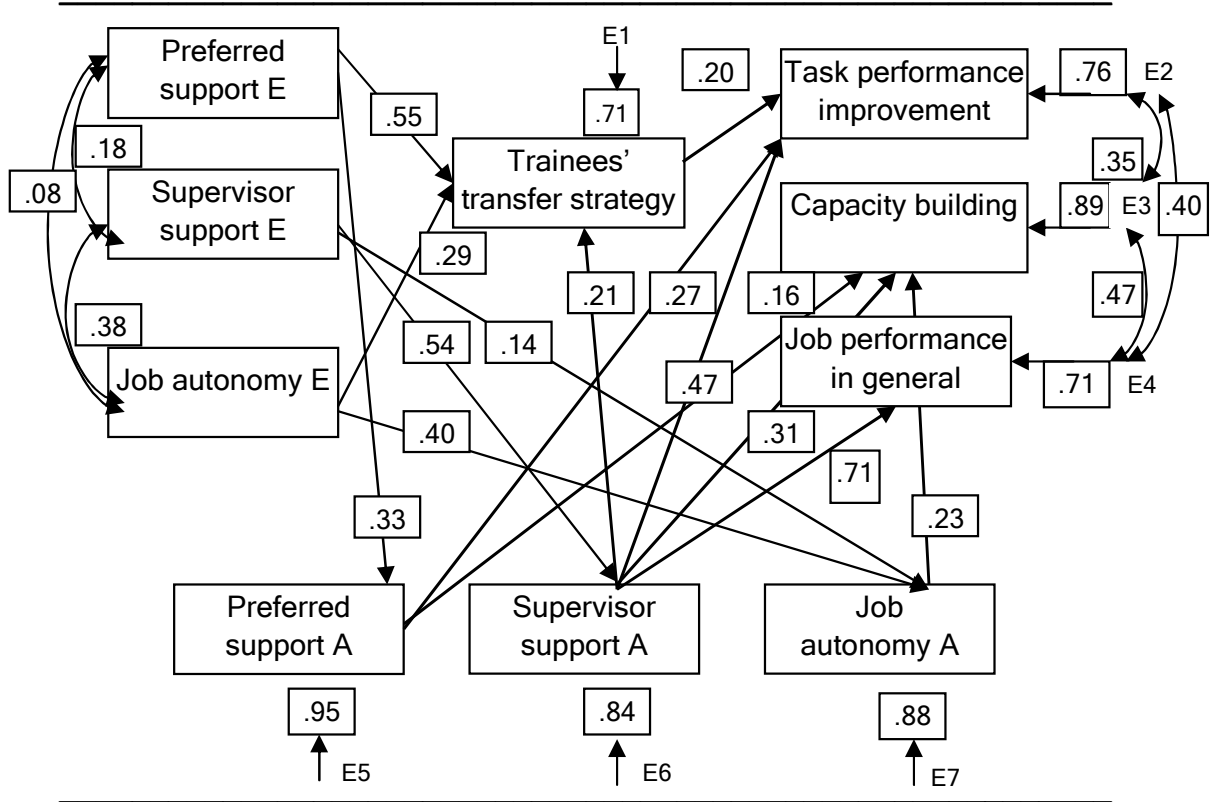

Note: $\mathrm{E}=$ End of training; $\mathrm{A}=$ After three months of training

The figure 6.4 shows that:

1) Work environment (including preferred support, supervisor support and job autonomy) at the end of the course (E) are significantly related to their perceptions three months later $(A)(\beta=.33 ; .29$ and .40 , relatively).

2) All of work environment variables after training: preferred support $A$, job autonomy $A$ and especially supervisor support $A$ are powerful variables in affecting transfer of training directly and indirectly. For example, job performance in general (item example is "In general, I think this training 
course has helped me increase my work performance") were directly predicted by supervisor support $A(\beta=.71)$. Task performance improvement (item example is "I can accomplish my job task better than by using new $K S A$ ") was directly predicted by (a) supervisor support $A$ directly $(\beta=.47)$ (and also indirectly, $\left.\beta=.21^{\star} .20=.04\right)$; (b) preferred support $A(\beta=.27)$, and (c) trainees' transfer strategy $(\beta=.20)$. Similarly, capacity building (item example is "My ability to implement work in general is increased") were directly predicted by supervisor support $A(\beta=.31)$, job autonomy $A(\beta=.23)$ and preferred support $A(\beta=.16)$.

3) None of preferred support $E$, supervisor support $E$ and job autonomy $E$ directly influence transfer of training. Instead, they only directly influence preferred support $A$, supervisor support $A$ and job autonomy $A$ or transfer strategies. Meanwhile, preferred support $A$, supervisor support $A$ and job autonomy $A$ or transfer strategies directly influence transfer of training. For example, supervisor support $E$ influences supervisor support $A(\beta=.54)$. In turn, supervisor support $A$ directly influence transfer of training $(\beta=.47 ; 31$; and 71 in terms of task performance improvement, capacity building and job performance in general, relatively).

4) Job autonomy A directly influences capacity building and job autonomy $E$ influences performance improvement through transfer strategy

5) Transfer strategy is directly influenced (in order of importance) by preferred support $E(\beta=.55)$, job autonomy $E(\beta=.29)$ and supervisor support A $(\beta=.21)$. In addition, transfer strategy influences directly the training transfer effects in terms of Task performance improvement $(\beta=.20)$. Moreover, the relation between supervisor support $A$ and task performance improvement is strengthened when trainees use transfer strategies.

Chapter 5 builds further on our previous studies (that addressed the separate and unique influence of training design, trainees' motivational perspectives and work environment variables on transfer of training), by exploring the extent to which the trainee's transfer of learning to the workplace is simultaneously influenced by the above factors (Figure 6.5).

The results indicate that the above combined factors predict transfer training effects directly and indirectly. Additionally, the model shows direct as well as indirect effects of trainees' use of transfer strategies. It indicates the important role of trainees' use of transfer strategies on transfer of training. The impacts of most above joint factors such as self efficacy, preferred support, and supervisor support on transfer are strengthened when the trainee uses transfer strategies. 
Figure 6.5 Path model toward training transfer effects

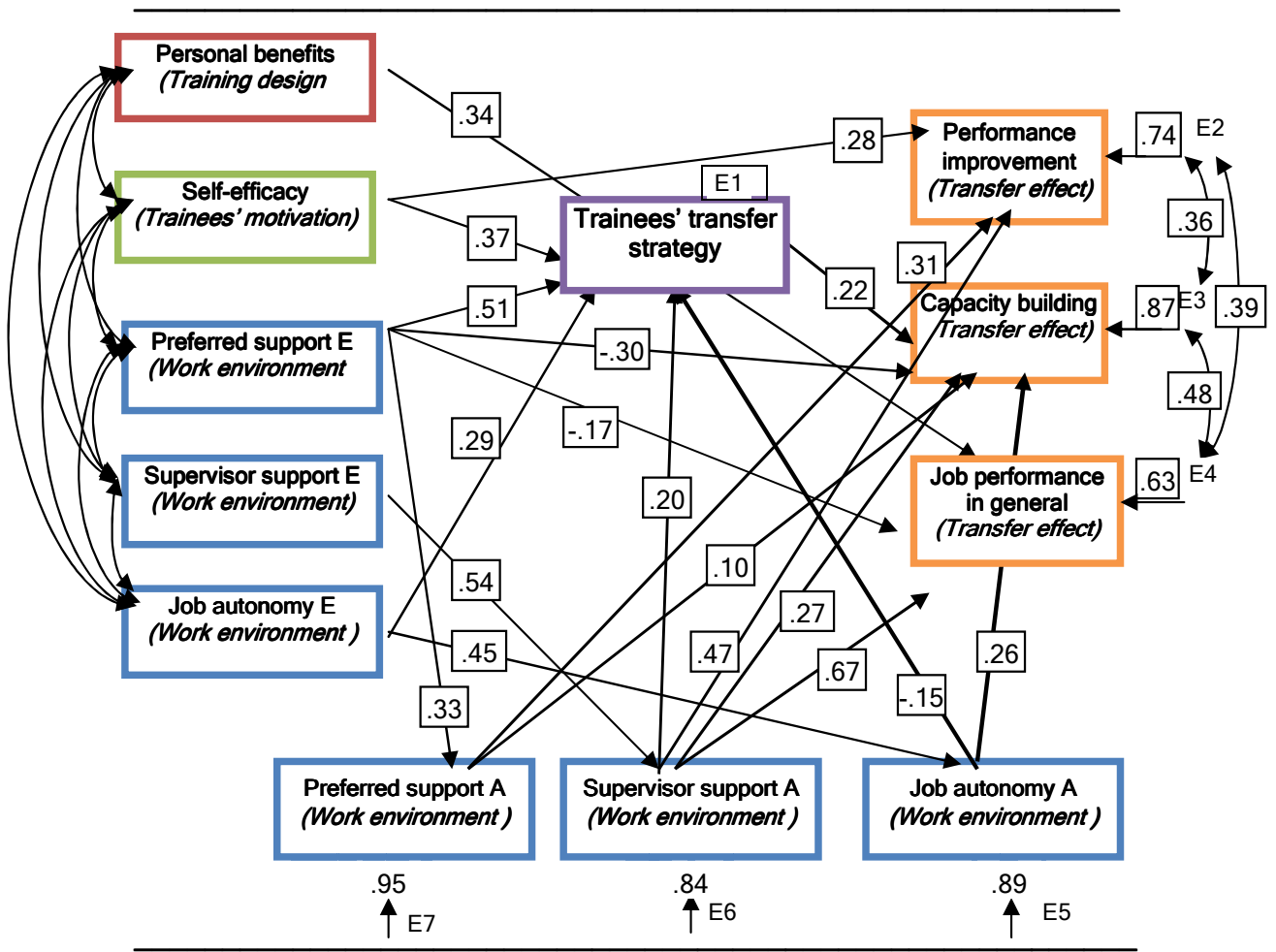

Note: $\mathrm{E}=$ End of training; $\mathrm{A}=$ After three months of training

The results of Figure 6.5 provide evidence that, (1) transfer design with constructivist principle (Personal course benefits) is powerful variables, and directly predict transfer of training in term of capacity building $(\beta=.34)$; (2), self-efficacy, a trainees' motivation is directly and indirectly (through transfer strategy), influencing transfer of training. (3) work environment factors including preferred support, supervisor support and job autonomy, both at the end of training (E) and perceived three months after the training (A), affect transfer of training directly and indirectly with supervisor support $A$ is a powerful variable; (4) transfer strategy directly affect transfer of training in term of capacity building $(\beta=.22)$ as well as plays a mediating role in relationship of preferred support $E$, supervisor $A$ and Job autonomy $A$ with training transfer. 
More precisely, regarding training design, personal course benefits directly and positively predict Job performance $(\beta=.34)$. The personal course benefits refer to principles of constructivist pedagogy. The results confirm prior researchers' arguments for applying characteristics of the constructivist learning environments(Lea, Stephenson, \& Troy, 2003; Pham, Gijselaers, \& Segers, 2010, in press; Tenenbaum, Naidu, Jegede, \& Austin, 2001).

Concerning the trainees' motivation, self-efficacy predicted the extent of transfer of training positively and significantly, both directly $(\beta=.28$ in terms of performance improvement) and indirectly, through transfer strategy in term of capacity building). The results confirm the role of self-efficacy in transfer of training (Cheng, 2000; Colquitt, Lepine, \& Noe, 2000; e.g. Gist, Stevens, \& Bavetta, 1991; Pham, Segers, \& Gijselaers, 2010b; Tannenbaum, Mathieu, Salas, \& Cannon-Bowers, 1991).

In terms of work environment, we found that preferred support, supervisor support and job autonomy, both at the end of training (E) and three months after the training $(A)$ affects transfer of training, directly and indirectly. Especially, the work environment A play a significant role in influencing transfer even more than the work environment $E$, with supervisor support $A$ is a powerful variable predict transfer of training. For example, supervisor support A directly predicts Job performance in general $(\beta=.67)$; Performance improvement $(\beta=.47)$ and Capacity building $(\beta=.27)$. This relation is strengthened when the trainee adopt transfer strategies. Specially, supervisor support A directly predicts Capacity building $(\beta=.27)$ and indirectly predicted through transfer strategy $\left(\beta=.20^{*} .22=.04\right)$.

We also found that while preferred support $A$ positively and directly affect Performance improvement and Capacity building $(\beta=.31$ and $\beta=10$ respectively), preferred support $E$ negatively and directly affect Capacity building and Job performance ( $\beta=-.30$ and $\beta=-.17$ respectively).

Job autonomy $E$ does not directly affect transfer of training, but indirectly affect Capacity building through transfer strategy, and directly affects Job autonomy $A(\beta=.45)$. Job autonomy $A$ positively and directly affects Capacity building $(\beta=.26)$, and negatively affects transfer strategy $(\beta=-15)$.

Transfer strategy is directly influenced Capacity building $(\beta=.22)$. In addition, the relation between supervisor support $A$ and Capacity building is strengthened when trainees use transfer strategies.

The results answer the research question that training design, the trainees' motivational perspectives, and work environment factors, taking into account the role of the trainees' transfer strategies, simultaneously contribute to the transfer of newly acquired knowledge, skills and attitudes on the job. 


\section{GENERAL CONCLUSIONS AND DISCUSSION}

There are a number of conclusions that are worth describing.

First, the results confirm prior researchers' arguments for applying characteristics of the constructivist learning environments (Lea, Stephenson, \& Troy, 2003; Pham, Gijselaers, \& Segers, 2010, in press; Tenenbaum, Naidu, Jegede, \& Austin, 2001). Training design should concentrate on the factors which meet trainees' personal benefits, referring to what the value-added of the training is for the trainee in terms of motivating them toward reflections and concept investigation; encouraging them making meaning of the learning content; taking into account their need and providing materials and resources to support learning.

Additionally, the results confirm the role of self-efficacy in transfer of training (Cheng \& Hampson, 2008; Colquitt, Lepine, \& Noe, 2000; Elangovan \& Karakowsky, 1999; Pham, Segers, \& Gijselaers, 2010b; Pugh \& Bergin, 2006; Velada, Caetano, Michel, Lyons, \& Kavanagh, 2007). This means that the trainee's who possess a strong self-efficacy will transfer what they have learned to their workplace. This relation is strengthened when the trainee uses transfer strategies.

Finally, the results confirm prior research indicating that work environment variables including preferred support, supervisor support and job autonomy influence transfer training effects, directly and in directly, with supervisor support after the training is a powerful variable (Bates, Holton, \& Seyler, 1996; Brinkerhoff \& Montesino, 1995; Cohen, 1990; Cromwell \& Kolb, 2004; Pham, Segers, \& Gijselaers, 2010a; P. Taylor, 1992).

The results support the suggestions by Alliger, Tannenbaum, Bennett, Traver, and Shotland (1997) and Nikandrou, Brinia and Bereri (2009) that repeated measures of trainees' perceptions are relevant in order to better understand transfer of training.

One of the most striking findings of the present study indicates the importance of what happens at the workplace after the training. For example, it is surprising that supervisor support as perceived at the end of the training was not found to be related to either transfer strategy nor to training transfer, whereas supervisor support three months later is a powerful variables directly affect transfer strategy $(\beta=.20)$ and transfer of training as well $(\beta=.67, \beta=.47$ and $\beta=.27$ in terms of job general improvement, performance improvement and capacity building respectively) and indirectly $\left(\beta=.20^{*} .22=.04\right)$ in terms of capacity building). Given the fact that MBA trainees work during the training, this effect might be explained by the possibility that during training, the trainees depend less on their supervisors in the workplace than they do when they return to their jobs (after training). Moreover, the power of trainees' perception three 
month after the training might be explained by various interactions during as well as after the training shape trainees' perception of work environment.

The results also indicated that trainees who believe and know in advance that they would need support (preferred support) will apply their learned knowledge and skills to work (in terms of performance improvement and capacity building).

We found the impact of the trainee's job autonomy three months after on capacity building significant $(\beta=.26)$, implying that the more the trainees' degree of freedom in executing of his/her job), the more (s)he develop his/her ability to organize and execute the work. This confirms prior research (e.g. Axtell \& Maitlis, 1997; Nijman, Nijhof, Wognum, \& Veldkamp, 2006).

Job autonomy A negatively affects transfer strategy $(\beta=-15)$. This could be explained in terms of the nature of transfer strategy, which includes analyzing work situations, preparing to deal with difficulties, and recognizing and monitoring opportunities to use acquired knowledge and skills on the job. The more job autonomy the trainee had before the training, the more freedom (s)he knows (s)he will have following the training, so less transfer strategy is needed.

Preferred support E negatively affect Capacity building and Job performance ( $\beta=-.30$ and $\beta=-.17$ respectively). Reasons remain to be elucidated, but there are several reasonable hypotheses. In terms of Capacity building, preferred support $E$ directly and significantly influences preferred support $A(\beta=.33)$. Based on the correlation between preferred support $A$ and $E(r=.33)$, preferred support $A$ directly predicts Capacity building, so it could be said that preferred support $E$ is suppressed by preferred support A. Again, the results confirm the importance of what happens at the workplace after the training (Kontoghiorghes, 2004; Tannenbaum \& Yukl, 1992; Vermeulen, 2002; Wexley \& Baldwin, 1986) and support the suggestions by Alliger, Tannenbau, Bennett, Traver and Shotland (1997) and Nikandrou, Brinia and Bereri (2009) that repeated measures of trainees' perceptions are relevant in order to better understand transfer of training.

Similarly, preferred support $E$ negatively affecting job performance $(\beta=-$ 17) might be explained by the nature of preferred support. Trainees need to have support to apply their learned knowledge and skills. Given the fact that most MBA trainees work during the training, they may (as part of their transfer strategy) ask for the needed support at work, and this might conflict with a supervisor's notion that, on the contrary, training will result in a need for less support.

In conclusion, while previous transfer of training models such as the pivotal Holton, Bates and Ruona (2000) model have been presenting a 
large set of influential variables, our study, nevertheless, indicates that a limited set of variables such as training design, trainees' characteristics, work environment factors and transfer strategy significantly predicts transfer training. This study adds to the existing knowledge base by providing an empirical study indicates the validity of a model that present a simultaneous joint influence of these factors on transfer of training. This study might stimulate further research using a complete conceptualization of such factors to predict training transfer. It provides empirical evidence to the aforementioned theoretical models.

The results of this study supported the findings of some previous studies while at the same time gave some new insights in the impact of transfer strategies, training design, trainees' characteristics, and work environment on transfer of training field. First, the study results confirm the mediating role of transfer strategy in the relation other factors influencing training transfer. Using transfer strategies will strengthen the relation between the training design, trainees' characteristics and work environment and transfer effects. Second, the study extends 11 items for questionnaire measuring the transfer effect. While a number of former studies have used often with very few items, this addition strengthen self-report measure with a more robust instrument. Besides, the present study adds a preferred support construct in the set of work environment components. This evaluative addition presents a milestone and an additional tool for measuring training transfer. The present findings provide empirical evidence that the more comprehensive the characteristics assessment, the better. Third, opposite of previous studies uses self report questionnaires to measure training transfer, we have measured transfer by trainees' supervisor as well. It helped to reduce the possibility of common method bias and to increase the reliability and validity of the relationships examined. Finally, with regards to methodology, while most of the cited transfer of training research has used trainees' perception of work environment either at the end of training or after training, this study uses both in two periods of time. Based on the results of this study, we can argue that in order to better understand the effect of transfer of training, we need to conduct follow-up assessments after the training for repeated measures of trainees' perceptions.

\section{IMPLICATIONS OF THE RESEARCH FOR MBA PROGRAMS AND RECOMMENDATIONS FOR FURTHER TRAINING PROGRAMS}

This study has several practical implications for improving MBA programs in order to enhance transfer of training. They are even more 
important because the marketplace for MBA is highly competitive, demanding from MBA suppliers to offer programs which add value to trainee's competencies.

First of all, if the training design is designed based on constructivist learning theory approach (i.e. bring personal benefits to trainees), it will affect trainees' linking up the course content with their daily work, in turns, it's much more likely transfer training (increase job performance in general). MBA trainees are experienced professionals. They enter MBA course in order to improve their job performance. Therefore, Training Providers should design training program using this approach to enhance transfer. Moreover, while both trainers and trainees should be open to negotiating the instructional goals and objectives, trainees' supervisors should also participate in these negotiations to facilitate trainees learning and maximize the training effects. The more line managers consider training is useful for trainees, the more support they will facilitate trainees to transfer, because they understand that it will help to increase trainees' contribution to their organizations.

Second, the use of transfer strategies strengthens transfer of training. Training Providers and Supervisors should encourage MBA trainees to formulate their transfer strategies during the training and after training. Supervisors should allow and reward trainees to use transfer strategies to apply learning on the job. This helps motivate trainees to apply new knowledge and skills performance in general). By doing do, supervisors positively influence trainees' confidence to learn new skills as well as their ability to transfer the new skills to the job

Third, the results imply self-efficacy turned out to be crucial motivational factor, which give rise to trainees' transfer strategies, and in turn leading to higher transfer of training. Therefore, training designers and trainers should think about how to help trainees pursue their self-efficacy during and after training. Research has revealed that self-efficacy is trainable (e.g.Karl, O'Leary-Kelly, \& Martocchio, 1993), therefore, in order to maximize transfer of training, faculty should train and regularly monitor trainees' self-efficacy and motivation to transfer in their trainees. Trainees' self-efficacy can be increased before they attend the training by providing them with trainingrelated information, such as the importance of training, training content, training method or training environment (Tai, 2006).

Specifically, it also indicates that to maximize return on training, trainers should regularly monitor trainees' self-efficacy. Line managers should encourage their employees with high self-efficacy to become training candidates. Especially, line managers are advised to work with the employee to choose the best MBA provider where training is designed to encourage the particular trainee's self-efficacy. This will help ensure that 
trainees apply to their job the learned knowledge and skills during and after training as well.

Fourth, with regard to work environment, the important role of preferred support, supervisor support and job autonomy at the end the training as well as after the training the results demonstrate the practical implications: Supervisor should recognize that trainees who believe and know in advance that they would needed support, and who have job autonomy will apply their learned knowledge and skills to work. It is also important for organizations to be aware of their responsibility in making transfer happen by letting trainees know that they will receive the support from the organization (preferred support), supervisor and job autonomy to successfully transfer the training. Therefore, supervisors as well as organizations should facilitate trainees during and after training, respond to trainees' need support, and ensure that trainees have opportunities to practice and apply newly learning on the job. Supervisors with positive perceptions toward support experience better transfer outcomes than managers who do not. The role of Supervisor after the training importantly related to the level of transfer outcome because out results indicate that how trainees perceive the work environment three months after training is a stronger indicator of transfer of training than trainees' perceptions of supervisor support at the end the training. The result also implies that the more the trainees' degree of freedom in executing his/her job), the greater their ability to organize and execute their work, resulting in effective transfer. Therefore, supervisors as well as organizations should allow and reward trainee to exercise more autonomy on the job. Besides, trainers should train supervisors about how to (a) support trainees during and after training; (b) respond to their needed support and (c) allow them to exercise more autonomy on the job.

Base on results of this study, we formulate a number of recommendations for further training programs. They are presented in Table 6.1. The recommendations refer to (1) the encouragement of developing and using transfer strategies; (2) the design of the training; (3) the selection of trainees; (4) supporting the development of trainees' self-efficacy and monitoring it during the training; (5) supervisor and colleagues' support; and (6) job autonomy. By doing so, it brings benefits first, for organizations, companies (increasing job performance and benefit/cost ratio of training employees); second, for training providers (attracting the interest of organizations and trainees, and as a results, having more income); and finally, for trainees (enjoying more autonomy on the job, having opportunity to exercise new skills, and (as a result of higher productivity) higher income). 
Table 6.1 Recommendations for Training Programs

\begin{tabular}{|c|c|c|}
\hline Recommendations & For Trainers & For Supervisors/Organizations \\
\hline $\begin{array}{l}\text { Developing a training } \\
\text { transfer strategy }\end{array}$ & $\begin{array}{l}\text { - Encourage trainees to formulate } \\
\text { and develop transfer strategies, } \\
\text { during the training } \\
\text { - Collect examples of training } \\
\text { transfer strategy and present these } \\
\text { explicitly as part of the training. } \\
\text { - Helping trainees to be well } \\
\text { prepared for transfer learning }\end{array}$ & $\begin{array}{l}\text { - Allow and reward successful trainee } \\
\text { to apply learning on the job } \\
\text { - Letting trainees know that they will } \\
\text { receive the support from the } \\
\text { organization } \\
\text { - Identifying organizational reasons } \\
\text { behind the failure of application. }\end{array}$ \\
\hline $\begin{array}{l}\text { Designing training } \\
\text { according to } \\
\text { constructivist principles, } \\
\text { focusing on trainees' } \\
\text { personal benefits }\end{array}$ & $\begin{array}{l}\text { - Training is designed to } \\
\text { concentrate on constructivist } \\
\text { principles (e.g. motivating trainees } \\
\text { toward reflections and concept } \\
\text { investigation; encouraging them } \\
\text { making meaning of the learning; } \\
\text { taking into account their needs and } \\
\text { providing them with materials and } \\
\text { resources to support their learning) } \\
\text { - Be open to negotiating the } \\
\text { instructional goals and objectives }\end{array}$ & $\begin{array}{l}\text { - Work with trainers and } \\
\text { trainees/employees on instructional } \\
\text { goals and objectives }\end{array}$ \\
\hline $\begin{array}{l}\text { Acquiring and } \\
\text { maintaining self-efficacy }\end{array}$ & $\begin{array}{l}\text { - Allow for argumentation, } \\
\text { discussions, debates among } \\
\text { learners and with trainers } \\
\text { - Training is designed to help } \\
\text { trainees to pursue their self-efficacy } \\
\text { during and after learning } \\
\text { - Regularly monitor trainees' self- } \\
\text { efficacy }\end{array}$ & $\begin{array}{l}\text { - Encourage employees with high self- } \\
\text { efficacy to become training candidates } \\
\text { - Work with the employee to choose } \\
\text { the best training provider where } \\
\text { training is designed to encourage their } \\
\text { self-efficacy. } \\
\text { - Show trainees that they are believed } \\
\text { having the ability to successfully learn } \\
\text { training and utilize such new } \\
\text { knowledge on the job. } \\
\text { - Inform trainees that applying learning } \\
\text { is valued by the organizations }\end{array}$ \\
\hline $\begin{array}{l}\text { Providing more } \\
\text { supervisor and } \\
\text { colleague support }\end{array}$ & $\begin{array}{l}\text { - Train supervisors about how to } \\
\text { support trainees during and after } \\
\text { training }\end{array}$ & $\begin{array}{l}\text { - Maintain facilitating trainees during } \\
\text { and after training } \\
\text { - Respond to their need for support } \\
\text { - Letting trainees know that they will } \\
\text { receive the support from the } \\
\text { organization }\end{array}$ \\
\hline $\begin{array}{l}\text { Providing more } \\
\text { autonomy on the job }\end{array}$ & $\begin{array}{l}\text { - Advise supervisors how to allow to } \\
\text { exercise more autonomy on the job }\end{array}$ & $\begin{array}{l}\text { - Allow and reward to exercise more } \\
\text { autonomy on the job }\end{array}$ \\
\hline $\begin{array}{l}\text { Selecting the right } \\
\text { candidates }\end{array}$ & $\begin{array}{l}\text { - Advise supervisors on how to } \\
\text { encourage employees most likely to } \\
\text { benefit from training to attend } \\
\text { training }\end{array}$ & $\begin{array}{l}\text { - Encourage employees most likely to } \\
\text { benefit from training to attend training }\end{array}$ \\
\hline
\end{tabular}




\section{WHAT IS NEXT?}

The results of this study also indicate some direction for future research.

First, this study offers evidence for the validity of training design, trainees' motivation and work environment affect training transfer in a Vietnamese MBA context. Therefore, future studies in different countries and different training contexts are highly desirable, in order to strengthen the crosscultural validity of the findings as well as examine the generalizability of our results. We will continue to test and validate our findings in our Marie Curie Project (FPT-People-2009-Intra-European Fellowship, FATT 255292) in the European countries settings.

Second, although this study has used questionnaires to measure transfer effects by trainee's self report and their supervisor assessment, we suggest looking for possibilities to implement ratings from multiple and objective measurement sources such as peers, subordinates and customers (360 degree assessment) in order to enhance inter-subjecting.

Third, as a next step in cross-validating a transfer of training model, in order to deepen our understanding of the transfer process, we recommend the additional use of qualitative research methods such as interviews. The results can highlight why and how specific training design, trainees' motivation and work environment aspect influence transfer of training.

Finally, although our final sample of 167 participants provided statistical power to test our hypotheses testing, including of larger sample sizes will enhance validity and generalization of the present findings.

\section{References}

Alliger, G. M., Tannenbaum, S. I., Bennett, W., Traver, J. H., \& Shotland, A. (1997). A metaanalysis of the relations among training criteria. Personnel Psychology, 50(2), 341358.

Axtell, C. M., \& Maitlis, S. (1997). Predicting immediate and longer-term transfer of training. Personnel Review, 26(30), 201-213.

Baldwin, T. T., \& Ford, J. K. (1988). Transfer of training: a review and directions for future research. Personnel Psychology, 41(1), 63-105.

Bates, R. A., Holton, E. F., \& Seyler, D. L. (1996). Validation of a transfer climate instrument. Paper presented at the Academy of Human Resource Development.

Brinkerhoff, R. O., \& Montesino, M. U. (1995). Partnerships for training transfer: lessons from a corporate study. Human Resource Development Quarterly, 6, 263-274.

Burke, L. A. (1997). Improving positive transfer: A test of relapse prevention training on transfer outcomes. . Human Resource Development Quarterly, 8(1).

Burke, L. A., \& Baldwin, T. T. (1999). Workforce training transfer: a study of the effect of relapse prevention training and transfer climate. Human Resource Management, 38(3), 227.

Burke, L. A., \& Hutchins, H. (2007). Training Transfer: An Integrative Literature Review. Human Resource Development Review, 6, 263-296.

Cheng, E. (2000). Test of the MBA knowledge and skills transfer. International Journal of Human Resource Management, 11(4), 837-852. 
Cheng, E., \& Hampson, I. (2008). Transfer of training: A review and new insights. International Journal of Management Reviews, 10(4), 327-341.

Cheng, E., \& Ho, D. (2001). The influence of job and career attitudes on learning motivation and transfer. Career Development International, 6(1), 20-27.

Cohen, D. J. (1990). What motivates trainees? Training and Development Journal, 36.

Colquitt, J. A., Lepine, J. A., \& Noe, R. A. (2000). Toward an Integrative Theory of Training Motivation: A Meta-Analytic Path Analysis of 20 Years of Research. Journal of Applied Psychology, 85(5), 678-707.

Cromwell, S. E., \& Kolb, J. A. (2004). An Examination of Work-Environment Support Factors Affecting Transfer of Supervisory Skills Training to the Workplace. Human Resource Development Quarterly, 15(4), 449 - 470.

Elangovan, A. R., \& Karakowsky, L. (1999). The role of trainee and environmental factors in transfer of training: an exploratory framework. Leadership \& Organization Development Journal, 20(5).

Ford, J. K., \& Weissbein, D. A. (1997). Transfer of training: An updated review and analysis. Performance Improvement Quarterly, 10, 22041.

Gist, M. E., Stevens, C. K., \& Bavetta, A. G. (1991). Effects of Self-efficacy and Post-training Intervention on the Acquisition and Maintenance of Complex Interpersonal Skills. Personnel Psychology, 44, 837-861.

Gollwitzer, P. M. (1999). Implementation intentions: Strong effects of simple plans. American Psychologist, 54, 493-503.

Hesketh, E. A., \& Laidlaw, J. M. (1997). 'Selling' educational events to healthcare professionals: Twelve tips on the function and design of trigger leaflets. Medical Teacher, 19(4), 250-256.

Holton, E. F., Bates, R. A., \& Ruona, W. E. A. (2000). Development of a Generalized Learning Transfer System Inventory. Human Resource Development Quarterly, 11(4), 333-360.

Karl, K. A., O'Leary-Kelly, A. M., \& Martocchio, J. J. (1993). The impact of feedback and selfefficacy on performance in training. Journal of Organizational Behavior, 14, 379394.

Kontoghiorghes, C. (2004). Reconceptualizing the learning transfer conceptual framework: empirical validation of a new systemic model. International Journal of Training and Development, 8(3), 1-25.

Latham, G. P. (1997). Overcoming mental models that limit research on transfer of training in organizational settings. Applied Psychology: An International Review, 46, 371-375.

Lea, S. J., Stephenson, D., \& Troy, J. (2003). Higher education students' attitudes toward student-centred learning: Beyond 'educational bulimia'? Studies in Higher Education, 28, 321-334.

Machin, M. A., \& Fogarty, G. J. (2003). Perceptions of training-related factors and personal variables as predictors of transfer implementation intentions. Journal of Business and Psychology, 18(1), 51-75.

Nijman, D., Nijhof, W., Wognum, A., \& Veldkamp, B. (2006). Exploring differential effects of supervisor support on transfer of training. Journal of European Industrial Training, 30(7), 529-549.

Nikandrou, I., Brinia, V., \& Bereri, E. (2009). Perspective on practice. Trainee perceptions of training transfer: an empirical analysis. Journal of European Industrial Training, 33(3), 255-270.

Noe, R. A., Sears, J., \& Fullenkamp, A. M. (1990). Relapse training: Does it influence trainees' post training behavior and cognitive strategies? Journal of Business and Psychology, 4(3), 317-328.

Pham, N. T. P., Gijselaers, W. H., \& Segers, M. S. R. (2010, in press). The effect of the trainees' perception of the training design on transfer of training: the case of Master 
of Business Administration (MBA) of Vietnam. In P. V. d. Bossche, W. Gijselaers \& R. Milte (Eds.), Advances in Business Education and Training. Springer.

Pham, N. T. P., Segers, M. S. R., \& Gijselaers, W. H. (2010a). Effects of the work environment on transfer of Master of Business Administration (MBA) training on the mediating role of the trainees' transfer strategies. International Journal of Training \& Development.

Pham, N. T. P., Segers, M. S. R., \& Gijselaers, W. H. (2010b). Understanding transfer of training effects from a motivational perspectives: A test of MBA programs. Business Leadership Review, 7(3), 1-25.

Pidd, K. (2004). The impact of workplace support and identity on training transfer: a case study of drug and alcohol safety training in Australia. International Journal of Training and Development, 8(4).

Pugh, K. J., \& Bergin, D. A. (2006). Motivational Influences on Transfer. Educational Psychologist, 41(3), 147-160.

Tai, W. T. (2006). Effects of training framing, general self-efficacy and training motivation on trainees' training effectiveness. Personnel Review, 35(1), 51-65.

Tannenbaum, S. I., Mathieu, J. E., Salas, E., \& Cannon-Bowers, J. A. (1991). Meeting trainees' expectations: the influence of training fulfillment on the development of commitment, self-efficacy, and motivation. Journal of Applied Psychology, 76(6), 759-769.

Tannenbaum, S. I., \& Yukl, G. (1992). Training and development in work organizations. Annual Review of Psychology, 43, 399-441.

Taylor, M. C. (2000). Transfer of learning in workplace literacy programs. Adult Basic Education, 10, 3-20.

Taylor, P. (1992). Training directors' perceptions about the successful implementation of supervisory training. Human Resource Development Quarterly, 3(243-259).

Tenenbaum, G., Naidu, S., Jegede, O., \& Austin, J. (2001). Constructivist pedagogy in conventional on-campus and distance learning practice: an exploratory investigation. Learning and Instruction, 11(2), 87-111.

Tziner, A., Haccoun, R. R., \& Kadish, A. (1991). Personal and situational characteristics influencing the effectiveness of transfer of training improvement strategies. Journal of Occupational Psychology, 64(2), 167-177.

Velada, R., Caetano, A., Michel, J., Lyons, B., \& Kavanagh, M. (2007). The effects of training design, individual characteristics and work environment on transfer of training. International Journal of Training and Development, 11(4), 282-294.

Vrasidas, C. (2000). Constructivism versus objectivism: Implications for interaction, course design, and evaluation in distance education. International Journal of Educational Telecommunications, 6(4), 339-362.

Wexley, K. N., \& Baldwin, T. T. (1986). Post-training strategies for facilitating positive transfer: An empirical exploration. Academy of Management Journal, 29(503-520). 


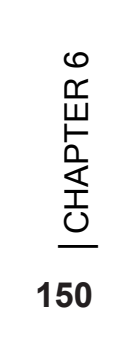




\section{Tóm tắt Luận án Tiễn sỹ}

Tên Luận án: "Tăng cường khả năng áp dụng những kiến thức và kỹ năng đã học vào thực tễ công việc của người học: nghiên cứu trường hợp các chương trình đào tạo Thạc sỹ Quản trị Kinh doanh (MBA) ở Việt Nam"

\section{I - Tổng quan chung}

Nếu các kiến thức và kỹ năng đã học không được người học áp dụng vào thực tế công việc, các chương trình giáo dục và đào tạo sẽ bị coi là lãng phí thời gian và tiên bạc. Vì vậy, hàng chục năm qua, các nhà nghiên cứu trong lĩnh vực phát triển nguồn nhân lực không ngừng trăn trở với câu hỏi làm thế nào để người học có thể áp dụng một cách có hiệu quả nhất những kiến thức và kỹ năng đã học vào thực tế công việc của họ (sau đây gọi chung là Hiệu quả Áp dụng). Nhìn chung, có ba nhóm nhân tố chính ảnh hưởng đến hiệu quả áp dụng. Đó là đặc điểm của chương trình và giáo trình giảng dạy; đặc điểm của người học và đặc điểm của môi trường làm việc của người học.

Mặc dù có nhiêu nghiên cứu đã cố gắng trả lời câu hỏi trên, song nhũng hiểu biết của chúng ta về nhũng vân đề liên quan đến Hiệu quả Áp dụng nói trên vẫn còn nhiều lỗ hổng. Những kết luận nghiên cứu trái ngược nhau buộc chúng ta phải xem lại cách tiếp cận cũng như xử lý vấn đề. Cần phải nghiên cứu, thiết kế một mô hình mới sao cho xác định được những yếu tố cơ bản ảnh hưởng đến việc áp dụng nhũng kiến thức và kỹ năng đã học vào thực tế công việc của người học.

Hơn nũa, những nghiên cứu về giảng dạy và đào tạo khẳng định rằng những kiến thức và kỹ năng đã học không phải đương nhiên sẽ được áp dụng vào thực tế công việc của người học một cách tự động. Những đặc điểm của người học và của môi trường làm việc có ảnh hưởng rất lớn đến hiệu quả áp dụng này. Đã có một vài tài liệu đề cập đến nhân tố thứ tư: kế hoạch chủ động áp dụng của người học, và tác dụng của nó đôi với Hiệu quả Áp dụng, song vẫn còn rất ít nghiên cứu về vân đề này.

Đặc biệt có rất ít nghiên cứu ảnh hưởng đồng thời của ba nhóm nhân tố nói trên đến hiệu quả áp dụng, và nhất là có tính đến nhân tố thư tư: kế hoạch chủ động để áp dụng của người học. Vì vậy, nghiên cứu này khảo sát ảnh hưởng đồng thời lẫn nhau của ba nhóm nhân tố nói trên và sự góp mặt của nhân tố thử tư đến Hiệu quả Áp dụng. Mục đích chính của nghiên cửu là đưa ra một mô hình tổng hợp mới, theo một cách tiếp cận đa chiêu và có hệ thổng, nhằm xem xét và đánh giá sự tương tác lẫn nhau của bốn nhân tố nói trên ảnh hưởng đến Hiệu quả Áp dụng, từ đó tìm ra các biện pháp để đẩy mạnh và tăng cường Hiệu quả Áp dụng. 


\section{II - Kễt cẫu Luận án}

Trước khi nghiên cứu mô hình tổng hợp theo một cách tiếp cận đa chiêu và có hệ thống, nhằm xem xét và đánh giá sự tương tác lẫn nhau của bốn nhân tố nói trên ảnh hưởng đến Hiệu quả Áp dụng, một sê-ri gôm bốn mô hình con được nghiên cứu riêng rẽ, xem xét ảnh hưởng của từng nhân tố trong số bốn nhân tố nói trên.

Hình 1. Ảnh hưởng của việc thiết kế Chương trình và giáo trình, có tính đến kễ hoạch chủ động áp dụng của người học, đến Hiệu quả Áp dụng.

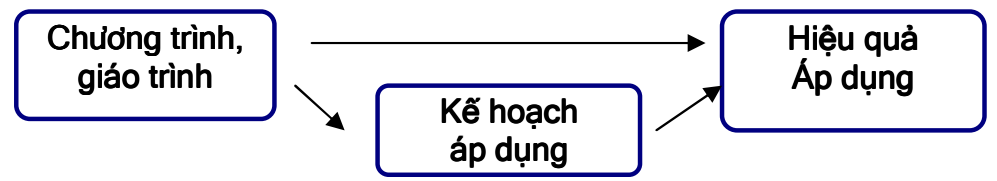

Hình 2. Ảnh hưởng của đặc điểm người học, có tính đến kế hoạch chủ động áp dụng của người học, đến Hiệu quả Áp dụng.

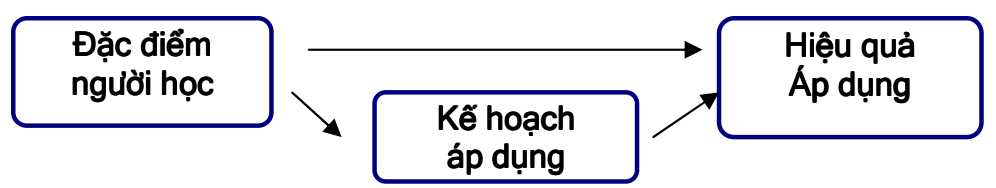

Hình 3. Ảnh hưởng của môi trường làm việc, có tính đến kế hoạch chủ động áp dụng của người học, đến Hiệu quả Áp dụng.

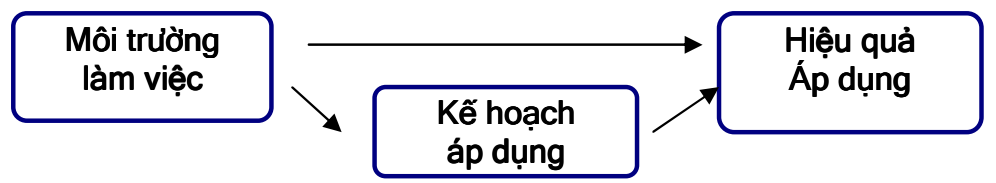


Hình 4. Mô hình đánh giá ảnh hưởng tổng hợp của chương trình và giáo trình, đặc điểm của người học và môi trường làm việc; có tính đến kế hoạch chủ động áp dụng của người học, đến Hiệu quả Áp dụng.

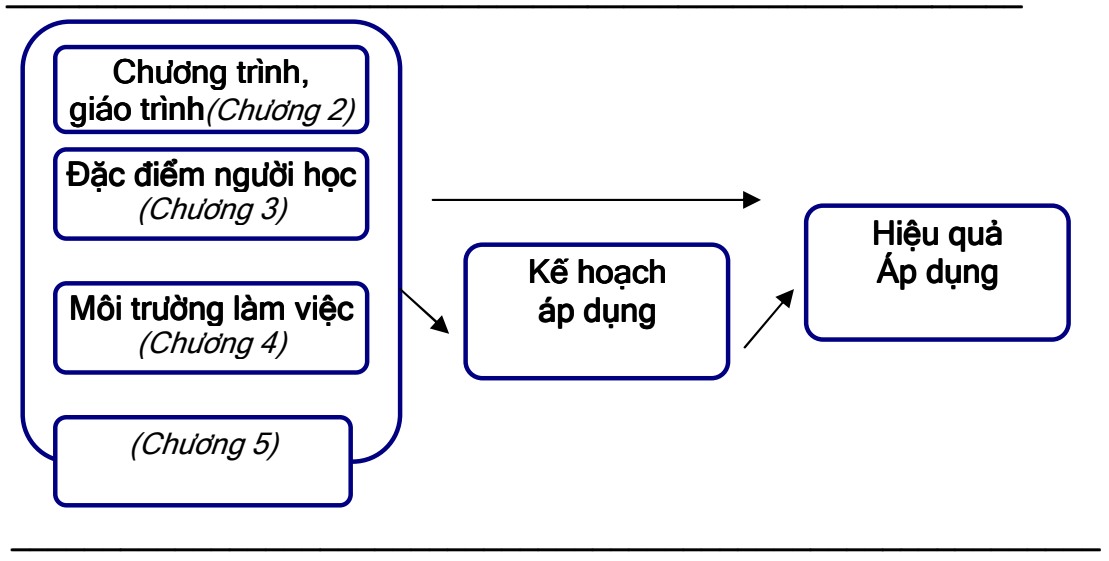

\section{III - Mẫu nghiên cứu}

Số liệu nghiên cứu được lấy tại Việt Nam. Các học viên từ tám chương trình Thạc sỹ Quản trị Kinh doanh (MBA) khác nhau ở miền Bắc và miên Nam đã tham gia trả lời Bảng hỏi. Số liệu được thu thập làm hai lần: lân 1 ngay sau khi kết thúc khóa học, và lân 2 , ba tháng sau khi kết thúc khóa học. Có 167 học viên tham gia trả lời Bảng hỏi lân1. 126 học viên trả lời Bảng hỏi lần 2. Tỷ lệ nam chiếm $61 \%$. Tuổi trung bình của học viên là 32 .

Chương trình MBA được lựa chọn cho nghiên cứu này bởi nhũng lý do chủ yếu sau đây: Thứ nhât, các chương trình MBA ngày càng trở nên quan trọng và có sức thu hút trên toàn thế giới. Số lượng học viên MBA không ngừng tăng lên kể từ Châu Mỹ, qua Châu Âu, đến Châu Á. Thứ hai, học viên $\mathrm{MBA}$ là những người có nghề nghiệp nhất định và có ít nhiêu kinh nghiệm công tác. Họ hiểu rằng theo học MBA là một cơ hội để phát triển nghề nghiệp của mình, bởi vì $\mathrm{MBA}$ là một chương trình đào tạo tập trung vào việc phát triển những kỹ năng nghề nghiệp, đặc biệt đi sâu vào các chức năng nền tảng của kinh doanh và năng lực quản lý. Thứ ba, các chương trình MBA ngày càng được chuẩn hóa trên thế giời, tạo nên sự ngày càng đồng nhất về mặt chương trình, giáo trình giảng dạy. Cuối cùng, mặc dù các chương trình MBA đang phát triển mạnh mẽ trên toàn thế giới, song những nghiên cứu về việc áp dụng những kiến thức đã học của nó vào thực tế công việc vẫn còn rất ít ỏi. 
Ở Việt Nam, giáo dục và đào tạo là một trong những ưu tiên hàng đâu của Chính phủ Việt Nam, được coi là quốc sách trong quá trình phát triển kinh tế và hội nhập thế giới. Rất nhiêu các cơ sở đào tạo trong nước cũng như liên kết với nước ngoài đang tập trung đào tạo MBA, ví dụ như các chương trình đào tạo MBA của Đại học Kinh tễ Quốc dân Hà Nội, Đại học Quốc gia Việt Nam, Đại học Ngọai Thương, Trung tâm đào tạo Việt-Pháp, Trường Quản lý Maastricht tại Việt Nam, ... Vì vậy, đánh giá hiệu qủa của các chương trình này là một cần thiết tất yếu khách quan.

Song trên thực tế ở Việt Nam, có rất ít các nghiên cứu đánh giá hiệu qủa của việc áp dụng kiến thức đã học vào thực tiễn công việc. Đặc biệt đến nay, những đánh giá hiệu qủa nói trên của các chương trình MBA là chưa có, trong khi chính sự đa dang của các chương trình MBA là một cơ hội quý giá cho việc tiến hành khảo sát thực địa, thu thập số liệu thực tế và triển khai nghiên cứu.

Vì vậy, trong điều kiện các chương trình đào tạo MBA ngày càng nhiêu về số lượng như hiện nay, việc xây dựng và phát triển một mô hình nghiên cửu tổng hợp, tìm ra các yếu tố ảnh hưởng đến hiệu quả việc áp dụng những kiến thức MBA đã học vào thực tế công việc thật sự là một nhu câu cấp thiết, góp phần tích cực vào việc nâng cao chất lượng đào tạo cũng như tăng cường hiệu quả việc áp dụng những kiến thức nói trên. Điều này rất cân thiết cho Việt Nam, một đất nước đang trong quá trình chuyển đổi, với tốc độ phát triển kinh tế nhanh chóng. Các chương trình đào tạo thực sự có hiệu qủa sẽ đáp ửng nhu câu cấp thiết về nguồn nhân lực cho đất nước, vì một mục tiêu phát triển bền vững

\section{IV - Kết quả nghiên cứu}

Kết quả nghiên cứu sử dụng sơ đồ đường dẫn (Path analysis) trong SEM (Structural Equation Modelling- mô hình phương trình câuu trúc), một kỹ thuật mô hình thống kê rất tổng quát, được sử dụng rộng rãi trong khoa học nghiên cứu hành vi. Kết quả nghiên cứu được thể hiện trên sơ đô đường dẫn như hình 2.

Hình 2 cho thây, việc thiết kễ chương trình, giáo trình giảng dạy dựa trên nguyên tắc học tập tích cực, lấy người học làm trung tâm, chú trọng đến các kỹ năng có ảnh hưởng rất lởn đến việc tăng cường Hiệu quả Áp dụng.

Ngoài ra, niêm tin của người học rằng họ sẽ học tốt và áp dụng tốt vào công việc cũng góp phân tăng cường Hiệu quả Áp dụng. Hiệu quả này càng lớn hơn nữa nếu người học có kế hoạch chủ động áp dụng.

Về môi trường làm việc, sự cân thiết được hỗ trợ từ cơ quan; sự hỗ trợ của Cấp trên cũng như quyền tự chủ trong công việc, sau khi kết thúc khóa học MBA, ảnh hưởng rất lởn đến Hiệu quả Áp dụng, trong đó sự hỗ trợ của 
Cấp trên đóng vai trò quyết định. Một lần nũa, Hiệu quả này càng lớn hơn nểu người học có kế hoạch chủ động áp dụng.

Hình 2- Sơ đồ đường dẫn đánh giá ảnh hưởng tổng hợp của chương trình và giáo trình; đặc điểm của người học; môi trường làm việc; có tính đến kế hoạch chủ động áp dụng của người học, đến Hiệu quả Áp dụng.

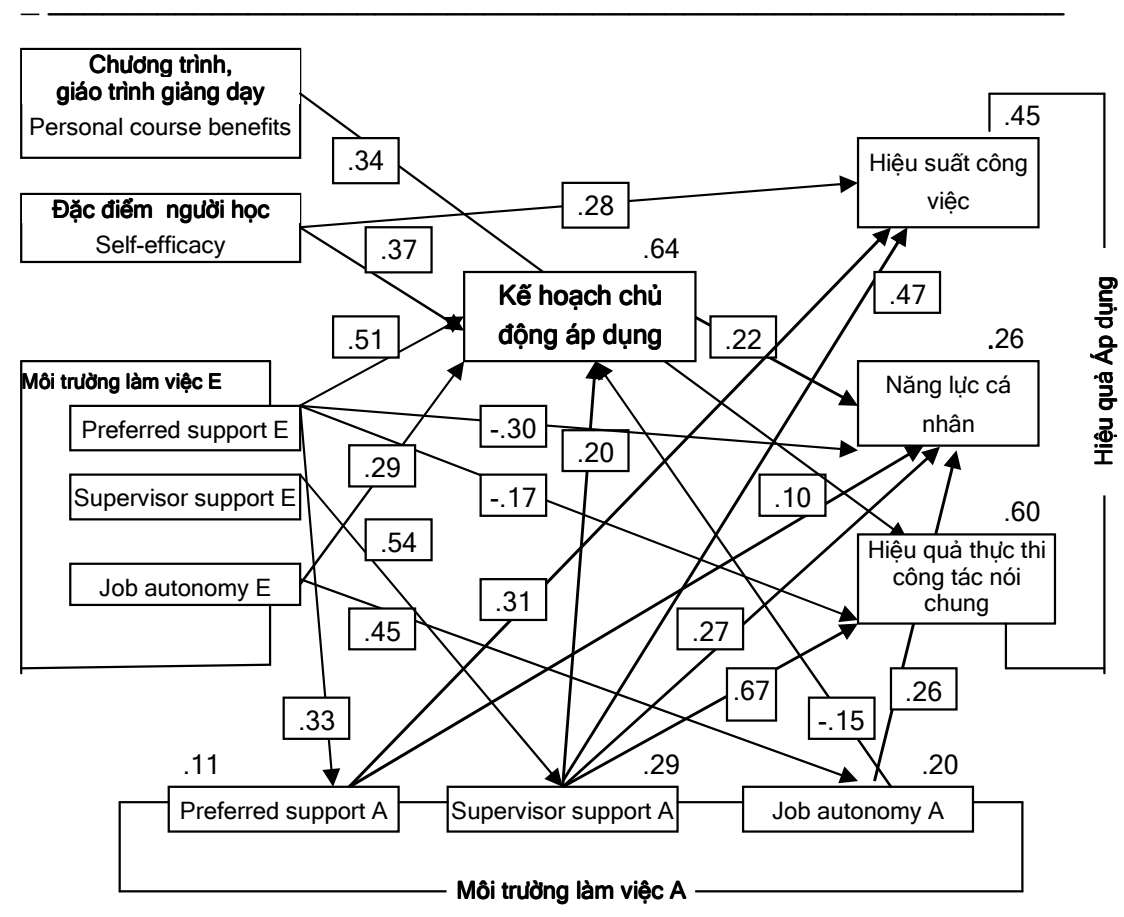

\section{Chú thích:}

Personal course benefits

Self Efficacy

Preferred support at the End of training

Supervisor support at the End of training

Job autonomy at the End of training

Preferred support three months After training

Supervisor support three months After training

Job autonomy three months After training
= Lợi ích khóa học mang lại cho người học

= Sự tự tin

= Sự cần thiết được hỗ trợ từ cơ quan ngay sau khi kết thúc khóa học MBA

= Sự hỗ trợ của Cấp trên ngay sau khikết thúc khóa học MBA

= Quyền tự chủ trong công việc ngay sau khi kết thúc khóa học MBA

= Sự cần thiết được hỗ trợ từ cơ quan sau khi kết thúc khóa học ba tháng

= Sự hỗ trợ của Cấp trên sau khi kết thúc khóa hoc ba tháng

= Quyền tự chủ trong công việc sau khi kết thúc khóa học ba tháng 


\section{V - Những đóng góp của Luận án}

Hiện nay chưa có một nghiên cửu nào xem xét ảnh hưởng đồng thời của nhóm các nhân tố: (1) chương trình và giáo trình giảng dạy; (2) đặc điểm của người học; (3) môi trường làm việc; và (4) kế hoạch chủ động áp dụng của người học, đên Hiệu quả Áp dụng. Luận án này đóng góp vào lý thuyểt giảng dạy và đào tạo qua việc cung cấp một mô hình đào tạo tổng hợp dựa trên nhửng nghiên cửu thực tế, từ đó chỉ ra những căn cử xác đáng để đánh giá ảnh hưởng đồng thời của nhóm bốn nhân tố nói trên đến Hiệu quả Áp dụng. Không dừng lại ở đó, kết quả của Luận án còn tạo đà cho những nghiên cửu trong tương lai, tiếp tục sủ dụng mô hình tổng hợp các nhân tố nói trên đến Hiệu quả Ảp dụng.

Một trong nhũng điểm mới nổi bật của Luận án là đưa vào và đánh giá ảnh hưởng tích cực của kể hoạch chủ động áp dụng của người học (trong mổi quan hệ tưởng hỗ với chương trình và giáo trình; với đặc điểm của người học; và với môi trường làm việc) đển Hiệu quả Áp dụng. Đây là điểm rất quan trọng khi mà hiện nay trên thế giới có rất ít nghiên cửu về tác động của kể hoạch chủ động áp dụng của người học đến Hiệu quả Áp dụng.

Ngoài ra, trong khi các nghiên cửu trước đây chỉ sử dụng một vài tiêu chí để đo đạc Hiệu quả Áp dụng, Luận án đã mở rộng thêm và xác nhận hiệu lực của 11 tiêu chínũa. Đây là một bước tiến mới, tạo ra một bộ tiêu chí mới hợp lệ và đây hiệu lực cho việc đo đạc Hiệu quả Áp dụng.

Luận án cũng bổ xung thêm tiêu chí Sự cần thiết được hố trợ của người học (preferred support construct), trong khóa học cũng như sau khi kết thúc khóa học, vào bộ tiêu chí đo đạc ảnh hưởng của môi trường trường làm việc đến Hiệu quả Áp dụng. Điêu này góp phân tăng cường sự chính xác và toàn diện của việc đo đạc ảnh hưởng của môi trường làm việc đên Hiệu quả Áp dụng. Hơn nữa, nó cung cấp thêm bẳng chửng thực tế là càng nhiêu các yếu tố liên quan được đánh giá, chất lượng và hiệu quả đánh giá càng cao.

Một khía cạnh mới nũ̃a không kém phần quan trọng của Luận án là phương pháp luận. Trong khi phần lớn các nghiên cứu trước đây chỉ đo đạc ảnh hưởng của môi trường làm việc đến Hiệu quả Áp dụng tại một thời điểm nhất định, hoặc là ngay khi khóa học kết thúc, hoặc là sau khi kết thúc một thời gian, Luận án này đo đạc tại cả hai thời điểm nói trên. Điêu này tạo tiền đề cho xu thể tiếp cận mới toàn diện hơn cần phải hướng tới trong tường lai khi nghiên cửu Hiệu quả Áp dụng.

Cuôii cùng, trong khi phần lớn các nghiên cứu trước đây chủ yếu đánh giá hiệu qủa áp dụng qua sự tự đánh giá của bản thân người học, Luận án này sử dụng kết quả đánh giá của cả Câp trên của người học. Điêu này góp phân khẳng định tính chính xác và khách quan của kết quả nghiên cửu.

Kết thúc Luận án, tác giả đã đưa ra một bảng kiến nghị năm điểm cụ thể cho các cơ sở đào tạo cũng như phía các cơ quan cử người đi học./. 


\section{About the author}

Nga Thi Phuong Pham started her academic career in Hanoi, Vietnam where she obtained a Bachelor Degree (Environmental Management major) from the Hanoi Water Resources Management University.

Since 1997, she has been working as a lecturer in Academy of Public Administration (APA), Ho Chi Minh National Academy of Political and Public Administration (HCM NAPPA) of Vietnam. APA is a key institution providing training program in public administration. It plays a critical role in providing administrative training to the top and middle government officials. Her teaching subject is Rural and Urban Public Management.

In addition to her lecturing responsibilities, she also carries out research on public management focusing on training management issues, and serves as visiting lecturer to other Vietnamese universities such as the Fine-Arts University, Hanoi Pedagogy Painting-Musical University, Culture University in Vietnam, with Environmental Management as a teaching subject.

In 1999, she received her Certificate of Public Policy from National University of Singapore.

In 2000, she received her Master Degree in Public Management from the Potsdam University in Germany with a thesis topic: Training of civil servants in public management: the lessons for Vietnam. Her study in Germany was supported by the InWent Scholarship (Capacity Building International-Internationale Weiterbildung und Entwicklung gGmbH).

She has also participated two national level projects (DANIDA Vietnam Public Administration Reform Project (2002-2003) and 2718 VIE Project of Asian Development Bank-Training Vietnam Government Officials (1997-1998) in Vietnam. Both projects consisted of a series of training design as well as training needs analysis.

Later, she studied at Maastricht School of Management (MsM, the Netherlands) and received the Master of Philosophy Degree (2006) with a thesis topic: Measuring the Effectiveness of Urban Management Training on Competence Development-The case of Vietnam.

Since 2005, she has been on leave from her academic position in Vietnam and is doing research in the field of Human Resource Management for a PhD degree at the University of Maastricht, the Netherlands.

In 2009, Nga Pham got the Marie Curie Grant from the European Commission for her Post-doc project on training transfer issue, starting from 2010 up to 2012. 


\section{Major Research Results and Publications}

Chapter in book/Articles in refereed international journal

Pham, N.T.P., Gijselaers, W.H. \& Segers, M.S.R. (2010, in press). The effect of the trainees' perception of the training design on transfer of training: the case of Master of Business Administration (MBA) in Vietnam. In P. Van den Bossche, W. Gijselaers, \& R. Milter (Editors). Advances in Business Education and Training III. Dordrecht: Springer (in press)

Pham, N.T.P., Segers, M.S.R. \& Gijselaers, W.H. (2010b). Understanding Transfer of Training Effects from a Motivational Perspective: A test of Master of Business Administration (MBA) in Vietnam. In Business Leadership Review, 7:3 (July 2010), 1-25.

Pham, N.T.P., Segers, M.S.R. \& Gijselaers, W.H. (2010a). Effects of the Work Environment on Transfer of Training: the case of Master of Business Administration (MBA) of Vietnam. In International Journal of Training and Development (Under review).

Pham, N.T.P., Gijselaers, W.H. \& Segers, M.S.R.(2010). Facilitating training transfer effects based on simultaneous influences of training design, trainees' motivation and work environment (Submitted).

\section{In Vietnamese journals/book}

Pham Thi Phuong Nga. Discussion the training and re-training on Vietnamese Urban Managers in Public Management. The State Organizational Review, Ministry of Home Affair, ISSN 0868 - 3697, 1+2I 2004.

Pham Thi Phuong Nga. About training methodology for civil servants in Vietnam. State Management Review, Academy of Public Administration (APA), ISSN 0866-2828, No 4-2003.

Pham Thi Phuong Nga (Co-authors). Administrative Dictionary, APA, Hanoi, 2002.

Pham Thi Phuong Nga. Concept of education, training and staff development for cadres, civil servant in the Human Resources Management. The State Organizational Review, Ministry of Home Affair, ISSN 0868 - 3697, No 11-2002).

\section{Additional information}

From July 1986 to March 1997, Nga Pham was an Editor of Scientific and Technical Journal of Hydro-Meteorological Service in Vietnam.

From 1996-2000, she was Journalist of Vietnam Journalist Association (1996-2000). 